\title{
Aggression and competition for space and food in captive juvenile tuatara (Sphenodon punctatus)
}

Laura Luise Barbara Wörner

A thesis submitted to Victoria University of Wellington

in fulfilment of the requirements for the degree of Master of Science in Conservation Biology

Victoria University of Wellington

Te Whare Wānanga o te Ūpoko o te Ika a Māui 


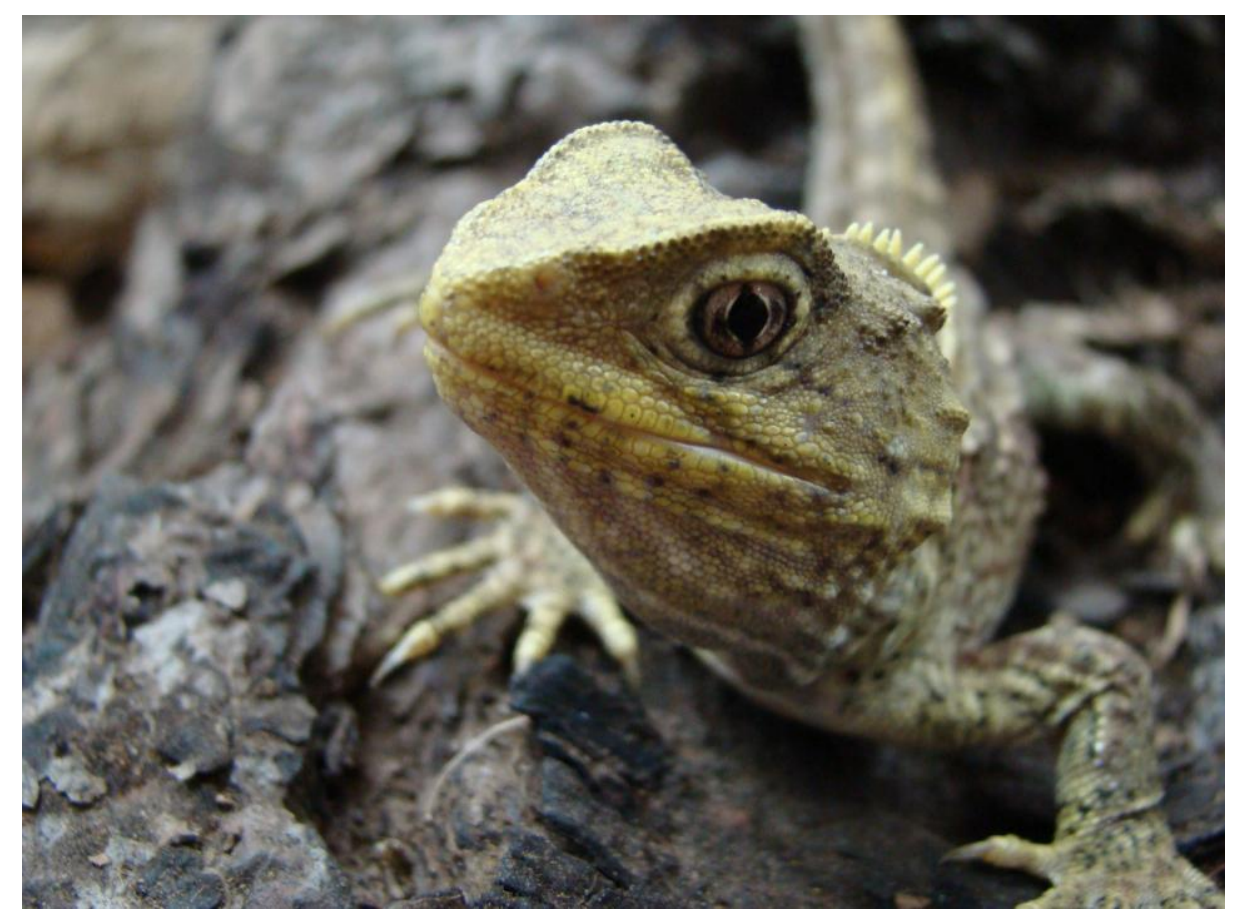

Photo: Juvenile tuatara (Sphenodon punctatus), approximately one year of age (C) Laura Wörner

Der unermeßlich reichen, stets sich erneuernden Natur gegenüber wird der Mensch, soweit er auch in der wissenschaftlichen

Erkenntnis fortgeschritten sein mag, immer das sich wundernde Kind bleiben und muß sich stets auf neue Überraschungen gefaßt machen. Max Planck (1858 - 1947)

$(\sim$ In the face of the immeasurably rich, ever regenerating nature, men, as far advanced in science as they might be, will always remain astonished children, and have to expect surprises.) 


\section{Abstract}

Intraspecific competition is of importance in the wild and captivity, as the interaction among individuals for resources can affect growth, survival, and ultimately fitness. Tuatara, Sphenodon punctatus, are endemic to New Zealand and the sole representatives of the reptile Order Rhynchocephalia, and their recovery plan outlines the importance of head-started individuals to supplement existing populations and provide stock to start new populations. Head-starting is a widespread conservation tool for raising juveniles in captivity prior to release in the wild, with the aim of reducing juvenile mortality and providing populations with more individuals. However, mortality differs between sexes and juvenile tuatara show enormous variation in size in captivity. I investigated aggression and competition for space and food in a tuatara head-starting facility to determine whether intraspecific competition may affect mortality and growth. Pairs of one-year-old tuatara, $S$. punctatus, were chosen according to sex and relative size, e.g. a big male and a small female or two similar sized females. Seven scenarios were replicated four times with different pairs. Behaviour (including two feeding trials) was recorded over a six day period via security cameras and direct observations. The number of aggressive conflicts differed among scenarios, and male-male dyads were significantly more aggressive than female-female dyads. Dominance hierarchies were established in 18 of 28 experimental pairs, with bigger animals being dominant. Conflicts include chasing, biting or colliding at full speed. One year old juveniles did not compete for space. They did not use space exclusively, but stopped clustering and had developed aggressive behaviour, suggesting that they are not territorial yet but in an early stage of transition towards territoriality as seen in older juveniles and adults. Space use and avoidance in space and time did not differ among social scenarios and the latter were negligible, but they marked a novel enclosure with urine and faeces. Juveniles competed directly and indirectly for food. Dominant individuals were likely to secure more food than submissive individuals. Females acquired less food when paired with males of bigger or similar size, and acquired about equal shares when paired with a smaller male. While bigger males acquired slightly more food when paired with smaller males, this was not the case in differently sized females. Interference behaviours such as chasing and food stealing were mostly directed from bigger towards smaller individuals. Captive group housing has consequences for competition and aggression, and may directly influence survival. As juvenile tuatara mortality is female-biased, and aggression against 
females in bigger male-biased groups common, I recommend keeping sexes separate, and assorting groups by size with more spacious enclosures for male groups. These modifications should improve health and numbers of juveniles for release, improve recruitment into the reproductive adult population, and ultimately create more successful head-starting facilities. 


\section{Acknowledgements}

First, I would like to thank my supervisor Nicola Nelson for giving me the opportunity to work on tuatara, which turned out to be a real New Zealand adventure. Thanks for the encouragement, support and advice throughout my study.

Thanks to Sue Keall, Laurent van Ham, Helen Cranshaw, Neville Higginson, Minyu Zhang and Cameron Jack for helping me with the set up and the ongoing work on my experiments and husbandry. Thanks to Barbara Blanchard, Bernard Goetz, Lindsay Hazley and Marianna Terezow for sharing their knowledge with me. Thanks to Jen Moore for collecting the eggs from which my study animals hatched.

Thanks to the many people for the valuable feed back on my drafts and presentations, particularly the Hatchet group at Victoria University of Wellington, Nicky, Sue, Elizabeth, Hilary, Amelia, Kim, Jen, Helen, Evan, Kristina, Ilse, Andy, Andrea, Monica, Heidy, Roz, Danielle and Dawson. I would like to thank Marc Hasenbank and Nokuthaba Sibanda for their statistical advice, and Stephen Hartley for one or two drop-in questions on statistics.

Thanks to all 'KK517' office mates, and all those that shared morning coffees and scones with me, and all the friendly SBS staff which made these last 18 months enjoyable. A special thanks to Elizabeth, Monica, Sue, and Amelia for offering me a place to stay during the last days of my thesis project and time in New Zealand.

I would like to acknowledge and thank all parties that supported this project financially: Victoria University of Wellington, Allan Wilson Centre for Molecular Ecology and Evolution, Studienstiftung des Deutschen Volkes, Nga Manu Nature Reserve, Society for Research on Amphibians and Reptiles in New Zealand, and my parents. This study was authorised by the Department of Conservation (DOC WE/311/RES) and by Victoria University of Wellington Animal Ethics Committee (2006R12).

Finally, and most importantly, I thank my family, especially my parents Ilse and Martin, partner Mario and friends, particularly Ariam, Gar Yin, Steffi, Elizabeth, 'den Jungs' Florian, Stefan, and Nicklas, Veronica and everyone involved with the Sailing Development Squad at Evans Bay Yacht and Motor Boat Club for the incredible 
support throughout this challenging project from close by and far, far away. I could not have made this without you. 


\section{Table of Contents}

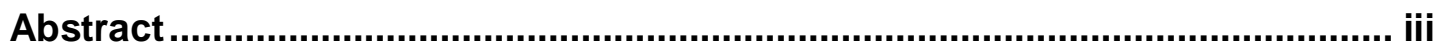

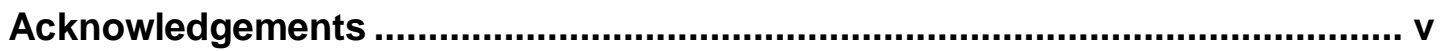

Table of Contents ..................................................................................... vii

CHAPTER ONE General introduction ..............................................................

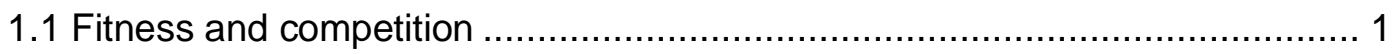

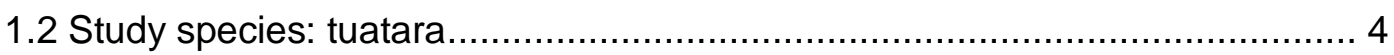

1.3 Head-starting and Tuatara Recovery Plan ........................................... 7

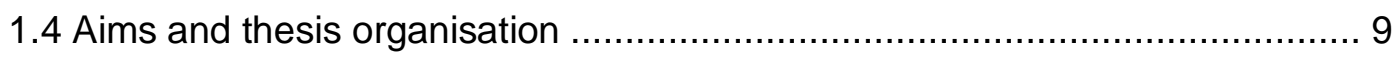

CHAPTER TWO Do agonistic behaviours depend on sex and size in juvenile

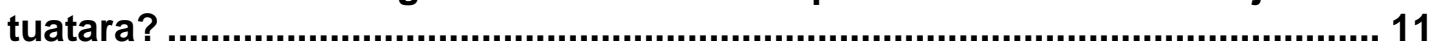

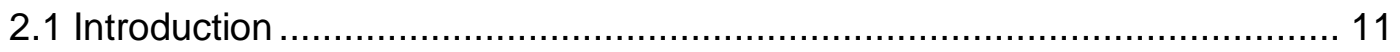

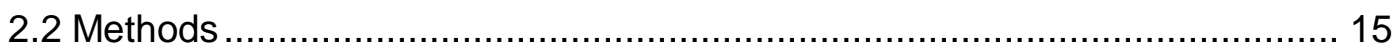

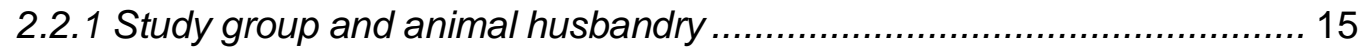

2.2.2 Experimental set-up and equipment .................................................. 15

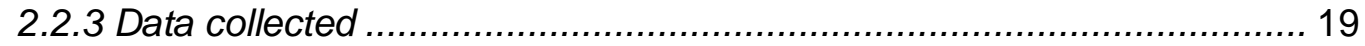

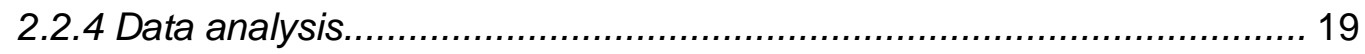

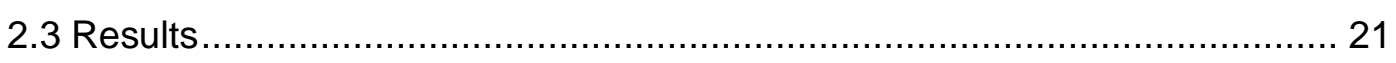

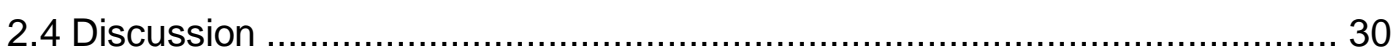

CHAPTER THREE Do captive juvenile tuatara compete for space? ................ 36

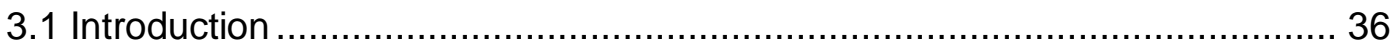

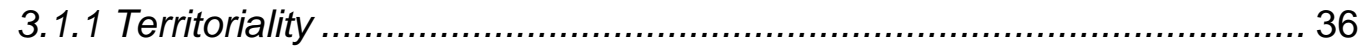

3.1.2 The use of chemical cues in territorial behaviour ................................. 37

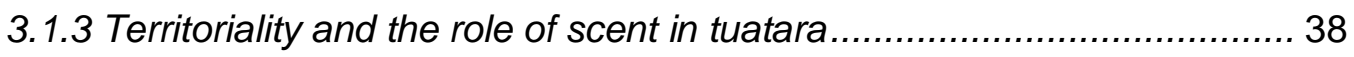

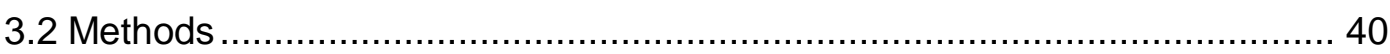

3.2.1 Study group, animal husbandry, experimental set-up and equipment.... 40

3.2.2 Data collected .............................................................................. 42

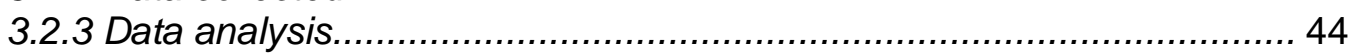

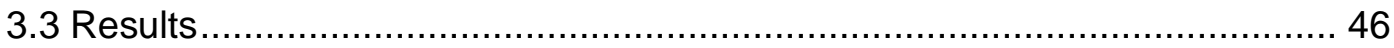

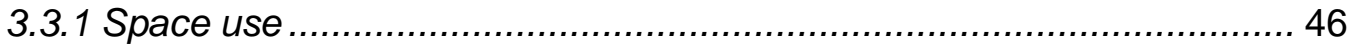

3.3.2 Patterns of excretion and scent marking........................................... 49

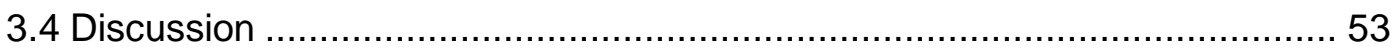

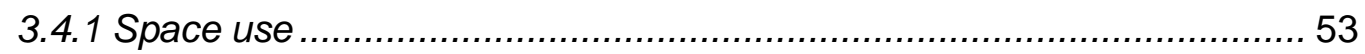

3.4.2 Patterns of excretion and scent marking .......................................... 55

CHAPTER FOUR Do captive juvenile tuatara compete for food? ..................... 59

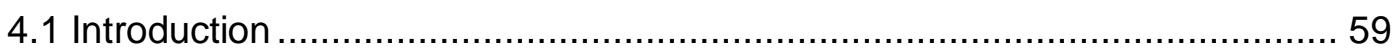

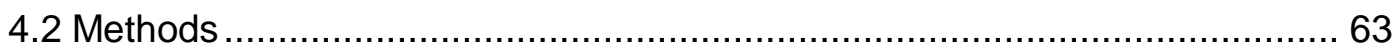

4.2.1 Study group, animal husbandry, experimental set-up and equipment... 63

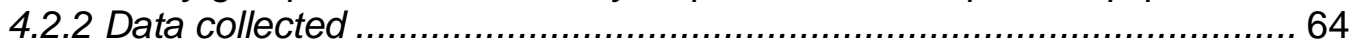




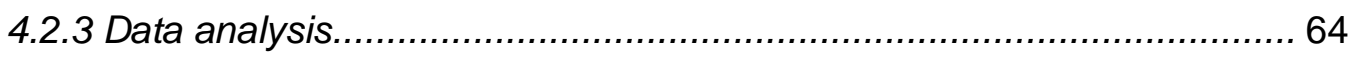

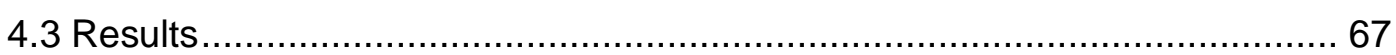

4.3.1 Comparisons among scenarios and broader groups ......................... 67

4.3.2 Influence of dominance hierarchies (dominant vs. submissive individuals)

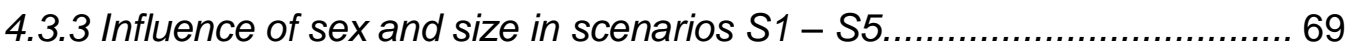

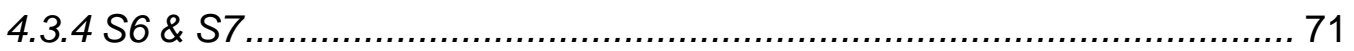

4.3.5 Direct and indirect competition ................................................ 72

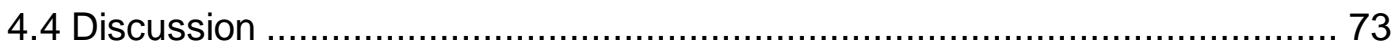

CHAPTER FIVE General discussion, implications and future research ......... 79

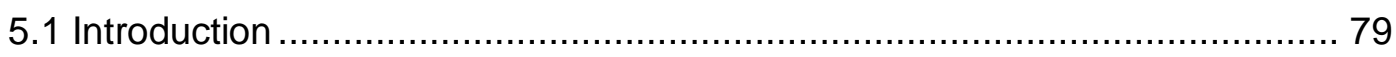

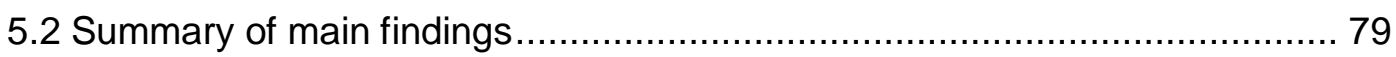

5.2.1 Chapter 2: Do agonistic behaviours depend on sex and size in juvenile

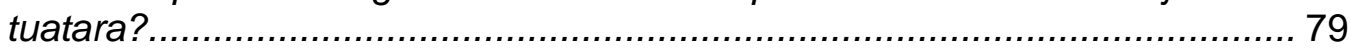

5.2.2 Chapter 3: Do captive juvenile tuatara compete for space?.................. 80

5.2.3 Chapter 4: Do captive juvenile tuatara compete for food? ................... 81

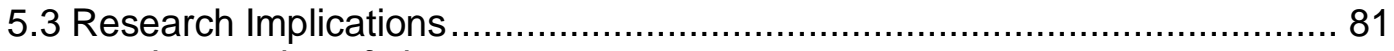

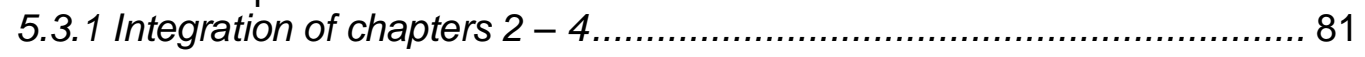

5.3.2 Implications for conservation management ..................................... 82

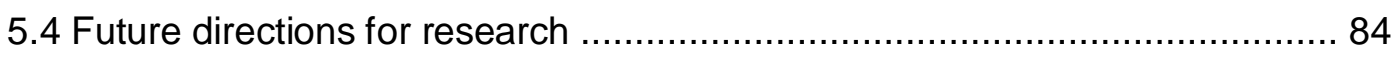

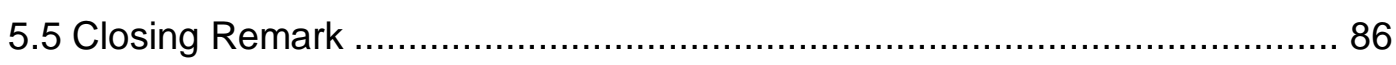

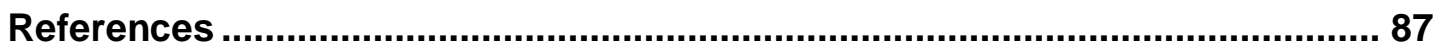

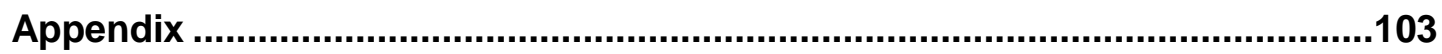




\section{CHAPTER ONE}

\section{General introduction}

\subsection{Fitness and competition}

Fitness is the extent to which an individual contributes genes to future generations.

An individual's fitness is often evaluated indirectly by performance in a trait expected to correlate with genetic contributions to future generations, such as its ability to survive and reproduce relative to its conspecifics (Darwin 1859; Endler 1986;

Freeman \& Herron 2004). Competition is an interaction that occurs among individuals of the same species (intraspecific) or different species (interspecific) for resources that limit their growth, survival, and ultimately their fitness (Birch 1957). Exploitation competition acts indirectly through the shared use of a limited resource, and interference competition involves individuals directly restricting the access of others to a resource (Park 1954; Birch 1957).

The outcomes of intraspecific competition are often positively correlated to predictors such as body size (Downes \& Shine 1998; Shine et al. 2000) and aggressiveness (Civantos 2000). Interference competition often works in favour of larger animals since a bigger body size can be indicative of increased physical strength and fighting ability (Beaugrand \& Zayan 1985; Dodson \& Schwaab 2001; Prenter et al. 2008; Sacchi et al. 2009). For example, larger swordtail males, Xiphophorus helleri, were more likely to win staged territorial contests which included displays and overt fighting (Prenter et al. 2008). More aggressive juvenile male lizards, Psammodromus algirus, had larger and better quality home ranges and higher survival than less aggressive conspecifics (Civantos 2000).

Competitive success may be defined as obtaining or maintaining a larger or better quality territory (Watson \& Miller 1971; Moore et al. In press), or a higher social rank (Pelletier \& Festa-Bianchet 2006), both of which are positively related to a number of fitness enhancing factors: increased access to food (Froese \& Burghard 1974; Boccia et al. 1988), mates (Campanella \& Wolf 1974; Clutton-Brock \& Albon 1979; Moore et al. In press), and optimal shelter (Downes \& Shine 1998), as well as higher breeding success (Watson \& Miller 1971). For example, higher ranked female spotted hyaenas, Crocuta crocuta, have priority access to food and other resources, 
and reproduce more successfully as they breed earlier and their offspring survival is higher (Holekamp et al. 1996).

Competitive failure between conspecifics may reduce an animal's fitness, as a loser may be disadvantaged by reduced access to food, deprivation of optimal shelter, or by direct injury inflicted during a fight (Grossman 1980; Packer et al. 1988; Downes \& Shine 1998). Being excluded from optimal habitat may have detrimental physiological consequences for ectotherms (Avery et al. 1982; Huey et al. 1989). Deprivations due to competitive failure can reduce survival probabilities (English \& Wilkinson 1982; Ferguson \& Fox 1984), growth rates (English \& Wilkinson 1982; Fraser 1990) and reproductive output (Holekamp et al. 1996; Moore et al. 2008), for example, through limited or no access to mates (Bulger 1993; Moore et al. 2008). The resulting stress can elevate stress hormone levels (Creel 2001), and can have a negative impact on individual phenotypic traits (Abbott \& Dill 1989; Santos et al. 2000) as well as offspring traits (Braastad 1998; Hayward \& Wingfield 2004). For example, juvenile Psammodromus algirus lizards have a lower probability of survival when they have to settle for smaller home ranges with less vegetative cover (Civantos 2000), and lower ranked male savanna baboons, Papio cynocephalus, have only limited access to oestrous females (Bulger 1993).

While display to signal dominance or ownership may be the most common form of interference competition, overt fighting is probably the most obvious (Clutton-Brock \& Albon 1979; Genner et al. 1999; Langkilde et al. 2005). Ritualized fights commonly show a typical progression from several rounds of assessing the opponent to more overt fighting (Greenberg 1977; Ridley 1995). One individual or group tends to retreat prior to major fighting (Greenberg 1977), hence fighting is the exception rather than the norm, and injuries are less common than might be expected (Ridley 1995). All interactions related to fighting, that is, both aggressive and submissive behaviours, can be summarised as agonistic behaviours (Scott \& Fredericson 1951). Aggression incorporates many diverse behaviours, for example antler clashes (Clutton-Brock \& Albon 1979) and signalling via body colouration (Bustard 1965), and can serve very different functions, including the establishment and maintenance of territories and dominance (Wilson 1975). Aggressive interactions affect access to habitats and resources in many taxa, including mammals (Slater et al. 2009), birds (Dickinson et al. 2009), fish (Genner et al. 1999), amphibians (Wells 1980) and reptiles (Stamps 1977). 
Territoriality and dominance hierarchies can be interpreted as the two ends of a behavioural continuum or two strategies which have consequences for the allocation of resources among individuals. Dominance hierarchies use an established relationship among individuals to allocate resources regardless of their location whereas territoriality functions to expel competitors from a specific area to gain priority access to local resources (Maher \& Lott 1995; Lott \& North 1998).

Dominance is defined as consistent agonistic asymmetry between two individuals regardless of space (Dewsbury 1982; Drummond 2006). The aim is to gain and maintain priority access to, or exclusive use of, specific objects and actions, such as food and mating (Wilson 1975). In dominance hierarchies, the aggressive displays and attacks by dominant animals are comparable in many aspects to those of territory holders. Submissive behaviours, for example avoiding eye contact or rolling onto one's back as seen in wolves, are used by lower ranked individuals to avoid physical injury (Fox 1973).

Varying definitions of territoriality have been used depending on the context, species and questions investigated. While most conceptual definitions include site-fidelity, defence of space and/or exclusive use, the numerous operational definitions indicate how difficult it is to measure territoriality in practice (reviewed by Maher \& Lott 1995). Territoriality and aggression are strongly linked. Signalling and aggressive displays by the resident act to repulse intruders, and overt fights are avoided whenever possible (Wilson 1975). Size and/or quality of an individual's territory are often positively related to its body size and level of aggressiveness (Civantos 2000; Afonso et al. 2008; Moore et al. In press). For example, more aggressive cock red grouses, Lagopus lagopus scoticus, defend larger territories than less aggressive conspecifics (Watson \& Miller 1971). Submission signals help a challenger to leave the territory without (further) physical injury (Wilson 1975). The acquisition of suitable habitat is positively linked to an adequate food supply, reduced predation vulnerability, refuges, access to mates and survival (Hinde 1956; Rand 1967; Civantos 2000; Moore et al. In press).

Food is often the ultimately limiting resource and therefore central to and of paramount importance for competition (Wilson 1975). Access to food may drive both spacing patterns and dominance hierarchies (Holekamp et al. 1996; Maher \& Lott 
2000). Growth is one out of three major life history categories (growth, reproductive effort, survival) among which time-energy budgets are divided to maximise fitness (Gadgil \& Bossert 1970). Higher food availability generally results in higher growth rates (Dunham 1978; Ballinger \& Congdon 1980; Stamps \& Tanaka 1981a). A higher growth rate confers a larger body size which can result in greater dominance, access to better territories, food and mates, earlier maturation, higher lifetime reproductive success as well as a lower risk of predation and higher survival rates (Froese \& Burghard 1974; Iverson 1978; Swingland \& Coe 1979; Gibbons et al. 1981; Ferguson et al. 1982; Ferguson \& Fox 1984; McKnight \& Gutzke 1993; Moore et al. In press), thus enhancing an individual's fitness in multiple ways.

When animals are held in captivity, competition for resources has to be carefully monitored to ensure their health and survival. When housed colonially natural behaviours such as aggression can have detrimental effects on submissive individuals through injuries, stress, and limited access to food, since opportunities for dispersal or avoidance are critically limited (Warwick 1995). Captive environments are also a chance to enhance our knowledge of a species' (captive) ethology in life stages which might be difficult to study in the wild. The captive environment further offers the opportunity for manipulations and reduction of confounding factors which would not be possible under natural conditions. I investigated aggression and competition for space and food in juvenile tuatara under experimental conditions, not only to shed light on some of the many unanswered questions about the biology of the elusive tuatara juveniles, but also to provide a basis to improve husbandry practises for head-starting and housing juveniles for conservation purposes.

\subsection{Study species: tuatara}

Tuatara, endemic New Zealand reptiles, are of international importance as the sole living representatives of the reptile Order Rhynchocephalia (Gunther 1867), a sister group to the Squamata (Rest et al. 2003) originating from the Mesozoic Era 200 million years ago (Huey \& Janzen 2008). Lizard-like in their appearance (Gunther 1867; Dawbin 1962), tuatara are medium-sized reptiles (Gaze 2001) with temperature-dependent sex determination (Cree et al. 1995; Nelson et al. 2004a). Tuatara have been recently recognized as a single species (Sphenodon punctatus) with characteristic geographic variants (Hay et al. 2009) rather than the two 
separate species, S. punctatus and S. guntheri (Daugherty et al. 1990; Daugherty et al. 1994). Tuatara are currently restricted to 39 offshore islands of varying size in the Cook Strait and off the north-east coast of the North Island and to one mainland reserve, constituting less than $0.5 \%$ of their original range which was widespread throughout New Zealand (Newman 1878; Cree \& Butler 1993; Gaze 2001; McKenzie 2007; Hay et al. 2009; Miller et al. In press). Introduced predators and habitat destruction are the main reasons for the population decline and restricted distribution (Gaze 2001). Tuatara are sexually dimorphic, with males being the bigger sex (Dawbin 1982). In early life stages, particularly in captivity, sexual dimorphism is not apparent (Oldman 2008). The predominantly nocturnal (Walls 1983; Gillingham \& Miller 1991) tuatara grow slowly, indeterminately, mature late at about $9-13$ years of age and may live for at least 100 years (Dawbin 1953, 1962; Castanet et al. 1988; Nelson et al. 2002a; Nelson, unpublished data). Reproductive output is low; females lay clutches of about seven to ten eggs on average every two to four years (Cree et al. 1991a; Cree et al. 1991b; Cree 1994).

The protection status of tuatara has been variable throughout time and is based on populations, subspecies and geographic variants. Currently, S. p. punctatus is listed as sparse, S. punctatus "Cook Strait" as range restricted and $S$. guntheri as nationally endangered within the New Zealand threat classification system (Hitchmough et al. 2007). The IUCN Red List lists S. punctatus (no differentiation into subspecies) as of lower risk / least concern and S. guntheri as vulnerable while acknowledging the need for an update (IUCN 2009). The Tuatara Recovery Plan by the New Zealand Department for Conservation recognises the need for management to preserve the genetic diversity of all existing tuatara stock thus retaining island diversity (Gaze 2001).

Tuatara are ground dwelling, occupy burrows, and aggressively defend territories throughout the year which vary in size depending on habitat type, population density, and sex, with males having bigger territories than females (Gillingham et al. 1995). Both sexes show high site fidelity and intersexual territory overlap (Gillingham et al. 1995; Moore et al. In press). Territorial encounters are most common among males during the mating season from January to March and are most probably driven by the males competing over the access to females (Gillingham \& Miller 1991; Gillingham et al. 1995; Moore et al. In press). Size reliably predicts the outcome of aggressive encounters among males with larger males being the winners (Moore et 
al. In press). Territorial encounters are complex, including body inflation and positioning, crest erection, chasing and biting. Ritualized displays can progress to overt aggression and fights can inflict serious physical injuries, but escalation is rare (Gillingham et al. 1995).

An adult tuatara's natural diet consists of a wide range of small animals, mainly large insects (Walls 1983). Juveniles prey predominantly on small insects (Dawbin 1962). Tuatara forage with a sit-and-wait approach, and primarily use visual cues to detect their prey (Walls 1981; Meyer-Rochow \& Teh 1991). A long-term decline in body condition of the Stephens Island and North Brother Island populations is probably a response to resource competition due to increased population density and low resource availability. Both islands have likely reached their carrying capacity (Hoare et al. 2006; Moore et al. 2007). Intriguingly, the decline in body condition was more pronounced in females than in males on North Brother Island (Hoare et al. 2006). Thus, it was suggested that this competition has a greater effect on females than males, possibly due to unequal access to food resources (Hoare et al. 2006). Even though no research has yet been conducted to follow up these speculations, evidence from translocations suggests competition for limited resources such as food is very likely. Once translocated, tuatara that had exhibited a stable mass for several years on their densely populated source island showed massive gains in mass (Nelson et al. 2002a). In captivity, dominant individuals are thought to secure and eat more food than submissive individuals, and are prone to obesity (Newman et al. 1979; Goetz, personal communication).

Tuatara hatchlings and young juveniles are cryptic in behaviour and colouration, and therefore hard to locate and study in the wild (Dawbin 1962; Mclntyre 1988; Miller et al. In press) which may be the main reason that knowledge on behaviour of early life stages is sparse. More is known about captive juveniles but the knowledge is mostly derived from husbandry observations rather than well designed, experimental studies (Goetz \& Thomas 1994a). Captive hatchlings and juveniles show higher growth rates than wild animals (Tintinger 1987; Goetz \& Thomas 1994a; Gruber 2007) and exhibit enormous plasticity in body size. Evidence exists for a female-bias in mortality rate in captivity (Gruber 2007).

Tuatara hatchlings are assumed not to defend territories as they cluster under one cover object when several are available (Nelson, Keall \& Hazley, personal 
communication). Territoriality is described in juveniles of three years and older (Goetz \& Thomas 1994a; Terezow 2005). The social organisation of young juveniles in the transition from hatchling to becoming territorial is not well understood, and is derived from a few mostly anecdotal and contradictory observations ranging from territorial (Blanchard 2002; Goetz, personal communication) to non-territorial (McIntyre 1988; Goetz \& Thomas 1994a; Terezow 2005). Indirect signs of aggression and overt aggression have been reported for juveniles, consisting of chases and tail loss (Nelson et al. 2004b; Terezow 2005). Husbandry observations on 2.5 - 4 year old captive juveniles suggest that social interactions influence spatial and temporal distribution, with detrimental effects on growth as well as behavioural and activity patterns of subordinates through differential access to resources such as food and shelter (Goetz \& Thomas 1994a).

\subsection{Head-starting and Tuatara Recovery Plan}

Tuatara are the focus of extensive conservation efforts. The New Zealand Department of Conservation's Tuatara Recovery Plan (2001 - 2011) outlines the long-term recovery goals: maintenance of genetic diversity by boosting existing island populations back to their original sizes and establishment of new wild populations in their pre-human range (Gaze 2001). The paradigm of declining populations, and also the paradigm of small populations are addressed (Caughley 1994). While some actions address the causes of decline directly (for example, rodent eradication on infested tuatara islands), others are aimed at augmenting populations suffering from small size (for example, by captive breeding and artificial incubation of eggs) and establishing of new populations as a form of demographic insurance (Gaze 2001).

Common conservation techniques for increasing the population sizes of oviparous reptiles, amphibians and bird species are artificial incubation of eggs harvested from the wild or captive breeding colonies, head-starting the resulting offspring, and releasing them into the wild (Cade \& Jones 1993; Haskell et al. 1996; Nelson et al. 2002a; Germano \& Bishop 2009). Head-starting, first developed for marine turtles (Pritchard 1979; Bowen et al. 1994), involves retaining immature animals in captivity until they reach a larger size, based on the premise that larger juveniles will have better prospects of survival in the wild than small, newly hatched young (Haskell et 
al. 1996; Kuehler et al. 2000; Pedrono \& Sarovy 2000; Bell et al. 2005; Alberts 2007; Griffiths \& Pavajeau 2008).

Artificial incubation, head-starting and translocations are nevertheless controversial conservation techniques. Success is not guaranteed (Dodd \& Seigel 1991; Fischer \& Lindenmayer 2000), but has improved over time (Germano \& Bishop 2009). Failures have been attributed to inadequate husbandry (Cree et al. 1994), lack of knowledge of species biology (for example, sex determining system [Taubes 1992]), altered behaviour due to captivity such as a reduction in predator avoidance (Alberts \& Phillips 2004; Perez-Buitrago et al. 2008), and unsuitable relocation habitat (Ehrenfeld 2000). Some discredit these techniques because they do not address the causes of decline (Frazer 1992; Congdon et al. 1994), may keep unfit individuals alive (Chiszar et al. 1993), and may deprive the environment of the ecological role of hatchlings and young juveniles (Frazer 1992). Nevertheless, if carefully implemented, head-starting can be an effective tool to alleviate the problems of small populations by enhancing juvenile survival and thus increasing population sizes with minimal impact on the source populations (Cree et al. 1994; Nelson et al. 2002a; King \& Stanford 2006). Head-starting should always be used in conjunction with further techniques that address the causes of decline (Gaze 2001).

Head-started tuatara juveniles are used as founders for new populations and to augment numbers of small populations (Gaze 2001; Nelson et al. 2002a; Nelson et al. 2004b). Eggs are sourced from wild populations (Cree et al. 1994; Nelson et al. 2002a) where hatching success is low (48\%; McIntyre 1988; Thompson et al. 1996), and juvenile mortality presumed to be high (4.4-5\% annual recruitment into adult populations; Castanet et al. 1988; Mitchell et al. 2009) most probably due to environmental factors and predation (McIntyre 1988; Cree et al. 1994). Only a limited number of clutches are collected for incubation at any given time and not all of a years output is taken (Nelson, unpublished data). So the possible reduction of an ecological function of hatchlings and juveniles should be negligible. Hatching success in captivity is high (>90 \%) and so are the numbers of juveniles reared to release size at around five years of age (Nelson et al. 2004b; Gruber 2007). Although head-starting may aim to keep all individuals alive, some still die during the captive phase (Gruber 2007), and other possibly unfit juveniles probably die once released, or contribute little or nothing towards the next generation's gene pool (Miller et al. In press; Moore et al. In press). Monitoring has revealed the survival of 
substantial numbers of juveniles post translocation, and weight and size gains, (Nelson et al. 2002a; Miller et al. In press), indicating short-term success. However, as tuatara are long-lived, late maturing, and have low reproductive output, an ultimate positive assessment via the confirmation of a self-sustaining population can only be accomplished during decades of long-term monitoring (Nelson et al. 2002a). The first translocated and monitored populations of tuatara were only established in 1995 (Nelson et al. 2002a).

To be an effective management tool, head-starting must result in greater recruitment into the population of reproductive adults than would occur naturally. Therefore, success depends on growth and survival during the captive period, the fate of headstarted individuals after release into the wild, and ultimately their overall fitness (King \& Stanford 2006). To enhance success of head-started individuals, it is important to remove stochastic environmental factors affecting survival in nature, and to allow for natural behaviour. However, while natural behaviours such as aggression in relation to territoriality or dominance are important components of a species' behaviour in the wild, they may have detrimental effects in captive holdings since dispersal or avoidance, probable submissive responses in the wild, are critically limited (Warwick 1995). A further challenge is ontogenetic changes in behaviour. While prevailing husbandry set-ups may be adequate at one time, they might not be adequate for all life stages (Warwick 1995). Some species will have to be housed individually (Taubes 1992; Warwick 1995), while others can and should be held in groups since this may prevent detrimental naivety to social interactions in later life stages (Burghard \& Layne 1995; Sakata et al. 2002). The latter is recommended for tuatara juveniles (Blanchard 2002).

\subsection{Aims and thesis organisation}

I asked the following questions to investigate aggression and competition for space and food in juvenile tuatara and to inform captive husbandry practices. (1) Do agonistic behaviours depend on sex and size in juvenile tuatara? (2) Do captive juvenile tuatara compete for space? (3) Do captive juvenile tuatara compete for food?

Chapter 2: Do agonistic behaviours depend on sex and size in juvenile tuatara? While husbandry observations suggest that social interactions affect growth and behavioural patterns in juvenile tuatara through differential access to resources 
(Goetz \& Thomas 1994a), the effect of social context (based on sex and size) on agonistic behaviours remain unknown. Detailed knowledge is needed to ensure good health and high survival of juvenile (head-started) tuatara. Therefore, I explored agonistic interactions in juveniles, and how they are affected by social context. I determined what predicted the directionality of aggression and whether juveniles established stable dominance hierarchies.

Chapter 3: Do captive juvenile tuatara compete for space?

Spatial organisation can affect activity, growth and survival of captive juvenile tuatara (Goetz \& Thomas 1994a), and therefore has implications for the health of captive colonies and the number of hatchlings raised to release-size in head-start facilities. I investigated if one-year-old juveniles use an exclusive area, or, if not, keep varying distances from each other or avoid each other in time depending on different social contexts. I investigated whether excretory patterns suggest scent marking in juveniles, and if this may be linked to their space use.

\section{Chapter 4: Do captive juvenile tuatara compete for food?}

The practice of releasing live food into an enclosure with several immature tuatara does not guarantee an equal distribution among individuals and fosters competition over food. No experimental research has ever been conducted on food distribution in captivity. I investigated intraspecific competition for food following up on my hypothesis that food availability within colonial holdings will differ among individuals. I analysed whether sex, size, and social rank affected the occurrence and intensity of food competition and distribution in juveniles.

In Chapter 5: General discussion, implications and future research I provide a synthesis and integration of the main findings of the study, broad implications and future avenues of research for tuatara biology and conservation.

This thesis is written as a series of manuscripts for publication, with each data chapter having its own introduction, methods, results and discussion. Hence, some repetition occurs among chapters. A common abstract is provided towards the beginning of the thesis, and a common reference list towards the end. 


\section{CHAPTER TWO}

\section{Do agonistic behaviours depend on sex and size in juvenile tuatara?}

\subsection{Introduction}

Organisms compete for limited resources, and two mechanisms of competition are distinguishable. Exploitation competition acts indirectly through the shared use of a limited resource, whereas interference competition involves individuals directly restricting the access of others to a resource (Park 1954; Birch 1957). While display to signal dominance or ownership may be the most common form of interference competition, overt fighting is probably the most obvious (Clutton-Brock \& Albon 1979; Genner et al. 1999; Langkilde et al. 2005). Ritualized fights commonly show a progression from several rounds of assessing the opponent to more open fighting (Greenberg 1977; Ridley 1995). However, one individual or group tends to retreat prior to major fighting (Greenberg 1977), so that fighting is the exception rather than the norm, and injuries are less common than might be expected (Ridley 1995).

Competitive success may be defined as obtaining or maintaining a larger or better quality territory (Watson \& Miller 1971; Moore et al. In press), or a higher social rank (Pelletier \& Festa-Bianchet 2006), both of which are positively related to a number of fitness enhancing factors: increased access to food (Froese \& Burghard 1974; Boccia et al. 1988), mates (Campanella \& Wolf 1974; Clutton-Brock \& Albon 1979; Moore et al. In press), and optimal shelter (Downes \& Shine 1998), as well as higher breeding success (Watson \& Miller 1971). For example, higher ranked female spotted hyaenas, Crocuta crocuta, have priority access to food and other resources, and reproduce more successfully as they breed earlier and their offspring survival is higher (Holekamp et al. 1996).

The outcomes of intraspecific competition are often positively correlated to predictors such as body size (Downes \& Shine 1998), aggressiveness (Civantos 2000), or residency status (Olsson \& Shine 2000). Interference competition often works in favour of larger animals since a bigger body size can be indicative of increased physical strength and fighting ability (Beaugrand \& Zayan 1985; Dodson \& 
Schwaab 2001; Prenter et al. 2008; Sacchi et al. 2009). For example, larger swordtail males, Xiphophorus helleri, are more likely to win staged territorial contests, which include displays and overt fighting (Prenter et al. 2008). More aggressive juvenile male lizards, Psammodromus algirus, have larger and better quality home ranges and higher survival than less aggressive conspecifics (Civantos 2000). Resident male snow skinks, Niveoscincus microlepidotus, win the majority of fights against non-resident conspecifics that do not differ significantly in any other factor but their residency (Olsson \& Shine 2000).

Competitive failure between conspecifics may reduce an animal's fitness, as a loser may be disadvantaged by reduced access to food, deprivation of optimal shelter, or by direct injury inflicted during a fight (Grossman 1980; Packer et al. 1988; Downes \& Shine 1998). Being excluded from optimal habitat may have detrimental physiological consequences for ectotherms (Avery et al. 1982; Huey et al. 1989). Deprivations due to competitive failure can reduce survival probabilities (English \& Wilkinson 1982; Ferguson \& Fox 1984), growth rates (English \& Wilkinson 1982; Fraser 1990) and reproductive output (Holekamp et al. 1996; Moore et al. 2008). The resulting stress can elevate stress hormone levels (Creel 2001), and can have a negative impact on individual phenotypic traits (Abbott \& Dill 1989; Santos et al. 2000) as well as offspring traits (Braastad 1998; Hayward \& Wingfield 2004). For example, juvenile Psammodromus algirus lizards have a lower probability of survival when they have to settle for smaller home ranges with less vegetative cover (Civantos 2000), and lower ranked male savanna baboons, Papio cynocephalus, have only limited access to oestrous females (Bulger 1993).

A facet of interference competition is aggression, which incorporates many diverse behaviours, for example antler clashes (Clutton-Brock \& Albon 1979) and signalling via body colouration (Bustard 1965), which can serve very different functions, including the establishment of territories and dominance (Wilson 1975). Aggressive interactions affect access to habitats and resources in many taxa, including mammals (Slater et al. 2009), birds (Dickinson et al. 2009), fish (Genner et al. 1999), amphibians (Wells 1980) and reptiles (Stamps 1977). Nevertheless, the obvious benefits must out weigh possible costs of overt aggression such as injury and death (Rubenstein 1982). 
Territoriality and dominance hierarchies can be interpreted as the two ends of a behavioural continuum which have consequences for the allocation of resources among individuals (Maher \& Lott 1995; Lott \& North 1998). Territoriality, the defence of an exclusive area (Noble 1939; Pitelka 1959; reviewed by Maher \& Lott 1995), and aggression are strongly linked. The size and/or quality of an individual's territory are often positively related to its level of aggressiveness (Watson \& Miller 1971; Moore et al. In press). For example, more aggressive cock red grouses, Lagopus lagopus scoticus, defended larger territories than less aggressive conspecifics (Watson \& Miller 1971). Aggression is particularly expected during the settlement period of territorial animals in a prospective habitat (Stamps \& Krishnan 1997). Signalling and aggressive displays by the resident act to repulse intruders, and overt fights are avoided whenever possible. Submission signals help a challenger to leave the territory without (further) physical injury (Wilson 1975).

In dominance hierarchies, the aggressive displays and attacks by dominant animals are comparable in many aspects to those of territory holders. Dominance is defined as consistent agonistic asymmetry between two individuals regardless of space (Dewsbury 1982; Drummond 2006). Instead of excluding competitors from an area, the aim is to gain and maintain priority access to or exclusive use of specific objects and actions, such as food and mating (Wilson 1975). Submissive behaviours, for example avoiding eye contact or rolling onto one's back as seen in wolves, Canis lupus, are used by lower ranked individuals to avoid physical injury (Fox 1973).

Agonistic behaviours, that is, all interactions related to fighting, both aggressive and submissive (Scott \& Fredericson 1951), occur commonly in all four extant reptile orders in the wild (Carpenter 1967; Gillingham et al. 1995; Seebacher \& Grigg 1997; Schofield et al. 2007) and in captivity (Froese \& Burghard 1974; Formanowicz et al. 1990; Morpurgo et al. 1993; Terezow 2005). Agonistic behaviour has been the focus of considerable research in some lizard families, especially the Iguanidae (see Carpenter \& Ferguson 1977 for review). Aggression in this family is linked to spacing patterns (Stamps 1977), territoriality (Stamps 1983a), mating, and courtship (Carpenter \& Ferguson 1977; Carpenter 1978). Examples of agonistic interactions include visual display patterns (push ups, head bobbing and face offs), fighting (biting and chasing), as well as a number of submissive behaviours (pressing the ventral region to the ground and holding the head down; Carpenter 1967; Brattstrom 1974). Aggression in lizards is generally more vicious in male-male encounters than 
intersexual or female-female encounters (Carpenter \& Ferguson 1977; Carpenter 1978; Formanowicz et al. 1990).

Tuatara, Sphenodon punctatus, are the sole living representatives of the ancient reptile Order Rhynchocephalia (Gunther 1867), a sister group of Squamata (Rest et al. 2003), and resemble lizards in appearance (Gunther 1867; Dawbin 1962). Aggression is reported for both male and female adult tuatara, though it is more prominent in males in the context of territoriality and competition for mates during mating season (Gillingham et al. 1995; Moore 2008). Size reliably predicts the outcome of aggressive encounters with larger males being the winners (Moore et al. In press). Tuatara display a complex behavioural repertoire during aggressive encounters, including body inflation and positioning, crest erection, chasing and biting. Ritualized displays progress to overt aggression when display is insufficient, but escalation is rare. Overt fights can inflict serious physical injury (Gillingham et al. 1995). Aggressive and territorial behaviours are established at a relatively early age in this long-lived species (Castanet et al. 1988), and seem to influence the spatial and temporal distribution of juveniles (Goetz \& Thomas 1994a; Terezow 2005 ; Goetz, personal communication). In captivity, dominant juveniles defend their territories, move around freely and displace subordinates. Less dominant juveniles can show reduced activity and/or remain longer in their burrows and exhibit restricted movements in smaller areas (Goetz \& Thomas 1994a). Chases are the most commonly observed overt aggression (Terezow 2005; Goetz, personal communication). Biting and other forms of overt aggression occur during feeding in captivity of one-year-old juvenile tuatara (Chapter 4). Indirect signs of aggression in juveniles such as tail loss are common (Nelson et al. 2004b), while lesions in the head area are rare in comparison (personal observation).

Observations of captive juvenile tuatara suggest that social interactions have an important effect on growth as well as behavioural patterns through differential access to resources (Goetz \& Thomas 1994a). However, the effects of sex and relative size of individuals (social context) on agonistic behaviours, and the directionality of aggression are unknown. Detailed knowledge of agonistic behaviours is important to ensure good health and high survival of juvenile tuatara, particularly during head-starting programs aimed at supplying juveniles to supplement or found new populations. To understand agonistic behaviours, I investigated the following questions. (1) Does the occurrence and number of 
agonistic interactions in juvenile tuatara depend on the social context (for example, are males more aggressive towards females than vice versa)? (2) Is there a clear directionality of aggression?

\subsection{Methods}

\subsubsection{Study group and animal husbandry}

Agonistic behaviours were observed in 23 one-year-old juvenile tuatara, $S$. punctatus, from June to October 2008. Eggs were sourced from Stephens Island in Cook Strait, New Zealand, for a study on paternity (Moore 2008), and were artificially incubated, and hatched at Victoria University of Wellington between the $10^{\text {th }}$ of April and the $1^{\text {st }}$ of June 2007.

At Victoria University of Wellington, tuatara were housed indoors in $600 \times 700 \times 350$ $\mathrm{mm}$ (width $\mathrm{x}$ length $\mathrm{x}$ height) aluminium enclosures (with wire mesh lids) with an average group size of five individuals per enclosure. The pens were artificially lit under a light:dark cycle of 12:12 hours provided by full spectrum fluorescent tubes (TRUE-LITE F40T12/T.L LONG LIFE), placed $750 \mathrm{~mm}$ above the enclosures. Photo phase began each day at $0700 \mathrm{~h}$, or at $0800 \mathrm{~h}$ after the beginning of daylight saving on the $28^{\text {th }}$ of September 2008. Juveniles experienced temperature fluctuations with a mean ( \pm one standard error [SE]) daytime temperature of $18.6 \pm 0.04{ }^{\circ} \mathrm{C}$ (range: 13.4 - 22.9), and night time temperature of $18.2 \pm 0.04 \stackrel{\circ}{\circ}$ (range: $13.6-22.4$; recorded with a StowAway ${ }^{\circledR}$ TidbiTß data logger). The animals were supplied with soil (50 mm depth), leaf litter, bark pieces for cover and water ad libitum. Food (invertebrates: crickets, mealworms and flies) was released into the enclosures once a week.

\subsubsection{Experimental set-up and equipment}

Experiments were set up in eight 350 x 600x $350 \mathrm{~mm}$ (width $\mathrm{x}$ length $\mathrm{x}$ height) enclosures at Victoria University of Wellington. The base of the experimental pens was covered with absorbent paper and gaps were sealed with tape. This substrate provided contrast for scotophasic filming in black and white. Digging was not possible. Each enclosure was furnished with two shelters (with a single entrance/exit each) and a water dish (Figure 2.1). Water was provided ad libitum via replenishment of the water dish and daily mist spraying. Blinds were installed to avoid visual disturbance of the animals by the investigator. All tests and 
observations were conducted by the same observer. Experiments were carried out under the same lighting and temperature regimes as described above for home enclosures (see Study group and animal husbandry) and juveniles were held in experimental enclosures for six days. Feeding occurred twice during experiments (after $72 \mathrm{~h}$ and $144 \mathrm{~h}$ ).

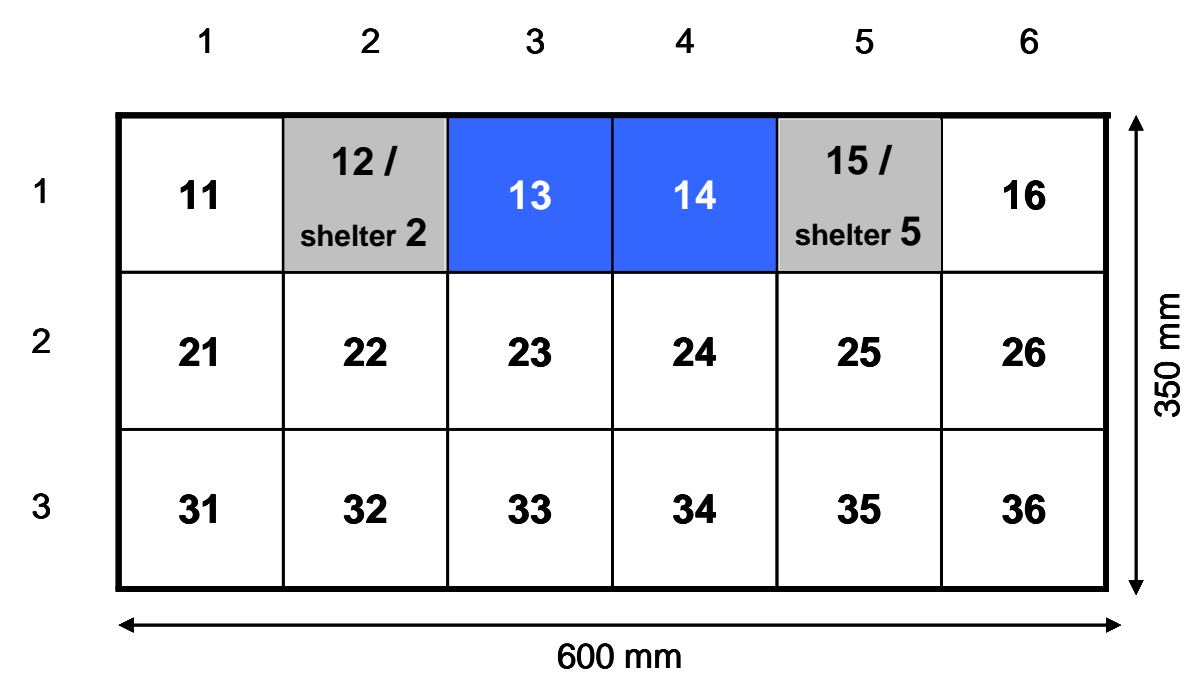

Figure 2.1 Experimental enclosure of $350 \times 600 \times 350 \mathrm{~mm}$ (width $\mathrm{x}$ length $\mathrm{x}$ height) with shelters (light grey) and water dish (dark grey). For analyses, the space was notionally divided into 20 equally sized squares. Squares 13 and 14 housed the water pen, and squares 12 and 15 were covered with the shelters. When tuatara were inside shelters they were described as occupying either square 2 or 5 ; when they were located on top of shelters they were described as occupying either square 12 or 15.

Each experimental group was comprised of two tuatara. Pairs were chosen according to seven scenarios based on sex and relative size, and each scenario was replicated four times with different pairs. The order of experiments was randomized. The seven scenarios were:

(S1) different sized males - big male vs. small male;

(S2) different sized females - big female vs. small female;

(S3) different sized male and female - big male and small female;

(S4) different sized male and female - big female and small male;

(S5) similar sized male and female;

(S6) similar sized males;

(S7) similar sized females.

Juveniles were sexed via laparoscopy two and a half months prior to the experimental period (Cree et al. 1990; Nelson 2001). All animals were measured (total length [TL]; snout-to-vent-length [SVL]; and mass) on the first day of each 
experimental set-up to assign pairs. Pairs were chosen according to the right sex combination and to either minimise or maximise their size differences for pairs of similar size or different size, respectively. Dyads with animals of different size had a mean ( $\pm 1 \mathrm{SE}$ ) TL difference of $50 \pm 6.7 \mathrm{~mm}$ (range: $16-98$ ), a mean SVL difference of $16.8 \pm 1.5 \mathrm{~mm}$ (range: $9-28$ ), and a mean mass difference of $14.1 \pm$ $1.2 \mathrm{~g}$ (range: $9.8-22.7$ ), while dyads with animals of equivalent size had a mean TL difference of $2 \pm 0.2 \mathrm{~mm}$ (range: $1-3$ ), a mean SVL difference of $1.0 \pm 0.3 \mathrm{~mm}$ (range: $0-3$ ), and a mean mass difference of $0.5 \pm 0.1 \mathrm{~g}$ (range: $0.0-1.0$; Table 2.1). The availability of tuatara of a certain sex and their body size ranges (Table 2.2) determined the possible maximal difference and similarity for each scenario.

Table 2.1 Mean body size differences of pairs used for each scenario (calculated as big minus small), and pooled for different sized scenarios (S1 - S4) and similar sized scenarios (S5 - S7). TL, SVL and mass (mean \pm 1 SE and ranges) are presented. S1: big male vs. small male, S2: big female vs. small female, S3: big male vs. small female, S4: big female vs. small male, S5: similar sized male and female, S6: similar sized males, S7: similar sized females.

\begin{tabular}{|c|c|c|c|c|c|c|}
\hline \multirow[t]{2}{*}{ Scenario } & \multicolumn{2}{|c|}{$\mathrm{TL}[\mathrm{mm}]$} & \multicolumn{2}{|c|}{ SVL [mm] } & \multicolumn{2}{|c|}{ Mass [g] } \\
\hline & $\begin{array}{c}\text { Mean } \\
\pm 1 \mathrm{SE}\end{array}$ & Range & $\begin{array}{l}\text { Mean } \\
\pm 1 \mathrm{SE}\end{array}$ & Range & $\begin{array}{c}\text { Mean } \\
\pm 1 \mathrm{SE}\end{array}$ & Range \\
\hline $\begin{array}{l}\text { Different } \\
\text { sized } \\
\text { scenarios } \\
\text { (S1-S4) }\end{array}$ & $50 \pm 6.7$ & $16-98$ & $16 \pm 1.5$ & $9-28$ & $14.1 \pm 1.2$ & $9.8-22.7$ \\
\hline S1 & $63 \pm 5.2$ & $51-76$ & $17 \pm 2.1$ & $14-23$ & $15.5 \pm 2.6$ & $10.7-21.5$ \\
\hline S2 & $30 \pm 4.2$ & $23-41$ & $15 \pm 0.8$ & $14-17$ & $11.2 \pm 0.7$ & $10.2-13.3$ \\
\hline S3 & $84 \pm 7.3$ & $69-98$ & $25 \pm 1.2$ & $23-28$ & $19.4 \pm 1.3$ & $16.9-22.7$ \\
\hline S4 & $24 \pm 3.6$ & $16-32$ & $10 \pm 0.6$ & $9-12$ & $10.2 \pm 0.2$ & $9.8-10.7$ \\
\hline $\begin{array}{l}\text { Similar } \\
\text { sized } \\
\text { scenarios } \\
\text { (S5-S7) }\end{array}$ & $2 \pm 0.2$ & $1-3$ & $1.0 \pm 0.3$ & $0-3$ & $0.5 \pm 0.1$ & $0.0-1.0$ \\
\hline S5 & $1 \pm 0.3$ & $1-2$ & $1 \pm 0.4$ & $0-2$ & $0.4 \pm 0.2$ & $0.1-0.7$ \\
\hline S6 & $3 \pm 0.3$ & $2-3$ & $0.3 \pm 0.3$ & $0-1$ & $0.6 \pm 0.2$ & $0.0-1.0$ \\
\hline S7 & $2 \pm 0.5$ & $1-3$ & $2 \pm 0.5$ & $1-3$ & $0.6 \pm 0.2$ & $0.2-0.9$ \\
\hline
\end{tabular}


Table 2.2 Size ranges of juveniles, showing TL, SVL and mass at the beginning (June 2008) and end (October 2008) of the experimental period. Length was measured $\pm 1 \mathrm{~mm}$ and mass $\pm 0.01 \mathrm{~g}$.

\begin{tabular}{|c|c|c|c|c|c|c|}
\hline & \multicolumn{2}{|c|}{ TL [mm] } & \multicolumn{2}{|c|}{ SVL [mm] } & \multicolumn{2}{|c|}{ Mass [g] } \\
\hline & June & Oct. & June & Oct. & June & Oct. \\
\hline Females & $130-164$ & $134-200$ & $79-97$ & 84-104 & $12.8-25.3$ & $16.1-36.4$ \\
\hline Males & $143-213$ & $158-245$ & $85-111$ & $91-112$ & $15.2-36.5$ & $18.9-42.9$ \\
\hline
\end{tabular}

Each tuatara was identified by its unique toe-clips and was additionally marked with non-toxic, semi-permanent correction fluid (Twink ${ }^{\mathrm{T} \mathrm{M}}$; for example a strip on their back or tail) for recognition in footage. There is no evidence that this method of marking would harm tuatara or change their behaviour (Towns et al. 2001; Terezow 2005; personal observation) and marks excluded the head area to avoid covering the pineal eye. Pairs were photographed prior to the start of experiments to allow for the detection of injuries sustained during an experiment. At random, one animal was placed in square 31 and the other in square 36 (Figure 2.1), facing the walls. The starting positions, time and date were noted. Between experiments, enclosures were emptied and cleaned with alcohol to remove any scent residue, and set up anew.

Due to the small number of tuatara available, repetition of individuals was unavoidable (Table A.1 in Appendix). Animals were returned to their home enclosures between experiments for a minimum of two days.

Tuatara were observed directly and/or remotely with surveillance cameras (Grand IP Camera Pro, Model 2, Grandtec) connected to a laptop (Dell ${ }^{\mathrm{TM}}$ Latitude $^{\mathrm{TM}}$ ATG D630). Cameras were mounted on specially designed lids to cover the experimental area completely and were not altered during experiments. Experiments were filmed continuously over the entire duration with a time-lapse of two images per second and footage was electronically compressed (WalkGuard [4, 9, 16 IPCam] Version5.1). The footage was viewed with the VLC media player 0.8.6h Janus (http://www.videolan.org/vlc). In addition to on-camera infrared light emitting diodes, one infrared light (IR) was fixed above each experimental enclosure to facilitate scotophasic observations. Tuatara are unable to detect IR light (Wojtusiak 1973; Meyer-Rochow 1988), hence it is assumed that the presence of IR lights had no influence on their behaviour. 


\subsubsection{Data collected}

I recorded all agonistic behaviours, and hence all interactions that were related to fighting, both aggressive and submissive (Scott \& Fredericson 1951). These included six aggressive categories: chasing, attacking (including lesions), posing, aggressive tail biting (including tail loss), following and pushing away from food (see Table 2.3 in results for definitions), as well as two submissive categories: avoidance, and cessation of foraging (see Table 2.4 for definitions). Only behaviours that could be unambiguously rated as agonistic are presented in Table 2.3 and Table 2.4 and used in analyses. I noted if tail biting (aggressive or not) happened during feeding or at other times. Biting directed at food items during feeding trials (for example food stealing; Chapter 4) was excluded, as was non-aggressive tail biting and following, which was linked to mistaking a tail for food (see discussion).

Experiments were recorded continuously. Due to the enormous amount of data generated, the experimental period was broken down into six 24 hour periods of which two were sampled: the second (P2) and fifth (P5). This choice was made before the start of experiments, allowing tuatara a day to settle in enclosures, and so that both sampling times were 24 hours after the last feeding and 24 hours prior to the next feeding event (Chapter 4) with one in the earlier half of the experiment and one in the later half. Out of those 2 days, the first 10 minutes of each hour were scored. Both feeding trials during each experiment (after 72 and 144 hours, 100 minutes each) were also sampled (Chapter 4). Data on agonistic behaviours were collected (1) remotely on footage at sampling times in P2 and P5, (2) through direct observations of the first 50 minutes of each feeding trial and remotely on footage during the second 50 minutes, (3) through direct observations of the first 50 minutes of each experiment, and (4) indirectly through comparison of appearance before and after the experiment with the help of photographs taken before the start of experiments (to check for new lesions or tail loss).

\subsubsection{Data analysis}

Statistical analyses were performed in R 2.6.2 (R-Development-Core-Team 2008). Means are reported with \pm one SE and statistical significance is inferred at $p<0.05$.

Agonistic behaviours could be scored several times in each experiment, as each occurrence was scored separately as a single event. The exception was the category cessation of foraging which was scored as one event per minute. The 
occurrence of aggressive, submissive and agonistic (dominant and submissive behaviour pooled) behaviours within an experiment were scored separately as binomial data and count data, and were subsequently used for the following tests. Similarly, the occurrences of those behaviours were scored for males and females. The binomial data sets were conservative in that at least two occurrences of, for example, submissive behaviour were necessary to rate an experiment or an individual in an experiment positive for submissive behaviour.

A preliminary investigation using Akaike's information criterion (AIC; Akaike 1973; Burnham \& Anderson 1998) was conducted to investigate whether housing prior to experiments influenced agonistic behaviours in experimental settings. Housing both animals of a dyad in the same enclosure (three experiments in different scenarios) or different enclosures (25 experiments) prior to an experiment was excluded as a factor in further analyses as models that included this factor were a worse fit for the data than models without $(\triangle \mathrm{AIC}>2$ for models including this factor in addition to scenario or sex).

Permutated general linear models ( $\mathrm{GGLMs)}$ for binary and count data were used to test whether there was a significant difference in the occurrences of aggressive, submissive and agonistic behaviours among scenarios. Pairwise comparisons were permutated and corrected for multiple comparisons with the sequential Bonferroni method (Peres-Neto 1999). Permutations (49999 in each test) were used as the data lacked independence. For each result the original, not permutated F-value and the degrees of freedom $\left(F_{(d f)}\right)$, as well as the permutated $p$-value $(p)$ are presented. For significant pairwise comparisons only the corrected $p$-value $\left(p_{\text {corrected }}\right)$ is presented. The Levene's test was used to test for equal variances, and normal distribution was tested using the Shapiro-Wilk test, where appropriate. Original data sets were used when data did not fit assumptions but could not be improved through transformation.

Binomial tests were used to determine if relative size explained the directionality of agonistic behaviour in scenarios with animals of differing size (S1 - S4) and if sex explained the directionality of agonistic behaviour in mixed sex scenarios (S3 - S5). This non-permutated test included only those experiments where a clear dominance structure was apparent, that is, when one juvenile was associated with a higher number of aggressive or submissive behaviours than its cage-mate. 


\subsection{Results}

Agonistic interactions were common in one-year-old juvenile tuatara with a total of 239 events recorded over all 28 experiments. Agonistic behaviour occurred in 25 of the 28 experiments, and clear dominance hierarchies were obvious in 18 experiments. The number of agonistic behaviours ranged from 0 to 57 events per experiment. The number of agonistic behaviours was greater during the fifth 24 hour period (P5) than the second 24 hour period (P2 [9 aggressive behaviours, 35 submissive behaviours], P5 [29 aggressive behaviours, 43 submissive behaviours]). Conversely, fewer agonistic behaviours were observed during the second feeding (F2) than during the first feeding ( $F 1$ [22 aggressive behaviours, 43 submissive behaviours], F2 [13 aggressive behaviours, 31 submissive behaviours]). When P2 and $\mathrm{F} 1$ were pooled to represent the first half of experiments, and compared with P5 and F2, pooled for the second half, there was no major change in the occurrences of agonistic behaviours over the experimental duration (first half [31 aggressive behaviours, 78 submissive behaviours], second half [42 aggressive behaviours, 74 submissive behaviours]).

Over all 28 experiments, 84 aggressive and 155 submissive behaviours were recorded; hence submissive behaviours were more common than aggressive behaviours. Avoidance accounted for $54 \%$ of all agonistic behaviours, and was thus the most common behaviour. Avoidance accounted for $83 \%$ of submissive behaviours ( $n=25$ participants), while stopping to forage was the less common of the two submissive categories, and accounted for $17 \%$ of submissive behaviours ( $\mathrm{n}$ $=4$ participants). Out of the six aggressive behavioural categories, three occurred in higher numbers: following accounted for $37 \%$ ( $n=7$ participants), attacking for 30 $\%$ ( $n=10$ participants), and posing for $21 \%$ ( $n=6$ participants) of aggressive behaviours. Chasing was less common and accounted for $7 \%$ of aggressive behaviours ( $n=3$ participants). Pushing a cage-mate away from food ( $n=1$ participant), and aggressive tail biting ( $n=2$ participants) were rare and each accounted for $2 \%$ of aggressive behaviours. Differences in behaviour between sexes, based on the number of females and males in which a particular behaviour occurred, were not statistically analysed because numbers for most behaviours were very low (Table 2.3 \& Table 2.4). No major differences were observed between the agonistic behavioural repertoires between sexes, but the two rarest behaviours were exhibited by one sex exclusively; pushing a cage-mate away from food occurred in one female only; aggressive tail biting occurred in two males only. 
Table 2.3 Definitions and occurrences of aggressive behaviours. The number of occurrences and number of animals displaying a particular behaviour are presented as total numbers, and for males $(\mathrm{m})$ and females $(\mathrm{f})$ separately.

\begin{tabular}{|c|c|c|c|c|c|c|c|}
\hline \multirow{2}{*}{$\begin{array}{l}\text { Aggressive } \\
\text { behaviours } \\
\text { Categories }\end{array}$} & \multirow[t]{2}{*}{ Definition } & \multicolumn{3}{|c|}{ \# of occurrences } & \multicolumn{3}{|c|}{$\begin{array}{l}\text { \# of animals } \\
\text { displaying } \\
\text { behaviour }\end{array}$} \\
\hline & & $\mathrm{m}$ & $f$ & total & $\mathrm{m}$ & $f$ & total \\
\hline $\begin{array}{l}\text { Pushing } \\
\text { away from } \\
\text { food }\end{array}$ & $\begin{array}{l}\text { - Pushing cage-mate away from food with head } \\
\text { - Snout closed }\end{array}$ & 0 & 2 & 2 & 0 & 1 & 1 \\
\hline Posing & $\begin{array}{l}\text { - Raising trunk from ground } \\
\text { - Standing stiff in pose } \\
\text { - Includes face-offs }\end{array}$ & 13 & 5 & 18 & 4 & 2 & 6 \\
\hline Following & $\begin{array}{l}\text { - Pursuing cage-mate in slow movement } \\
\text { - Cage-mate attentive to following \& likely keeping its distance in response }\end{array}$ & 24 & 7 & 31 & 6 & 1 & 7 \\
\hline Chasing & $\begin{array}{l}\text { - Pursuing cage-mate in a rapid movement } \\
\text { - Cage-mate likely to run off }\end{array}$ & 4 & 2 & 6 & 1 & 2 & 3 \\
\hline Attacking & $\begin{array}{l}\text { - Bite or bite attempt at the head or anterior of trunk } \\
\text { - Chase including collisions at full speed and/or including bite or bite attempt at } \\
\text { the head or anterior of trunk } \\
\text { - Lesion in skin contracted during experiment, discovered after experiment }\end{array}$ & 18 & 7 & 25 & 5 & 5 & 10 \\
\hline $\begin{array}{l}\text { Aggressive } \\
\text { tail biting }\end{array}$ & $\begin{array}{l}\text { - Bite or bite attempt directed at the end of the tail } \\
\text { - Repeated following with repeated bites or bite attempts } \\
\text { - If seizing tail, not letting go for several seconds } \\
\text { - Tail loss (a portion of the end of the tail), observed during experiment or } \\
\text { discovered after experiment }\end{array}$ & 2 & 0 & 2 & 2 & 0 & 2 \\
\hline
\end{tabular}


Table 2.4 Definitions and occurrences of submissive behaviours. The number of occurrences and number of animals displaying a particular behaviour are presented as total numbers, and for males $(m)$ and females $(f)$ separately.

\begin{tabular}{|c|c|c|c|c|c|c|c|}
\hline \multirow{2}{*}{$\begin{array}{l}\text { Submissive } \\
\text { behaviours } \\
\text { Categories }\end{array}$} & \multirow[t]{2}{*}{ Definition } & \multicolumn{3}{|c|}{ \# of occurrences } & \multicolumn{3}{|c|}{$\begin{array}{c}\text { \# of animals } \\
\text { displaying } \\
\text { behaviour }\end{array}$} \\
\hline & & $\mathrm{m}$ & $f$ & total & $\mathrm{m}$ & $f$ & total \\
\hline $\begin{array}{l}\text { Cessation of } \\
\text { foraging }\end{array}$ & $\begin{array}{l}\text { - Abrupt stop in foraging in the presence of cage-mate } \\
\text { - May or may not be in response to aggressive behaviour }\end{array}$ & 1 & 26 & 27 & 1 & 3 & 4 \\
\hline Avoidance & $\begin{array}{l}\text { - Trying to keep a certain distance from other tuatara } \\
\text { - Walking and running } \\
\text { - At times in response to the movement of its cage-mate (aggressive or non- } \\
\text { aggressive), at other times independent of such behaviour (cage-mate not } \\
\text { necessarily moving) }\end{array}$ & 84 & 44 & 128 & 12 & 13 & 25 \\
\hline
\end{tabular}


A total of 13 tail biting events was observed and the probability of a tail biting event was about ten times greater during feeding ( 0.19 tail bites per hour feeding vs. 0.02 tail bites per hour outside feeding). Of the 13 tail biting events only two were rated aggressive and were included in pGLMs and Table 2.3. In one case a bigger male kept following a smaller male (S1), tried biting its tail repeatedly within a few minutes, seized the tail and did not let go for several seconds, resulting in tail loss. In the second case, tail loss was discovered at the end of the experiment which included two similar sized males (S6). Tail loss, most probably through tail autotomy, was limited to those two occurrences over all experiments. Missing tail parts were not recovered. One was immediately eaten by the biting tuatara (direct observation). It was presumed that the second lost tail part was also eaten (discovered after the termination of the experiment, no direct observation). All other 11 cases of tail biting including associated following behaviour were rated non-aggressive and excluded from analysis and Table 2.3. In those cases, animals approached tails as they approach food items: a slow approach focused on the desired item, with back limbs twitching occasionally. Tails were released immediately once the bitten animal moved, it did not lead to tail loss and never occurred in combination with aggressive behaviours. Non-aggressive tail biting, exhibited by seven different animals (five males and two females), occurred in eight experiments out of four scenarios: S1, S2, S5, and S6. Four animals of relatively larger size bit smaller ones; smaller animals did not bite bigger ones. Three similar sized individuals bit others of similar size.

Dominance hierarchies were established in $87.5 \%$ of dyads with different sized animals (14 of 16 dyads; $\mathrm{S} 1$ - S4), but only in $33.3 \%$ of dyads with similar sized animals (4 of 12 dyads; S5 - S7; Table 2.5). Dominance hierarchies could not be discerned in experiments in which no aggressive behaviours and no or few submissive behaviours (relatively equally distributed between both animals) were observed, hence those experiments were excluded from tests. This was the case in two experiments of scenarios with different sized animals (S1 - S4), one of S2 (big female vs. small female) and one of S4 (big female vs. small male). Relatively larger juveniles were significantly more likely to show aggressive than submissive behaviours $(p=0.002)$, and thus being ranked first (dominant) in the established hierarchy. Relatively smaller juveniles were significantly more likely to show submissive than aggressive behaviours $(p=0.002)$, and thus being ranked second (submissive). 
Table 2.5 Scenarios and experiments in which clear dominance hierarchies were established.

\begin{tabular}{lcc}
\hline Scenario & \multicolumn{2}{c}{$\begin{array}{c}\text { Experiments in which a clear } \\
\text { dominance hierarchy was established }\end{array}$} \\
\hline & $\mathrm{n}$ & $\%$ \\
${$\cline { 2 - 3 }$} }$ & 4 & 100 \\
S2: Big female vs. small female & 3 & 75 \\
S3: Big male vs. small female & 4 & 100 \\
S4: Big female vs. small male & 3 & 75 \\
S5: Similar sized male and female & 1 & 25 \\
S6: Similar sized males & 2 & 50 \\
S7: Similar sized females & 1 & 25 \\
\hline
\end{tabular}

A clear dominance hierarchy could be determined in $66.7 \%$ of mixed sex dyads ( 8 of 12 dyads; S3 - S5; Table 2.5). This was not the case in the remaining four experiments, one of S4 (big female vs. small male) and three of S5 (similar sized male and female) which were thus excluded from tests. Neither sex was more likely to respond aggressively ( $p=0.73$ ) or submissively $(p=0.73$ ), and therefore no sex was more likely to be dominant over the other.

In established dominance hierarchies, the aggressive juvenile was dominant during the whole course of an experiment, and was ranked first. The submissive juvenile remained submissive, and was ranked second. With one exception, juveniles responded submissively to aggressive encounters. In one case, a face-off between males of different size during the first 50 minutes of an experiment, an aggressive response occurred to an aggressive encounter. This was also the only experiment in which a smaller animal dominated a bigger animal.

The social context (scenario) influenced the number of aggressive behaviours (count data) during experiments but the trend was not statistically significant $\left(\mathrm{F}_{(6)}=\right.$ 2.08; $p=0.07$; Figure 2.2; Table 2.6). Aggressive behaviours were more common in both male only scenarios ( $\mathrm{S} 1$ : big male vs. small male [11.50 \pm 6.51 , range: $0-26$ ], S6: similar sized males [3.25 $\pm 2.14 \mathrm{SE}$, range: $0-9]$ ), and experiments of S4 (big female vs. small male [ $4.75 \pm 3.30$, range: $0-14]$ ). The remaining scenarios showed a lower number of occurrences (S2: big female vs. small female [1.00 \pm 0.41 , range: $0-2$ ], S3: big male vs. small female [0.25 \pm 0.25 , range: $0-1]$, S5: 


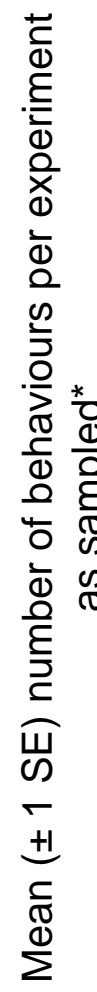

40

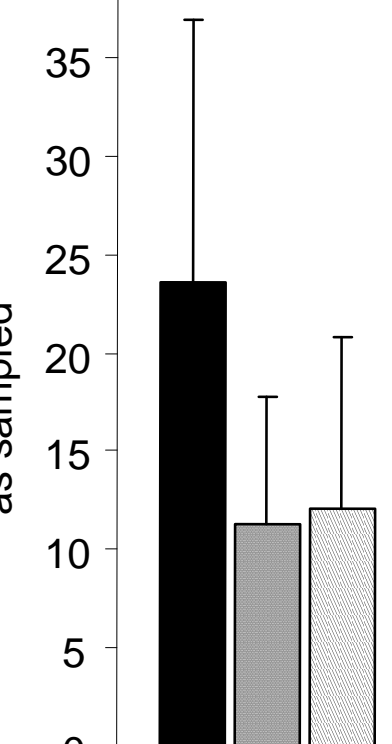

0

S1: big male vs. small male

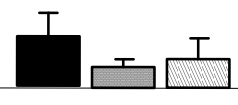

S2: big female vs. small female

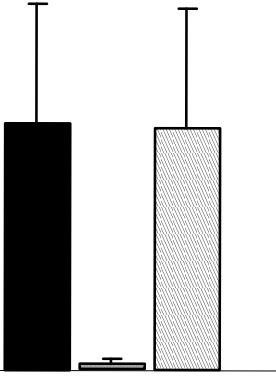

S3: big male

vs. small female

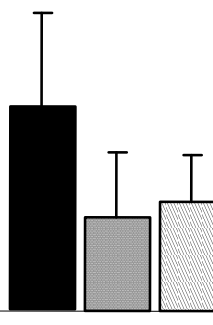

S4: big female vs. small male

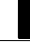

S5:

5: similar sized male and female
Agonistic behaviour

Aggressive behaviour

Submissive behaviour

Figure 2.2 Mean ( $\pm 1 \mathrm{SE}$ ) number of agonistic, aggressive and submissive behaviours per experiment for each scenario (count data; based on four experiments per scenario). Agonistic behaviours are all interactions related to fighting, that is, the sum of both aggressive and submissive behaviours. $\left(^{*}\right)$ Data on behaviours were collected (1) remotely on footage at sampling times in the second and fifth $24 \mathrm{~h}$ period of the experiments (P2 \& P5; $4 \mathrm{~h}$ each), (2) through direct observations of the first 50 minutes of each feeding trial and remotely on footage during the second 50 minutes, (3) through direct observations of the first 50 minutes of each experiment, and (4) indirectly through comparison of appearance before and after the experiment with the help of photographs taken before the start of experiments (to check for new lesions or tail loss). 
Table 2.6 pGLMs investigating agonistic, aggressive and submissive behaviours among all scenarios or a subset of scenarios with scenario or sex as factor, based on experiments with or without the behaviours (binomial data) or on absolute numbers of behaviours in experiments (count data). F, df, $\mathrm{p}$ and significant pairwise comparisons are presented. S1: big male vs. small male, S2: big female vs. small female, S3: big male and small female, S4: big female and small male, S5: similar sized male and female, S6: similar sized males, S7: similar sized females.

\begin{tabular}{|c|c|c|c|c|c|c|c|}
\hline Data & Factor & $\begin{array}{l}\text { Behavioural } \\
\text { variable }\end{array}$ & $\begin{array}{l}\text { Data } \\
\text { type }\end{array}$ & $\mathrm{F}$ & df & $p$ & $\begin{array}{l}\text { Significant } \\
\text { pairwise } \\
\text { comparisons }\end{array}$ \\
\hline \multirow{6}{*}{ 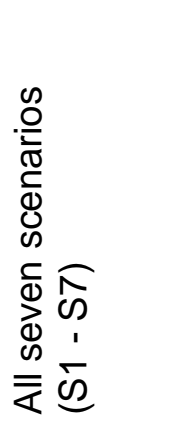 } & \multirow{6}{*}{ 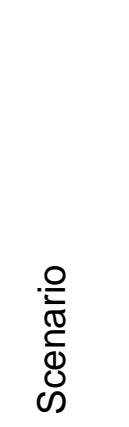 } & \multirow{2}{*}{$\begin{array}{l}\text { Agonistic } \\
\text { behaviour }\end{array}$} & Binomial & 1.50 & 6 & 0.28 & none \\
\hline & & & Count & 1.71 & 6 & 0.13 & none \\
\hline & & \multirow{2}{*}{$\begin{array}{l}\text { Aggressive } \\
\text { behaviour }\end{array}$} & Binomial & 1.40 & 6 & 0.24 & none \\
\hline & & & Count & 2.08 & 6 & 0.07 & none \\
\hline & & \multirow{2}{*}{$\begin{array}{l}\text { Submissive } \\
\text { behaviour }\end{array}$} & Binomial & 0.95 & 6 & 0.51 & none \\
\hline & & & Count & 1.29 & 6 & 0.21 & none \\
\hline \multirow{6}{*}{ 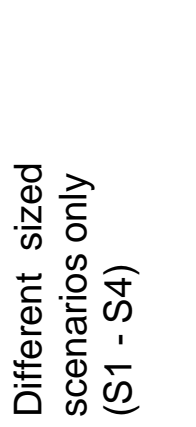 } & \multirow{6}{*}{ 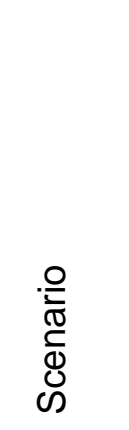 } & \multirow{2}{*}{$\begin{array}{l}\text { Agonistic } \\
\text { behaviour }\end{array}$} & Binomial & 1.57 & 3 & 0.048 & none \\
\hline & & & Count & 1.28 & 3 & 0.31 & none \\
\hline & & \multirow{2}{*}{$\begin{array}{l}\text { Aggressive } \\
\text { behaviour }\end{array}$} & Binomial & 1.00 & 3 & 0.42 & none \\
\hline & & & Count & 1.98 & 3 & 0.10 & none \\
\hline & & \multirow{2}{*}{$\begin{array}{l}\text { Submissive } \\
\text { behaviour }\end{array}$} & Binomial & 0.80 & 3 & 0.75 & none \\
\hline & & & Count & 0.93 & 3 & 0.40 & none \\
\hline \multirow{6}{*}{ 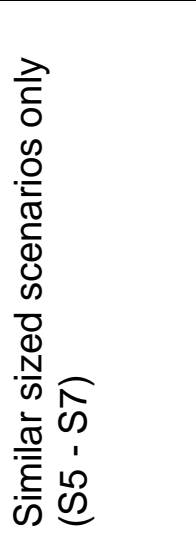 } & \multirow{6}{*}{ 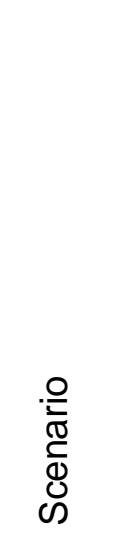 } & \multirow{2}{*}{$\begin{array}{l}\text { Agonistic } \\
\text { behaviour }\end{array}$} & Binomial & 0.27 & 2 & 0.50 & none \\
\hline & & & Count & 1.59 & 2 & 0.26 & none \\
\hline & & \multirow[t]{2}{*}{$\begin{array}{l}\text { Aggressive } \\
\text { behaviour }\end{array}$} & Binomial & 3.00 & 2 & 0.19 & $\begin{array}{l}\text { S5 vs. S6: } \\
\text { p }_{\text {corrected }}<0.001 \\
\text { S6 vs. S7: }\end{array}$ \\
\hline & & & Count & 2.12 & 2 & 0.19 & $\begin{array}{l}\mathrm{p}_{\text {corrected }}<\mathbf{0 . 0 0 1} \\
\text { none }\end{array}$ \\
\hline & & \multirow{2}{*}{$\begin{array}{l}\text { Submissive } \\
\text { behaviour }\end{array}$} & Binomial & 0.27 & 2 & 0.50 & none \\
\hline & & & Count & 0.84 & 2 & 0.52 & none \\
\hline \multirow{6}{*}{ 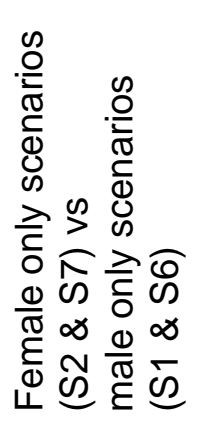 } & \multirow[b]{6}{*}{ હ } & \multirow{2}{*}{$\begin{array}{l}\text { Agonistic } \\
\text { behaviour }\end{array}$} & Binomial & 093 & 1 & 0.13 & n.a. \\
\hline & & & Count & 3.36 & 1 & 0.06 & n.a. \\
\hline & & \multirow{2}{*}{$\begin{array}{l}\text { Aggressive } \\
\text { behaviour }\end{array}$} & Binomial & 2.74 & 1 & 0.03 & n.a. \\
\hline & & & Count & 3.63 & 1 & 0.049 & n.a. \\
\hline & & \multirow{2}{*}{$\begin{array}{l}\text { Submissive } \\
\text { behaviour }\end{array}$} & Binomial & 0.93 & 1 & 0.13 & n.a. \\
\hline & & & Count & 2.12 & 1 & 0.06 & n.a. \\
\hline
\end{tabular}


similar sized male and female [0.00 \pm 0.0 , range: $0-0$ ], and S7: similar sized females $[0.25 \pm 0.25$, range: $0-1])$. Agonistic and submissive behaviours were apparent in all scenarios with no significant differences, and pairwise comparisons were not significant after Bonferroni corrections (Figure 2.2; Table 2.6).

When housed with a juvenile of different size (S1 - S4), social context (scenario) significantly influenced the number of experiments in which agonistic behaviours occurred (binomial data; $p=0.048 ; F_{(3)}=1.57$ ). Agonistic behaviours were observed in two experiments of $S 2$ ( $50 \% ; n=4$; big female vs. small female), in three experiments of $S 1$ (75\%; $n=4$; big male vs. small male), and in all four experiments of S3 (100\%; $n=4$; big male vs. small female) and $S 4(100 \% ; n=4 ;$ big female vs. small male). However, no significant differences in aggressive or submissive behaviours were found among different sized scenarios when analysed independently (Table 2.6; Figure 2.2).

Pairwise comparisons between similar sized scenarios (S5 - S7) showed that S6 (similar sized males) had significantly more experiments in which aggressive behaviours occurred (50\%; 2 of 4 ) than did S5 (0\%; 0 of 4; similar sized male and female; binomial data; S5 vs. S6: $p_{\text {corrected }}<0.001$ ) or S7 (0\%; 0 of 4; similar sized females; binomial data; S6 vs. S7: $\left.p_{\text {corrected }}<0.001\right)$. Comparisons of agonistic and submissive behaviours among similar sized scenarios showed no significant differences (Table 2.6; Figure 2.2).

Aggressive behaviours occurred in significantly more experiments (binomial data) and were significantly more numerous (count data) during male-male scenarios (S1 \& S6) than during female-female scenarios (S2 \& S7; binomial data $\left[p=0.03 ; F_{(1)}=\right.$ $2.74]$, count data $\left[p=0.049 ; F_{(1)}=3.63\right]$ ). Agonistic and submissivebehaviours (both count data, but not binomial data) followed the same trend but were not significantly significant (Table 2.6; Figure 2.2).

Comparisons between sexes based on participants showed no statistically significant differences between agonistic, aggressive or submissive behaviours (Table 2.7). Across all 28 experiments, nine male participants showed aggressive behaviours (count data); four of those displayed more than one aggressive behaviour (conservative binomial data). A total of six female participants showed aggressive behaviours (count data); three of those displayed more than one 
aggressive behaviour (conservative binomial data). Aggressive males showed a pattern of a higher mean number of aggressive behaviours (6.8 \pm 2.6 ; range: $1-21$ ) than did aggressive females (3.8 \pm 1.9 ; range: $1-13$; based on count data). Across all experiments, 12 male participants showed submissive behaviours (count data); eight of those displayed more than one submissive behaviour (conservative binomial data). A total of 13 female participants showed submissive behaviours (count data); ten of those displayed more than one submissive behaviour (conservative binomial data). Males and females showed a relative similar mean number of submissive behaviours per individual (males [7.1 \pm 3.0 ; range: $1-38]$, females [5.4 \pm 2.2 ; range: 1 -30]; based on count data). Across all 28 experiments, 17 male participants showed agonistic behaviours (count data); 11 of those displayed more than one agonistic behaviour (conservative binomial data). The number of male participants exhibiting agonistic behaviours is not the sum of male participants showing aggressive and submissive behaviours as some participants showed both aggressive and submissive behaviours. A total of 19 female participants showed agonistic behaviours (count data); 13 of those displayed more than one agonistic behaviour (conservative binomial data). Males that exhibited agonistic behaviours showed a pattern of a higher mean number of agonistic behaviours than did females (males [8.6 \pm 2.4 ; range: $1-38$ ], females [4.9 \pm 1.6 ; range: $1-30$ ]; based on count data).

Table 2.7 pGLMs investigating agonistic, aggressive and submissive behaviours between sexes, based on all participants ( $n=56 ; 28$ males, 28 females) from all scenarios ( $S 1-S 7$ ) showing or not showing the behaviours (binomial data) or on absolute numbers of behaviours (count data). F, df, $p$ and significant pairwise comparison are presented. S1: big male vs. small male, S2: big female vs. small female, S3: big male and small female, S4: big female and small male, S5: similar sized male and female, S6: similar sized males, S7: similar sized females.

\begin{tabular}{|c|c|c|c|c|c|c|c|}
\hline Data & Factor & $\begin{array}{l}\text { Behavioural } \\
\text { variable }\end{array}$ & $\begin{array}{l}\text { Data } \\
\text { type }\end{array}$ & $\mathrm{F}$ & $d f$ & $p$ & $\begin{array}{l}\text { Significant } \\
\text { pairwise } \\
\text { comparisons }\end{array}$ \\
\hline \multirow{6}{*}{ 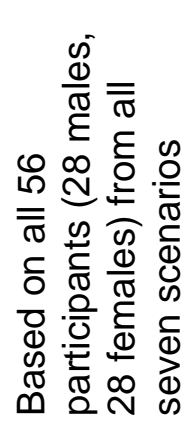 } & \multirow{6}{*}{ હ } & \multirow{2}{*}{$\begin{array}{l}\text { Agonistic } \\
\text { behaviour }\end{array}$} & Binomial & 0.28 & 1 & 0.75 & n.a. \\
\hline & & & Count & 0.87 & 1 & 0.36 & n.a. \\
\hline & & \multirow{2}{*}{$\begin{array}{l}\text { Aggressive } \\
\text { behaviour }\end{array}$} & Binomial & 0.57 & 1 & 0.25 & n.a. \\
\hline & & & Count & 1.45 & 1 & 0.25 & n.a. \\
\hline & & \multirow{2}{*}{$\begin{array}{l}\text { Submissive } \\
\text { behaviour }\end{array}$} & Binomial & 0.32 & 1 & 0.55 & n.a. \\
\hline & & & Count & 0.09 & 1 & 0.74 & n.a. \\
\hline
\end{tabular}




\subsection{Discussion}

The incidences of aggression differed among social scenarios, whereas submissive behaviours showed no significant differences. Males were more aggressive towards males than females towards females. Size influenced the directionality of aggression and thus the social ranking of individuals with relatively bigger juveniles acting aggressively and smaller ones submissively regardless of sex. Clear dominance hierarchies were established in 18 out of the 28 experiments, predominantly but not exclusively in scenarios with different size dyads.

The directionality of aggression was influenced by relative size not sex, with bigger juveniles reacting aggressively and smaller ones submissively. When a juvenile behaved aggressively, the cage-mate, usually of smaller or similar size, reacted submissively. A tuatara juvenile that had established itself as the dominant individual in an experimental enclosure, remained dominant for the duration of the experiment. Observations by other captive holders indicate concurrence with this pattern. For example, larger juveniles may charge and chase smaller juveniles of similar age (Goetz, personal communication), and immature tuatara housed with bigger individuals may die of injuries inflicted by attacks (Buller 1879). Ultimately, when a crucial size difference is reached, larger tuatara will eat smaller conspecifics (Newman et al. 1979).

One year old tuatara showed a subset of the aggressive territorial behavioural repertoire of adults (Gillingham et al. 1995) but had no set territories (Chapter 3). Posing, chasing and biting were common in juveniles, but face-offs were extremely rare, and body inflation and crest erection were not observed. Aggression may be linked to the development of territorial behaviour during ontogeny. At one year of age, establishment of dominance hierarchies could facilitate the onset of territoriality during later life stages (Goetz \& Thomas 1994a; Gillingham et al. 1995). Furthermore, interference competition for food during feeding trials showed the same directionality as aggression, where bigger juveniles were aggressive towards smaller individuals. When food resources are limited, dominant juveniles are able to acquire significantly more food than their submissive cage-mates which is likely to exacerbate size differences (Chapter 4).

Aggressive and submissive behaviours are commonly correlated with size and dominance in reptiles. Typically, the largest male lizard (SVL) holds the highest 
dominance rank, and the most dominant individual is also the most aggressive (Brattstrom 1974). Smaller female skinks, Scincella lateralis, show more submissive behaviours than larger females, but such behaviour was not reported for males (Akin 1998). Bigger and/or dominant captive juvenile crocodiles, Crocodylus niloticus and Crocodylus porosus, are more aggressive, and aggression is predominantly directed against smaller, lower ranked individuals (Bustard \& Maharana 1983; Morpurgo et al. 1993). Adult crocodiles, Crocodylus moreleti, react aggressively towards smaller and younger conspecifics (Hunt 1977). Moreover, captive turtles form dominance hierarchies based on size (Evans 1940; Froese \& Burghard 1974).

The frequency of aggressive behaviours in immature tuatara did not change noticeably during the six day experiments. Six days may not be enough time to settle and stabilize a dominance relationship in tuatara juveniles. However, social ranks remained constant, which suggests that the dominance structure was stable. Changes in social status are rare in captive adult tuatara (Hazley \& Nelson, personal communication) and juvenile lizards, Anolis aeneus (Stamps \& Krishnan 1994b). Thus it is likely that the level of aggressive behaviours may be normal for tuatara juveniles kept at comparable densities in captivity, and may be necessary to establish and maintain a hierarchy. This finding contrasts with display behaviour in the western fence lizard, Sceloporus occidentalis, observed by Brattstrom (1974). All individuals are aggressive on the first day but the behaviours diminished during the following days. The decline is clearly observable after five days, and ultimately, after 15 days, only the most dominant individual shows a few aggressive behaviours. In some captive iguanid lizards higher activity in response to the removal of the most dominant individual settles within 24 hours or less (Carpenter 1967). Nevertheless, Torr \& Shine (1996) observed a finding similar to mine, a relatively stable level of aggression, in captive groups of Sceloporus occidentalis, the same lizard species in which Brattstrom (1974) made his observations (see above).

Aggressive behaviours were more frequent in male-male dyads than female-female dyads, suggesting a more intense struggle for dominance in males compared to females. However, dyads of a small, submissive male and a big, aggressive female also had high numbers of aggressive behaviours, possibly because a big female may need more overt aggression to maintain her perceived superior status due to 
size. Over all seven scenarios tested, there is no clear division between either only intrasexual or intersexual aggression.

My finding of more aggression among males is similar to occasional observations in adult tuatara. Conflicts, usually between large males, have been documented in captivity (Gans et al. 1984; Keall, personal communication). In the wild, aggressive behaviour during intrasexual site defence is documented. However, male encounters appear to be more frequent and resulted in more conspicuous and elaborate behaviour than female encounters (Gillingham \& Miller 1991; Gillingham et al. 1995). In mature life stages, aggression in tuatara is linked to intrasexual competition and is therefore more prominent in same sex encounters (Gillingham \& Miller 1991; Gillingham et al. 1995; Moore 2008). In wild adult tuatara, both sexes were equally likely to react aggressively towards a same sex model in their teritory; males more often reacted with a display-response whereas females were more likely to react with overt aggression (Ramstad et al., unpublished data). As this contrasts with my findings in immature tuatara, it is likely that intrasexual and intersexual aggression patterns may change during ontogeny, possibly with the establishment of territories (Goetz \& Thomas 1994a), or perhaps in line with maturation (Dawbin 1962).

Even though aggression is documented in immature reptiles in relation to spacing patterns, dominance hierarchies and food competition (Stamps 1978; Stamps \& Tanaka 1981b; Stamps 1983a; Stamps 1983b; Taubes 1992; Morpurgo et al. 1993; Civantos 2000), specific information on whether sex affects the extend and directionality aggression before maturation is, to my knowledge, lacking. For this reason the following comparisons are derived from studies on mature reptiles. More aggression among male juvenile tuatara and a pattern of a higher average of aggressive behaviours in aggressive male than aggressive female juvenile tuatara is consistent with observations in other adult reptiles. In the lizard Abronia vasconcelosii, male-male contests were longer, more aggressive and involved more interaction than encounters between females or female and male encounters (Formanowicz et al. 1990). Even though females of the iguanid lizard species Tropidurus spp. from the Galapagos Islands and Uta stansburiana are aggressive towards other females, and dominant females chase others from their territories, fighting and aggression are more prominent and elaborate in male iguanid lizards (Carpenter 1967). Males of the crocodile Crocodylus porosus (Gopi \& Pandav 2009) 
and the turtle Emys orbicularis (Rovero et al. 1999) are more aggressive than females. In contrast to juvenile tuatara, observations in adult reptiles show that there is generally a relatively clear division between either more intrasexual or intersexual aggression. For example, in adult ground skinks, Scincella lateralis, aggression was more prevalent in intersexual contests (Akin 1998), whereas intersexual pairs of adult alligator lizards, Abronia vasconcelosii, showed the least aggression in comparison with intrasexual pairs (Formanowicz et al. 1990).

Tail biting was observed on 13 occasions in this study. Tail loss is common in captive juvenile (Nelson et al. 2004b) and wild adult tuatara (Dawbin 1949, 1962; Gillingham et al. 1995). Bites directed at the tail are linked to aggressive encounters in territorial adults and happen during fights (Gillingham \& Miller 1991; Gillingham et al. 1995). Tail loss through tail autotomy was observed once in this context (Gillingham et al. 1995) and various authors have presumed occurrences were due to fighting exclusively (Robb 1980; Gans et al. 1984; Gillingham et al. 1995). In captive juveniles, tail loss can also occur during moulting, but was assumed to be commonly inflicted by attacks from juvenile cage-mates (Nelson et al. 2004b). Therefore, Nelson et al. (2004b) suggested, based on findings of her study on captive reared juvenile tuatara, that artificially incubated individuals may be less aggressive than naturally incubated tuatara juveniles, as only $73 \%$ of the former but $100 \%$ of the later had lost a part of their tail at ten months of age (group housing; both incubation regimes separately). However, as most tail bites were related to mistaking a tail for food, as I will outline below, tail loss may not reflect on the level of aggressiveness. Incidences of tail biting in juveniles were ten times more likely to happen during feeding than non feeding times and were, apart from two exceptions, unrelated to any other aggression. Also, the approach towards a tail was similar to the careful approach to a food item and not an aggressive lunge. The occurrence of twitching back limbs observed during tail biting incidents has only ever been associated with feeding, and not aggression (personal observation). For these reasons, I suggest that there are two forms of tail biting in juveniles: one aggressive and rare since it was only observed twice in this study, and the more common one when a tail is mistaken for a food item. Walls (1981) experimented with the feeding behaviour of wild adult tuatara and found that any object of appropriate size, even feathers and leaves that were moved attracted attention and could elicit repeated biting in tuatara. During feeding, even immobile objects of appropriate size such as faeces can elicit biting (personal observation). Also, even the two tail biting 
instances that were rated aggressive cannot preclude motivation to feed rather than pure aggression as the cause. Ingestion of a lost tail was directly observed in one case, similar to the observation by Gillingham et al. (1995) of an uninvolved wild tuatara ingesting an autotomized, wriggling tail after a biting attack between two other tuatara.

The main confounding factors of my study are a small sample size and the lack of independence due to the limited number of study subjects, equipment and time. Although human disturbance was kept as low as possible, normal husbandry procedures and further experiments on feeding efficiency (Cranshaw 2009) may have affected study animals. Juveniles were used over a four month period and effects of learning and developmental variation were possible (Froese \& Burghard 1974). Furthermore, the social rank a tuatara had within its home enclosure and/or prior experimental pairs may have influenced its behaviour (Beaugrand \& Zayan 1985; Schuett 1997; Drummond \& Canales 1998). Some more subtle agonistic behaviours such as body inflation or crest erection and possibly head nodding may have been present but could not be recorded due to small juvenile body size and the camera angle and quality. Nevertheless patterns in the occurrence and directionality of agonistic behaviours were obvious and supported by observations in other reptiles.

Aggression in juvenile tuatara is dependent on social context, and the occurrence and direction of aggression have consequences for captive management. Both factors may ultimately influence survival. Continued aggression has strong implications for the health and the energy budget of juveniles, since agonistic behaviours may result in serious injuries and death (Bustard \& Maharana 1983; Taubes 1992), are energetically expensive (Brattstrom 1974) and can be a constant stressor in a captive environment (Warwick 1995). Further, females are outcompeted by bigger and similar sized males for food (Chapter 4). Gruber (2007) found a female-biased mortality rate in mixed sex groups of captive head-started tuatara. A male-biased sex ratio in adult lizards, Lacerta vivipara, can lead to increased aggression towards females with detrimental effects for their survival and reproduction (Le Galliard et al. 2005). Holding juveniles in pairs (as in my study) is laborious and costly, hence not practical for head-starting facilities, and a solution has to incorporate bigger group settings. Therefore, I recommend housing female and male juveniles separately. Further, I would sort same sex groups by size and 
suggest more spacious enclosures for male groups as they are more aggressive towards each other. However, the sex of each individual must be known for this to be practical. Determining the sex of juveniles is feasible via knowledge of incubation temperatures (tuatara have a temperature-dependant sex determination; Cree et al. 1995; Nelson et al. 2004a), laparoscopy (Cree et al. 1990; Nelson 2001) and/or a via an analysis of external phenotypic traits (Oldman 2008). Both of the latter techniques are available from about one year of age and/or circa $60 \mathrm{~mm}$ snout-tovent-length (Nelson 2001; Oldman 2008).

Dominance relationships may vary in altered contexts, for example, between a group of two vs. a group of several individuals (Hand 1986). Research is needed to determine how my findings apply to larger groups. An experimental evaluation of how space influences the occurrence of aggressive behaviours, how this may change during ontogeny and whether density influences space defence should be encouraged. With a bigger sample size, factors such as maternal effects, incubation regime, and possible kin recognition could be explored, since there is some evidence to suggest that differences may occur (Nelson et al. 2004b, 2006). 


\section{CHAPTER THREE}

\section{Do captive juvenile tuatara compete for space?}

\subsection{Introduction}

Intra- and interspecific contest competition for resources (winners vs. losers; Birch 1957 ) is a significant pressure on the survival of many organisms (Beaver 1974; Minot 1981; Ferguson \& Fox 1984; Railsback et al. 2005). Space is probably the most important resource, and its acquisition may have important fitness implications, as it affects access to most other resources such as food, shelter, refuges, mates, nest, spawning, basking and display sites (Brattstrom 1974; Wilson 1975; Maher \& Lott 2000). Therefore, most vertebrates and many advanced invertebrates live by rigorous rules of social spacing and competitive superiority (Wilson 1975).

\subsubsection{Territoriality}

Varying definitions of territoriality have been used depending on the context, species and questions being investigated. While most conceptual definitions include sitefidelity, defence of space and/or exclusive use, the numerous operational definitions indicate how difficult it is to measure territoriality in practice. While I agree with a conceptual definition that includes all three main factors stated above, my operational definition of a territory will be limited to an exclusively used area for practical reasons (reviewed by Maher \& Lott 1995).

A territory may be defended by threat, combat or any other behaviour that evokes avoidance in other individuals (Noble 1939). Territoriality can have strong implications on survival and fitness particularly in species with high intrasexual competition (Formica et al. 2004). The acquisition of suitable habitat is positively linked to an adequate food supply, reduced predation vulnerability, refuges, access to mates and survival (Hinde 1956; Rand 1967; Civantos 2000; Moore et al. In press). Phenotypic measures, such as body size, and behavioural measures, such as aggression, can be predictors for territory size and/or quality (Watson \& Miller 1971; Civantos 2000; Afonso et al. 2008). Competition for space and other resources may even affect circadian rhythms of conspecifics, leading to time territoriality, a form of desynchronisation where individuals are active at different 
hours due to social displacement (Regal \& Connolly 1980). For example, dominant brown trout, Salmo trutta (Alanara et al. 2001), and male dragonflies, Plathemis Iydia (Campanella \& Wolf 1974), use more favourable times of the diel cycle than submissive individuals.

Social and spatial organisation and agonistic behaviours can vary with age and/or sex. For example, young blue tangs, Acanthurus coeruleus, defend territories against other juveniles but rarely against adults which are non-territorial (Bell \& Kramer 2000). In the iguanid lizard Sceloporus jarrovi, adults defend territories against adults of the same sex and juveniles. Juveniles defend territories against other juveniles. Adult and juvenile territories of $S$. jarrovi may overlap spatially but never temporally, since adults and juveniles have different peak activity periods (Simon 1976; Simon \& Middendorf 1976). Male marine iguanas, Amblyrhynchus cristatus, defend an open area of habitat during the breeding season while female site defence is limited to a nest burrow on communal nesting beaches (Carpenter 1967).

Owning and defending a (better quality/larger) territory may come at a certain cost such as more aggressive interactions including a higher risk of physical injury, attraction of parasites, and an elevated visibility to predators (Ewald et al. 1980; Baker 1983; Stapley \& Keogh 2004). In western gulls, Larus occidentalis, owners of larger territories spend more time in territorial defence than conspecifics with smaller territories (Ewald et al. 1980). Further, time spent defending a territory against conspecifics reduces the time available for other tasks such as mating, feeding and hiding from predators (Warner \& Hoffman 1980; Ydenberg \& Krebs 1987; DiazUriarte 1999, 2001). For example, territorial water skinks, Eulamprus heatwolei, showed reduced predator avoidance compared to their floating conspecifics, probably due to territorial defence, which can potentially affect their survival (Stapley \& Keogh 2004).

\subsubsection{The use of chemical cues in territorial behaviour}

Many territorial vertebrates use scent marking, the deposition of informative chemical cues in the form of urine, faeces and other secretions for territorial marking (for example reptiles [Jansson et al. 2005], amphibians [Jaeger et al. 1986; Gautier \& Miaud 2003] and mammals [Gorman 1984; Brashares \& Arcese 1999; Palagi \& Norscia 2009]). Scent marks can identify an individual as the holder of a territory 
and thereby discourage aggressive behaviour (Gosling 1982; Gosling \& McKay 1990; Gautier \& Miaud 2003). Individuals should prefer to defend their territory through indirect cues of territorial ownership, such as scent, as opposed to direct encounters which inherently involve high physical danger (Rubenstein 1982; Gorman 1984; Gosling \& McKay 1990). However, scent marking does not always indicate territorial behaviour (Johnson 1973; Hutchings \& White 2000). Faecal matter, urine and other secretions may be used to mark the location of food resources (Kruuk 1992) and to convey other information such as species identity (Sokolov \& Gromov 1993), social status (Rostain et al. 2004) or reproductive status (Beach \& Gilmore 1949). Male giant pandas, Ailuropoda melanoleuca, use urine to discriminate the reproductive status of females (Swaisgood et al. 2002). Further, in the otter, Lutra lutra, scent marking with faeces is linked to the use of fresh water, food and dens, and may signal priority of use of resources to conspecifics (Kruuk 1992).

Territoriality is common in many reptiles, especially lizards (Carpenter 1967; Brattstrom 1974; Stamps 1983a), and olfaction and vomeronasal detection play an important role during courtship, mating and other conspecific interactions (Cooper \& Burghardt 1990; Young 1998). Many lizards exhibit sexual dimorphism in odour glands, especially femoral pores, and have elaborated chemosensory systems, including the olfactory and the vomeronasal system, which can be used to detect pheromones (Mason 1992). Males carry out territorial marking with scent secretions or faeces, and can identify a rival and estimate its competitive competence via scent, suggesting that lizards use scent marking in intraspecific communication (Lopez et al. 1998; Aragon et al. 2000; Jansson et al. 2005; Carazo et al. 2007; Martin \& Lopez 2007; Carazo et al. 2008). For example, the wall lizard, Podarcis hispanica, uses scent marks from conspecifics to discriminate their competitive competence (Carazo et al. 2007) and juveniles of the lberian rock lizard, Lacerta monticola, distinguish between faeces of conspecific juveniles, mature females, and males and avoid adult males based on this information (Moreira et al. 2008).

\subsubsection{Territoriality and the role of scent in tuatara}

Tuatara, Sphenodon punctatus, sole living representatives of the reptile Order Rhynchocephalia (Gunther 1867), are predominantly nocturnal (Walls 1983; Gillingham \& Miller 1991) and have stable territories all year round (Gillingham et al. 1995; Moore 2008). The size of territories varies depending on habitat type, 
population density and sex. Territories of males are bigger than those of females, which possibly arises as a result of males competing for females (Gillingham et al. 1995; Moore et al. In press).Territorial encounters are complex, including body inflation and positioning, crest erection, chasing and biting. Ritualized displays can progress to overt aggression. Fights can inflict serious physical injuries, but escalation is rare (Gillingham et al. 1995).

Tuatara have an elaborate olfactory system similar to that of their genetic sister group, the Squamata (Rest et al. 2003), including the vomeronasal organ (Parsons 1970; Young 1998) and highly visible, large nostrils (personal observation). However, the degree to which the lizard-like (Gunther 1867; Dawbin 1962) tuatara use chemosensory cues for mediating intraspecific social interactions is unknown (Gans et al. 1984; Gillingham et al. 1995). Most findings regarding intraspecific communication in this species are linked to vision only (for example mating, male combat and territorial behaviour), and even though they are highly territorial (Gillingham et al. 1995; Moore 2008), scent marking has never been witnessed (Gillingham et al. 1995). Tuatara do not conspicuously sniff nor tongue-flick (Gillingham et al. 1995; Besson et al. 2009). However, mate choice is influenced by compatibility of genes at the major histocompatibility complex (MHC; Eggert et al. 1999; Boehm \& Zufall 2006). As MHC mate choice is linked to olfaction (Eggert et al. 1999; Boehm \& Zufall 2006), MHC-related mate choice suggests that tuatara may use olfactory cues in social interaction (Miller et al. 2009). The lipophilic composition of the cloacal gland secretion of tuatara is consistent over years and may provide a mechanism for individual recognition by conspecifics (Flachsbarth et al. 2009). Tuatara are able to discriminate prey odour (Besson et al. 2009), and Refsnider (2008) observed a tuatara probing at the ground after consuming an egg which is further proof that scent may be more important for the species than previously thought.

It is assumed that tuatara hatchlings are not territorial, as they choose to hide with conspecifics under one cover object when several are available, and show no aggression (Susan Keall \& Lindsay Hazley, personal communication). However by $2.5-3$ years of age, social interactions influence the spatial and temporal distribution with probably detrimental effects on growth, behaviour and activity in subordinates through differential access to resources (Goetz \& Thomas 1994a; Terezow 2005). Observations consistently suggest territoriality in juveniles of three 
years and older (Goetz \& Thomas 1994a; Terezow 2005), and aggressive behaviour linked to territoriality follows a cathemeral pattern in older juveniles (Terezow 2005). However, how and when territoriality initiates is not well understood. The few, mostly anecdotal and contradictory observations of previous studies and husbandry observations range from highly territorial to non-territorial between the age of six to 30 months (McIntyre 1988; Goetz \& Thomas 1994a; Blanchard 2002; Terezow 2005; Goetz, personal communication). Aggressive behaviours observed in this study (Chapter 2) could facilitate space competition.

Understanding space use and possible competition over this resource in juveniles is important for providing appropriate captive facilities allowing for sufficient food supply, high survival and minimization of aggression and thus injuries. Therefore, the suitability of housing conditions in head-start facilities has implications for the health and survival of hatchlings raised for release into the wild. I investigated whether one-year-old captive juvenile tuatara use space exclusively, and if space use and avoidance in space and time differed with social context (based on sex and relative size of a conspecific). I investigated whether excretory patterns suggest scent marking in captive juveniles, and if this may be linked to their use of space.

\subsection{Methods}

\subsubsection{Study group, animal husbandry, experimental set-up and equipment}

Space use and patterns of excretion were observed in one-year-old captive tuatara, S. punctatus, from June to October 2008. The study group, husbandry conditions, experimental set-up and equipment are described in detail in the methods of Chapter 2. Briefly, tuatara were observed directly and/or remotely with surveillance cameras (Grand IP Camera Pro, Model 2, Grandtec) during the whole duration of the six day experiments in enclosures with two shelters (with a single entrance/exit each) and a water dish (Figure 3.1). Water was provided ad libitum and feeding occurred twice during the six day experiments (after $72 \mathrm{~h}$ and $144 \mathrm{~h}$ ). Blinds were installed to avoid visual disturbance of the animals by the investigator. All tests and observations were conducted by the same observer. 


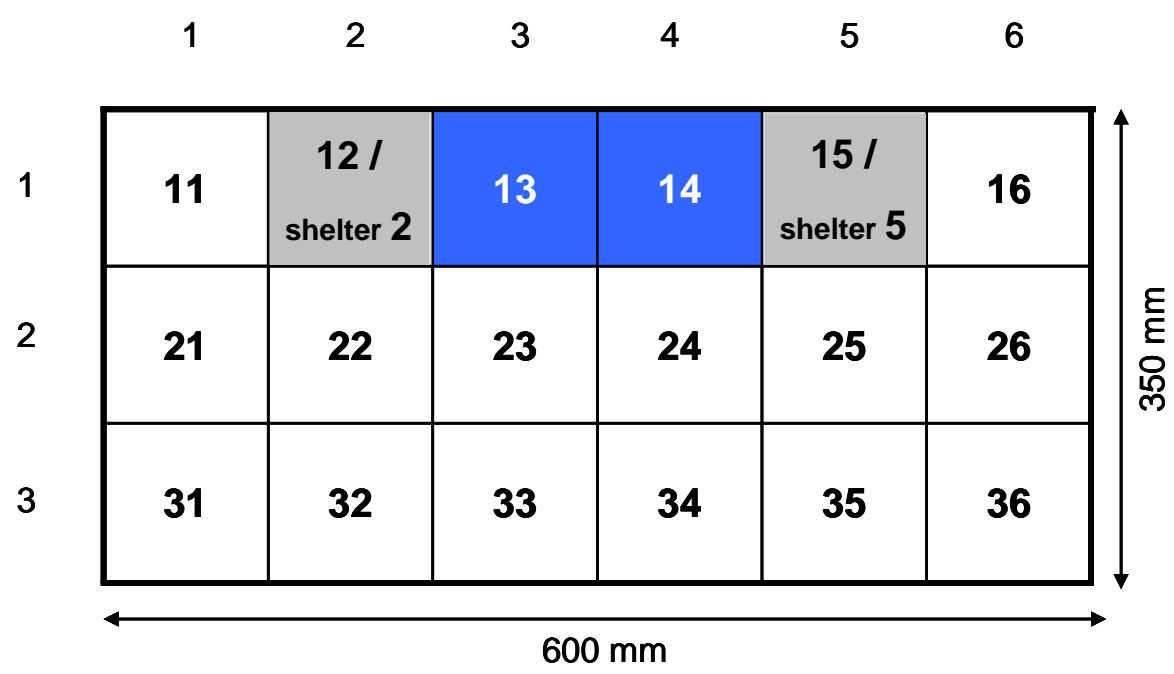

Figure 3.1 Experimental enclosure of $350 \times 600 \times 350 \mathrm{~mm}$ (width $\mathrm{x}$ length $\mathrm{x}$ height) with shelters (light grey) and water dish (dark grey). For analyses, the space was notionally divided into 20 equally sized squares. Squares 13 and 14 housed the water dish, and squares 12 and 15 were covered with the shelters. When tuatara were inside shelters they were described as occupying either square 2 or 5 ; when they were located on top of shelters they were described as occupying either square 12 or 15.

Experimental pairs were chosen according to seven scenarios based on sex and relative size, and each scenario was replicated four times with different pairs. Pairs were chosen to achieve a particular sex combination and to either minimise or maximise their size differences for pairs of similar size or different size, respectively. The seven scenarios were:

(S1) different sized males - big male vs. small male;

(S2) different sized females - big female vs. small female;

(S3) different sized male and female - big male and small female;

(S4) different sized male and female - big female and small male;

(S5) similar sized male and female;

(S6) similar sized males;

(S7) similar sized females.

Each tuatara was identified by its unique toe-clips and was marked with non-toxic, semi-permanent correction fluid (Twink ${ }^{\mathrm{TM}}$; e.g. a strip on their back or tail) for recognition in footage. Due to the small number of tuatara available, repetition of individuals was unavoidable (Table A.1 in Appendix). Between experiments, enclosures were emptied and cleaned with alcohol to remove any scent residue, and set up anew. 


\subsubsection{Data collected}

Experiments were recorded continuously. Due to the enormous amount of data generated, the experimental period was broken down into six 24 hour periods of which two were sampled: the second (P2) and fifth (P5). This choice was made before the start of experiments, allowing tuatara a day to settle in enclosures, and so that both sampling times were 24 hours after the last feeding and 24 hours prior to the next feeding event (Chapter 4) with one in the earlier half of the experiment and one in the later half. Out of those two days, the first ten minutes of each hour were scored which resulted in two times four hours of data, eight hours of data in total. In those eight hours, emergence, location and time spent at each location, distance between tuatara and communal or separate use of shelters were recorded. In addition, the 10 minutes immediately before and after feeding trials were sampled to investigate the number of shelters used by participants and if shelters were used communally. The total time sampled was eight hours and 40 minutes. Feeding trials were 100 minutes long and occurred from $72 \mathrm{~h}$ and $144 \mathrm{~h}$ after the experimental start, respectively (Chapter 4).

The experimental enclosure was notionally divided into 20 equally sized squares (Figure 3.1) and this scheme was used for further references to location. The time a tuatara spent in each of those squares was noted in seconds.

Emergence was defined as presence outside of shelters per minute with the reference point being half of a tuatara's snout-to-vent-length (SVL). For example, a tuatara was considered out if at least half its SVL was out, even though the rest of its body may be inside a shelter. Data were collected according to the following definitions: out for a whole minute accounted 60 seconds towards the total time spent emerged, inside a shelter accounted 60 seconds towards the total time spent inside shelters. If a tuatara disappeared into a shelter or emerged from a shelter during a minute, 30 seconds were allocated towards the total time spent inside shelters and 30 seconds towards the total time spent outside, resulting in continuous data during the course of $\mathrm{P} 2$ and $\mathrm{P} 5$, respectively.

The distance between tuatara was measured in a straight line between the centres of the squares in which individuals were located at the beginning of each minute. When an individual was inside a shelter, the calculation of distance took into account that it would have to leave the shelter first before accessing any other part 
of the enclosure. In these cases, the distance along a straight line was measured from the middle of the shelter to the middle of the square in front of the shelter plus the straight line distance from there to the position of the other individual.

Shelters were defined as communal if both tuatara were recorded in the same shelter at the same time for a total of at least 50 minutes (not necessarily consecutive minutes) during the 520 minutes sampled. Otherwise, shelter use was defined as separate. Recorded data were binomial. The 50 minutes cut off was arbitrarily determined based on the following information: tuatara were inside shelters approximately half of the sampled time ( 260 minutes) and about $20 \%$ was viewed as a reasonable assessment of repeat behaviour, that is, tuatara were not actively avoiding sharing a shelter with each other.

Data on urination were collected through direct observations during the first 50 minutes of experiments. The occurrence of the semi-solid part of the tuatara urine (Dawbin \& Hill 1969) rather than the liquid was recorded as the liquid portion of the excreta was not detectable most of the time due to the wetness of the absorbent paper. The number of urinations per scenario and the individual responsible were recorded. Numbers should be treated as underestimates since some juveniles urinated during the immediate preparation of experimental starts. Unfortunately, no further data on urination outside that time frame could be gathered as the quality of the footage did not allow for its detection.

Data on the occurrence of faeces were collected from the complete footage of six days of each experiment. For each faecal deposit, the individual responsible (whenever possible), the square in which it was located and the 24 hour period in which it was deposited (six 24 hour periods: P1 - P6) was recorded. The numbers of faeces in the water dish should be treated as underestimates. Faeces were not always easy to detect at this location because after faecal matter was deposited into the water, it dissolved into smaller particles thus making the detection of subsequent faeces in the water dish more difficult given the limitations of the quality of the footage. Deposition of faeces inside shelters was recorded at the end of an experiment. 


\subsubsection{Data analysis}

All statistical tests were conducted in R 2.6.2 (R-Development-Core-Team 2008). Means are reported as \pm one standard error (SE) and statistical significance is inferred at $p<0.05$.

A preliminary investigation using Akaike's information criterion (AIC; Akaike 1973; Burnham \& Anderson 1998) was conducted to investigate whether housing prior to experiments influenced behaviour in experimental settings. Housing both animals of a dyad in the same enclosure (three experiments in different scenarios) or different enclosures (25 experiments) prior to an experiment was excluded as a factor in further analyses as models that included this factor were a worse fit for the data than models without $(\triangle \mathrm{AIC}>2$ for models including this factor in addition to scenario or location).

To check if juveniles used space differently depending on the social context, Mantel randomization tests were used (Mantel 1967; Smouse et al. 1986). The nonEuclidean distance matrix of an experiment was based on the times each animal spent in each of the 20 squares of the enclosure in P2, P5, and both combined. The mean distance resulting from the four experiments per scenario was compared among scenarios. The Mantel randomization tests (with 49999 randomisations), checking for a correlation between two distance matrices, were used to compare the distance matrices in 21 pairwise comparisons between all seven scenarios in P2, P5, and both combined. Results were corrected with the sequential Bonferroni method for multiple comparisons (Peres-Neto 1999).

To estimate avoidance in time, a similarity index was calculated for each experiment. The similarity index was based on the continuous emergence data gathered in P2 and P5; it accounts for the sample minutes that both animals spent inside or outside shelters at the same time out of the overall time sampled. The index was calculated for P2 only, P5 only and both combined and used to compare among scenarios in permutated general linear models ( $\mathrm{pGLMs}$ ) described below.

To estimate avoidance in space, the average distance between tuatara was calculated and used for comparisons among scenarios in pGLMs described below. The distance data were organized to calculate an average for different situations in P2 only, P5 only and P2/P5 combined. (1) An average distance in space was 
calculated for day time $(0810-1800 \mathrm{~h})$, night time $(2010-0600 \mathrm{~h})$ and crepuscular phase $(0600-0810 \mathrm{~h}$ and $1800-2010 \mathrm{~h}$ ) periods. (2) An average distance in space was calculated for when both animals were outside at the same time, inside a shelter at the same time or when one was outside while the other one was inside. The data set of both animals being inside at the same time was incomplete for P2, as in one dyad both animals were always either outside or inside at the same time; P2 was thus not included in the analysis. (3) An overall average distance in space.

pGLMs for continuous data with scenario as a factor were used to test whether there were a significant difference among scenarios in either the avoidance in time or the avoidance in space. For the avoidance in time, the similarity indices derived above were used; for the avoidance in space the average distance between tuatara in different situations were used. pGLMs for count data with scenario as factor were used to test whether juveniles defecated or urinated differently among scenarios, thus probably scent marking differently depending on their competitor. pGLMs for continuous data with location as a factor were used to test for significant differences between the time spent on top of shelters and on any remaining square outside, and between the time spent inside shelters and on any square outside. For all pGLMs, pairwise comparisons were permutated and corrected for multiple comparisons with the sequential Bonferroni method (Peres-Neto 1999). Permutations (49999 in each test) were used as the data lacked independence. For each result the permutated $p$ value $(p)$, the original, not permutated $F$-value and the degrees of freedom $\left(F_{(d f)}\right)$ are presented; for pairwise comparisons the corrected $p$-value ( $\left.p_{\text {corrected }}\right)$ is presented. The Levene's test was used to test for equal variances, and the Shapiro-Wilk test for normal distribution, wherever appropriate. Original data sets were used when data did not fit assumptions but could not be improved through transformation.

A permutated proportion test was used to determine if sex influenced the number of urinations. A second permutated proportion test was used to identify if the amount of faeces differed among (1) three options: shelters, water dish or the remaining open squares, and (2) two options: on top and in front of shelters or any other square. The test took into account the time spent at each of those locations and the number of equivalent squares. Binomial tests (not permutated) were use to determine if the number of experiments with communal shelter use vs. non-communal shelter use was significantly different from random (14:14), and if the number of participants that 
used both shelters vs. those that used only one shelter was significantly different from random (28:28).

\subsection{Results}

\subsubsection{Space use}

Juveniles spent significantly more time inside shelters $(1.69 \pm 0.13 \mathrm{~h}$ per shelter; range: $0-5.24 ; 3.37 \pm 0.16 \mathrm{~h}$ for both shelters; range: $0.68-5.70)$ than on any square outside $\left(0.26 \pm 0.01 \mathrm{~h}\right.$ per square; range: $0.00-1.82 ; F_{(1)}=321.92, p<$ 0.0001 ). Females spent $3.12 \pm 0.27 \mathrm{~h}$ (range: $0.68-5.62$ ) and males spent $3.65 \pm$ $0.15 \mathrm{~h}$ (range: $2.16-5.70$ ) inside shelters respectively; the difference was not statistically significant $\left(F_{(1)}=2.90, p=0.09\right)$. The average time spent on top of shelters (square 12 and 15) was significantly higher than the average for outside squares $\left(0.41 \pm 0.03 \mathrm{~h}\right.$ per shelter top square; range: $0.02-1.82 ; F_{(1)}=17.36, p<$ $0.0001)$. Averages reported here are based on the amount of time all animals spent in each location during all sampling times in P2 and P5 combined divided by the number of all animals $(n=56)$. In significantly more experiments shelters were used communally ( 25 of $28 ; p<0.0001$ ). No patterns were found in the three experiments with separate use of shelters which occurred in S1, S3 and S7. Significantly more participants used both shelters ( 46 of $56 ; 28$ experiments with two participants; $p<$ $0.0001)$. No patterns were found in the remaining 10 participants which used one shelter only (occurrence was recorded in several scenarios [S1, S3, S4, S6, and S7], in both sexes, in similar, relatively smaller and bigger sized individuals, and it occurred in some individuals once and in others repeatedly).

Tuatara did not avoid their cage-mates since one individual was emerged when the other individual was inside a shelter in only $23 \% \pm 0.02$ of the time sampled. Also, social context (scenario) did not differentially affect avoidance patterns in time (P2 $\left[F_{(6)}=1.32, p=0.29\right], P 5\left[F_{(6)}=1.49, p=0.21\right], P 2$ and $P 5$ combined $\left[F_{(6)}=1.48, p=\right.$ 0.22]). Pairwise comparisons showed no significant differences. The following averages of emergence are based on all experiments and all sampling times in P2 and P5. For example, an animal was considered emerged (outside of shelters) at $2000 \mathrm{~h}$ if it spent at least 5.5 minutes outside of shelters between $2000-2010 \mathrm{~h}$. In the eight hours sampled, juveniles were more often outside during the night (2010 $0600 \mathrm{~h}$ ) than during the day (0810 - $1800 \mathrm{~h}$; Figure 3.2). At nocturnal sampling times, $92 \pm 0.01 \%$ of individuals were emerged. The greatest percentage emerged 


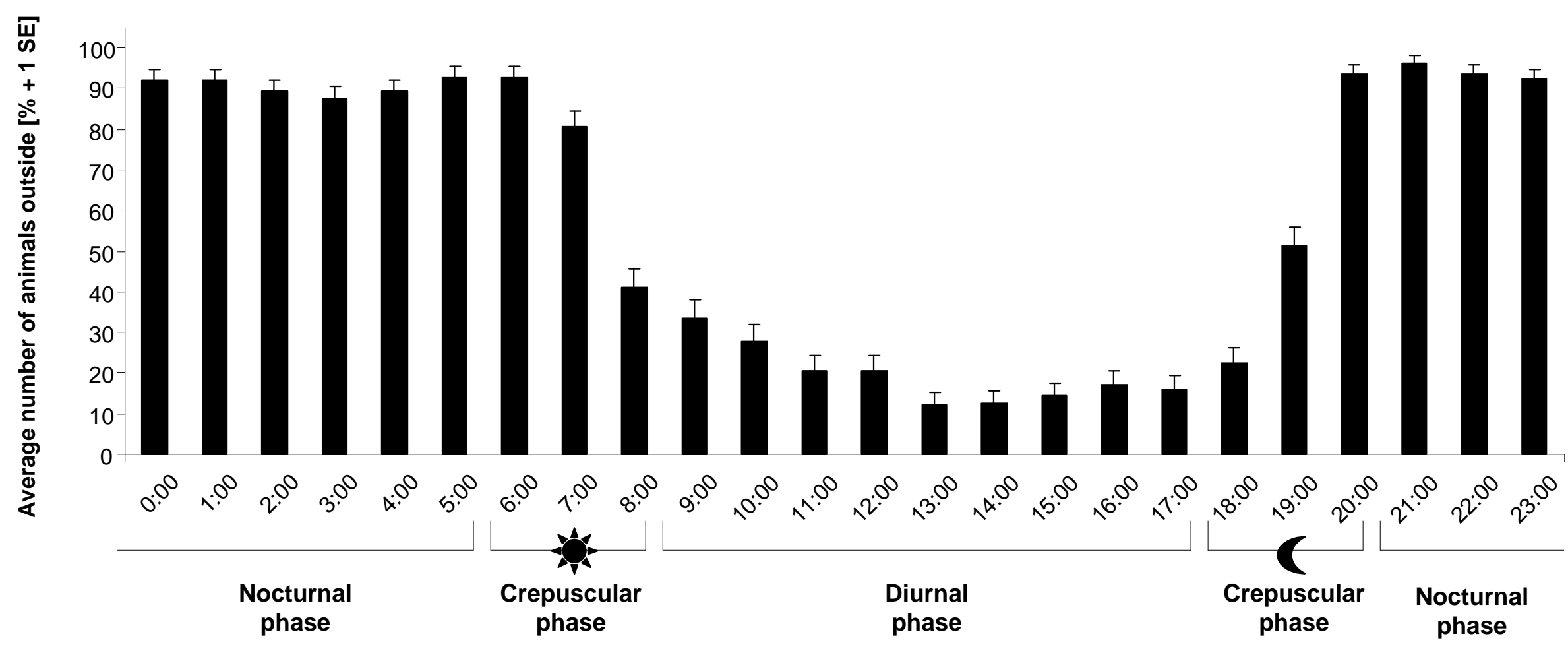

Time of day

Figure 3.2 Average number of tuatara outside of shelters during ten minutes sampling times (in $\% \pm 1 \mathrm{SE}$ ). Averages of emergence are based on all experiments and all sampling times in P2 and P5. For example, an animal was considered emerged (= outside of shelters) at $2000 \mathrm{~h}$ if it spent at least 5.5 minutes outside of shelters between $2000-2010 \mathrm{~h}$. More animals were outside during the night than during the day. The crepuscular phases were transitional phases between nocturnal and diurnal phases. 
from $2100-2110 \mathrm{~h}(96 \pm 0.02 \%)$. At diurnal sampling times, only $19 \pm 0.01 \%$ of individuals were emerged. The lowest percentage emerged from $1300-1310 \mathrm{~h}$ (12 $\pm 0.03 \%)$. The crepuscular phases $(0600-0810 \mathrm{~h}$ and $1800-2010 \mathrm{~h})$ were transition zones with $64 \pm 0.02 \%$ of individuals emerged with a steep decline from $93 \pm 0.02 \%$ at $0600-0610 h$ to $41 \pm 0.05 \%$ at $0810-0810 h$ and a steep rise from $22 \pm 0.04 \%$ at $1800-1810 \mathrm{~h}$ to $94 \pm 0.02 \%$ at $2000-2010 \mathrm{~h}$ (Figure 3.2).

The average distance between two juveniles when both were outside at the same time was $25.4 \pm 0.37 \mathrm{~cm}$ (range: 19.8 - 32.1; pooled data from P2 \& P5). The average distance between two juveniles when both were inside shelters at the same time was $23.5 \pm 2.95 \mathrm{~cm}$ (range: $0.0-52.0$; pooled data from P2 \& P5, excluding the experiment in which this situation, both in at the same time, did not occur). Individuals do not avoid differently among scenarios since the average distance in space between animals did not differ significantly among scenarios in all tested situations* in P2 only, P5 only and P2 and P5 combined (Table 3.1). Pairwise comparisons showed no significant differences.

Table 3.1 Results of pGLMs of the average distance between juveniles among scenarios in different situations during P2 only, P5 only and P2 and P5 combined. The average distance between a dyad does not differ significantly among scenarios in all tested situations*

\begin{tabular}{|c|c|c|c|c|c|c|}
\hline \multirow[t]{2}{*}{ Situation* } & \multicolumn{2}{|c|}{ P2 } & \multicolumn{2}{|c|}{ P5 } & \multicolumn{2}{|c|}{$\begin{array}{l}\text { P2 \& P5 } \\
\text { combined }\end{array}$} \\
\hline & $\mathrm{F}_{6}$ & $p$ & $\mathrm{~F}_{6}$ & $p$ & $F_{6}$ & $p$ \\
\hline Overall & 0.45 & 0.83 & 0.59 & 0.73 & 0.98 & 0.19 \\
\hline $\begin{array}{l}\text { Both outside at } \\
\text { the same time }\end{array}$ & 0.85 & 0.54 & 0.24 & 0.95 & 0.58 & 0.74 \\
\hline $\begin{array}{l}\text { Both inside at the } \\
\text { same time }\end{array}$ & \multicolumn{2}{|c|}{$\begin{array}{c}\text { n.a. } \\
\text { (see methods) }\end{array}$} & 0.39 & 0.87 & \multicolumn{2}{|c|}{$\begin{array}{c}\text { n.a. } \\
\text { (see methods) }\end{array}$} \\
\hline $\begin{array}{l}\text { One outside, one } \\
\text { inside }\end{array}$ & 1.58 & 0.20 & 0.67 & 0.67 & 0.66 & 0.68 \\
\hline Daytime & 0.73 & 0.63 & 0.77 & 0.60 & 0.34 & 0.91 \\
\hline Night time & 2.26 & 0.07 & 0.61 & 0.71 & 1.23 & 0.33 \\
\hline $\begin{array}{l}\text { Crepuscular } \\
\text { phase }\end{array}$ & 0.31 & 0.93 & 0.65 & 0.69 & 0.46 & 0.83 \\
\hline
\end{tabular}


During P2 or P5 respectively, most animals spent time in all possible locations outside, and in at least one shelter. No patterns were found in the few exceptions in which participants were not recorded in all possible locations outside, and in at least one shelter. In P2 and P5 combined, every individual spent time in every possible location outside of shelters and in at least one shelter. There were no significant differences in the use of space between individuals of a dyad among scenarios based on the time spent in any location in P5 and when P2 and P5 were combined; all matrices were significantly correlated after the sequential Bonferroni corrections (all $p<0.05$ ). During P2 most matrices were significantly correlated (all $p<0.05$ ) except S5 (similar sized male and female). However, S5 showed a non-significant trend towards correlation with S1 (pcorrected $=0.08)$, S3 (pcorrected $=0.09), S 4$ $($ pcorrected $=0.11)$, S6 $($ pcorrected $=0.06)$ and S7 $($ pcorrected $=0.07)$ after sequential Bonferroni corrections, indicating that the difference between the space use in S5 during P2 and all other scenarios was minor

\subsubsection{Patterns of excretion and scent marking}

In the course of all 28 experiments, 98 faeces were recorded overall, of which 95 could clearly be linked to an individual. When depositing faecal matter, juvenile tuatara lift a part of their tail combined with a forward motion of the whole body in such a way that they do not squash the faeces nor do they retain faecal material on their tails or bodies. Females and males produced about the same number of faeces (49 and 46 respectively; not significantly different: $p=0.84$ ). A total of $94 \%$ of participants (53 of 56) defecated at least once during an experiment. Forty five of fifty six (80.4\%) participants defecated once or twice during an experiment, fewer defecated more than twice ( 8 of $56 ; 14.3 \%$ ) and only three of 56 did not defecate at all (5.4\%; Figure 3.3).

Most participants $(71.4 \%)$ deposited faecal material during P1. The number of participants defecating subsequently decreased over P2 (26.8 \%) and P3 (16.1\%). A similar pattern as seen in P1 - P3 can be observed in P4 - P6, although on a smaller scale. A total of $33.9 \%$ of participants excreted faecal matter in P4, fewer excreted in P5 (12.5 \%) and even fewer in P6 (8.9 \%; Figure 3.4). The highest number of faeces (P1; 19 from female participants, 21 from male participants; not significantly different: $p=0.87$ ) occurred at least 48 hours after juveniles had been fed in their home enclosures. The second highest number, about half of that found 
during $\mathrm{P} 1$, occurred within $\mathrm{P} 4$, that is, in the 24 hour period including and following the first experimental feeding (Figure 3.4).

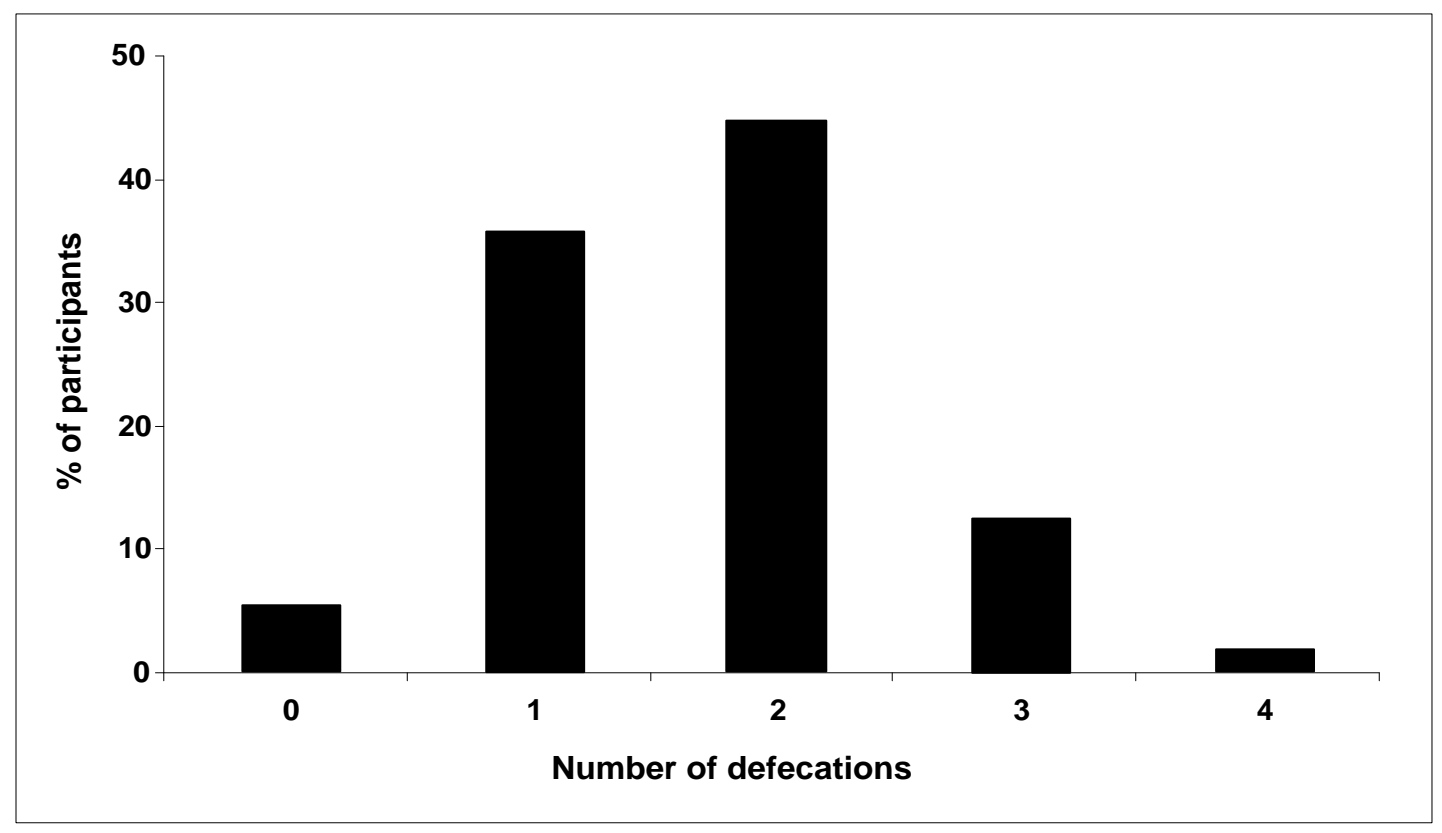

Figure 3.3 Percentage of participants depositing no, one, two, three or four faeces, based on all experiments.

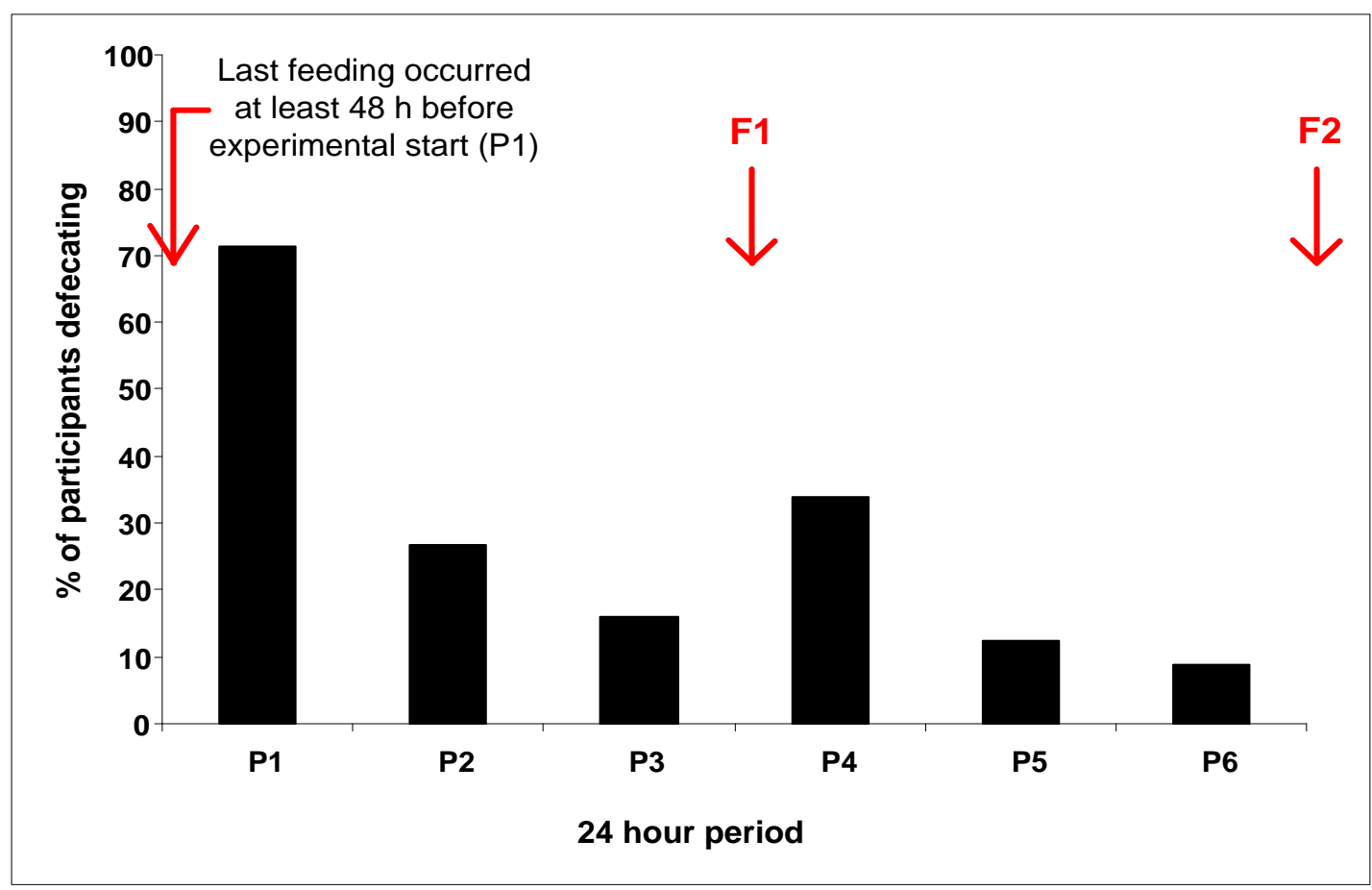

Figure 3.4 The percentage of participants $(n=56)$ defecating in each of the six 24 h periods (P1 - P6); based on all experiments ( $n=28$; two participants per experiment). F1: first feeding trial (72 $\mathrm{h}$ after experimental start), F2: second feeding trial (144 $\mathrm{h}$ after experimental start). 
A range from 1 - 7 faeces was found in each square when all experiments were pooled, with the majority of squares experiencing between one and five faeces (Figure 3.5). The distribution of juvenile tuatara faeces differed significantly between the water dish, the inside of the shelters and the remaining open area $(p=0.003)$, with the highest occurrences in the water dish and the least inside shelters. The occurrence of faeces on top and in front of shelters (square 12, 22, 15 and 25 combined) was not significantly different when compared with all remaining outside squares $(p=0.20)$. Apart from a few exceptions $(n=5)$, the majority of participants that did excrete more than once did not excrete in the same location $(n=33)$.

\begin{tabular}{|c|c|c|c|c|c|}
\hline $\begin{array}{l}11 \\
3\end{array}$ & $\begin{array}{l}12 / \\
\text { shelter } 2 \\
\mathbf{1 1 / 1}\end{array}$ & 17 & 16 & $\begin{array}{c}15 / \\
\text { shelter } 5 \\
\mathbf{4 / 1}\end{array}$ & $\begin{array}{l}16 \\
\end{array}$ \\
\hline$\overline{21}$ & 22 & 23 & 24 & 25 & 26 \\
\hline 5 & 2 & 5 & 4 & 12 & 2 \\
\hline$\overline{31}$ & 32 & 33 & 34 & & 36 \\
\hline 1 & 2 & 1 & 1 & 4 & 3 \\
\hline
\end{tabular}

Figure 3.5 Experimental enclosure of $350 \times 600 \times 350 \mathrm{~mm}$ (width $\mathrm{x}$ length $\mathrm{x}$ height) with shelters (light grey) and water dish (dark grey; small number in upper left corner: square number). Total number of faeces found in each square of the enclosures (large central number), based on all participants and experiments..

The number of faeces did not differ among scenarios $\left(F_{(6)}=1.79 ; p=0.16\right)$. However, different sized females (S2) defecated significantly less than did similar sized females $\left(S 7 ; p_{\text {corrected }}=0.04\right.$; Table 3.2). The number of faeces in the water dish did not differ among scenarios $\left(F_{(6)}=1.63 ; p=0.17\right)$. However, similar sized males (S6) defecated significantly less in the water dish than did similar sized males and females (S5; $p_{\text {corrected }}=0.04$; Table 3.3).

In all 28 experiments, 16 urinations in a total of 12 different experiments were recorded: $57.1 \%$ of experiments with no excretion $(n=16), 42.9 \%$ with at least one individual excreting $(n=12)$ and $14.3 \%$ with both individuals excreting $(n=4)$. No one participant urinated more than once during the first 50 minutes of experiments. Males were significantly more likely to urinate than females $(p=0.007)$. No body motion similar to defecation was obvious during urination. The highest numbers of urinations occurred in both male-male dyads (S1 \& S6), the lowest in female-female dyads (S2 \& S7) and dyads of a similar sized male and female (S5), but the 
difference among scenarios was not statistically significant $\left(F_{(6)}=2.28 ; p=0.07\right.$;

Table 3.4). Pairwise comparisons were not significant after Bonferroni corrections.

Table 3.2 Number of faeces per scenario based on occurrences in all four experiments per scenario. F: female, M: male.

\begin{tabular}{llll}
\hline Scenario & Total & Mean \pm SE & Range \\
\hline S1: big M \& small M & 12 & $3 \pm 0.41$ & $2-4$ \\
S2: big F \& small F & 10 & $2.5 \pm 0.65$ & $1-4$ \\
S3: big M \& small F & 15 & $3.75 \pm 0.63$ & $2-5$ \\
S4: big F \& small M & 14 & $3.5 \pm 0.65$ & $2-5$ \\
S5: similar M \& F & 12 & $3 \pm 0.41$ & $2-4$ \\
S6: similar M \& M & 13 & $3.25 \pm 0.25$ & $3-4$ \\
S7: similar F \& F & 19 & $4.75 \pm 0.63$ & $3-6$ \\
\hline
\end{tabular}

Table 3.3 Faeces located in water dish in each scenario based on the total number of occurrences in all four experiments per scenario. F: female, M: male.

\begin{tabular}{llll}
\hline Scenario & Total & Mean \pm SE & Range \\
\hline S1: big M \& small M & 4 & $1 \pm 0$ & $1-1$ \\
S2: big F \& small F & 5 & $1.25 \pm 0.48$ & $0-2$ \\
S3: big M \& small F & 5 & $1.25 \pm 0.48$ & $0-2$ \\
S4: big F \& small M & 6 & $1.5 \pm 0.29$ & $1-2$ \\
S5: similar M \& F & 7 & $1.75 \pm 0.63$ & $0-3$ \\
S6: similar M \& M & 0 & $0 \pm 0$ & $0-0$ \\
S7: similar F \& F & 5 & $1.25 \pm 0.63$ & $0-3$ \\
\hline
\end{tabular}

Table 3.4 Urinations in the first 50 minutes of experiments based on all four experiments per scenario. F: female, M: male.

\begin{tabular}{llll}
\hline Scenario & Total & Mean \pm SE & Range \\
\hline S1: big M \& small M & 4 & $1 \pm 0.41$ & $0-2$ \\
S2: big F \& small F & 0 & $0 \pm 0$ & $0-0$ \\
S3: big M \& small F & 3 & $0.75 \pm 0.48$ & $0-2$ \\
S4: big F \& small M & 3 & $0.75 \pm 0.48$ & $0-2$ \\
S5: similar M \& F & 0 & $0 \pm 0$ & $0-0$ \\
S6: similar M \& M & 5 & $1.25 \pm 0.25$ & $1-2$ \\
S7: similar F \& F & 1 & $0.25 \pm 0.25$ & $0-1$ \\
\hline
\end{tabular}




\subsection{Discussion}

\subsubsection{Space use}

Captive tuatara at one year of age did not compete for space. Shelters were used communally in most experiments, and even after four days in the experimental enclosure, most tuatara used all outside space available to them. Spatial and temporal avoidance were negligible and did not differ with social context. Within the limits of my operational definition, the findings on space use suggest that one-yearold juveniles did not use space exclusively thus did not occupy territories.

Competition for space may be absent due to my choice of experimental design. Competition may be reduced when only two individuals are present. In addition, shelters used in this study were designed to be equal in location and size. If more individuals were present to compete, and/or if shelters were of differing quality or if less shelters than individuals were provided, competition may have been enhanced. Moreover, six days may not be enough time for tuatara juveniles to set up territories. However, if space is a defended resource in one-year-old tuatara, I would have expected to observe a pattern towards the end of the experiment (P5), of more exclusive space use and/or differences among scenarios, which I did not observe. For example, territorial juvenile lizards, Anolis aeneus, establish spatial relationships within three days when released into a new location (Stamps \& Krishnan 1994b, a).

The defence of space may also be related to density. If lizards are forced together in unnaturally high densities in captivity, and dispersal is impossible, dominance hierarchies frequently emerge in species that are otherwise territorial (Carpenter 1967; Brattstrom 1974; Wilson 1975; Prieto \& Ryan 1978; Warwick 1995). This is a mostly superficial dominance system where, in the case of despotism, one individual actually keeps its territory while just tolerating the existence of other conspecifics (Wilson 1975). For example, male green anoles, Anolis carolinensis, shift from their territorial system to a dominance hierarchy when unnaturally crowded (Greenberg et al. 1984; Forster et al. 2005). Possible changes in juvenile tuatara spacing behaviour with differing densities may account for the seemingly conflicting observations of spatial organisation (McIntyre 1988; Goetz \& Thomas 1994a; Blanchard 2002; Terezow 2005; Goetz, personal communication; this study), especially since dominance hierarchies were established in the majority of experimental dyads during this study (Chapter 2 ). 
Captive tuatara develop territoriality during their ontogeny. At one year of age, juveniles are transitioning between the non-aggressive clustering of captive hatchlings (Keall \& Hazley, personal communication) and the territorial organisation of older juveniles (Goetz \& Thomas 1994a; Terezow 2005) and adults (Gillingham et al. 1995; Moore et al. In press). The transition is a gradual process. Juveniles stopped clustering at all times and had moved to a more variable use of shelter by sharing it at some times and using it singularly at others. Aggression, which may be linked to territorial behaviour, was observed during this study (Chapter 2). One year olds showed a subset of the territorial behavioural repertoire of adults (Gillingham et al. 1995). Posing, chasing, and biting were the most common aggressive behaviours in the juveniles; face-offs were extremely rare, and body inflation and crest erection were not observed (Chapter 2). Even though territories are not yet established, aggressive behaviour patterns, which are absent in hatchlings (Keall \& Hazley, personal communication), provide a mechanism for driving spatial distribution in later life stages. In the interim, aggressive behaviour may be used to establish dominance hierarchies (Chapter 2) and compete for food (Chapter 4), which might be the most important resource to compete over at one year of age. For example, juvenile lionesses, Panthera leo, show a gradual transition from no territorial defence to full group-territorial defence during their ontogeny (Heinsohn et al. 1996).

Aggressive behaviour and territoriality can be well developed during immature life stages in lizards (Simon \& Middendorf 1980; Stamps 1983a). For species that mature quickly (for example Sceloporus jarrovi which reach adulthood at around five months; Ballinger 1973), juveniles perform actions related to territoriality from 13 days onwards, with territories established in the summer of birth (Simon \& Middendorf 1980). Tuatara are long-lived and mature at about $9-13$ years (Castanet et al. 1988), hence it is not surprising that those behaviours develop over a period of years rather than after a few weeks. Further, aggressive territorial displays of adult and juvenile lizards are similar (Stamps 1978), which is consistent with my finding of a subset of adult aggressive behaviour in juvenile tuatara.

Given that the occurrence of aggression differs among scenarios (Chapter 2), it is intriguing that juveniles do not avoid conspecifics differentially based on social context. Keeping a certain distance from a conspecific may prevent attacks (Brattstrom 1974) or if not, at least allows a head start for retreat. However, all scenarios with elevated incidences of aggression also showed increased numbers 
of submissive behaviours (Figure 2.2). Therefore, I conclude that in order to avoid aggression, juveniles reacted with more submissive behaviours rather than keeping a constant security distance. This might be more energy efficient and more feasible given the spatial constraints of the enclosures (Brattstrom 1974).

One-year-old juvenile tuatara show a predominantly nocturnal emergence pattern which is in accordance with findings for older juveniles in captivity and in the wild (McIntyre 1988; Terezow et al. 2008) and wild adults, even though adults may also be seen basking during the day (Walls 1983; Gillingham \& Miller 1991). No evidence of time territoriality was found during this study. In order to reduce competition and related aggression, less dominant individuals can shift their activity phase and consequently avoid the more dominant conspecifics in time in a wide range of species (Regal \& Connolly 1980; Railsback et al. 2005). For example, the social hierarchy of captive tegu lizards, Tupinambis teguixin, was related to immediate differences and shifts in circadian rhythms. Intermediate ranked lizards would often shift to time territories to avoid the dominant animal whereas the lowest ranking lizard was either synchronised with the dominant individual or had a rhythm completely uncoupled from the light cycle (Regal \& Connolly 1980). Whereas in spontaneously hypertensive rats (SHR), more dominant rats synchronised their activity, and the least dominant individual desynchronized in time and occupied a different time territory (Regal \& Connolly 1980). A lack of time territoriality based on the emergence of tuatara juveniles may have several explanations. It might not be a behavioural response that is applicable to captive juvenile tuatara or a longer experimental period may be needed to detect shifts in tuatara behaviour. In addition, the competitive pressure in the experimental dyads may not be sufficient to motivate shifts of circadian rhythms. Thus experiments on larger groups are needed to evaluate whether time territoriality may develop in settings of more than two tuatara juveniles.

\subsubsection{Patterns of excretion and scent marking}

In the first 50 minutes, $28.6 \%$ of individuals urinated, and $42.9 \%$ of experiments had at least one urination event. Males were significantly more likely to urinate than females. Defecations in the first 24 hours were elevated but not sex- or scenariospecific, nor linked to recent feeding since animals were not fed for a minimum of 48 hours prior to experiments. Higher numbers of faeces were found in the water dish, despite likely underestimation due to detection issues (see methods), while the 
occurrence inside shelters was significantly low. Individual participants demonstrated no site tendency for defecation site.

I interpret my findings as marking of a novel enclosure, which, to my knowledge, has not been described in tuatara in the published literature. Scent marking after transferral into new enclosures is reported for captive mammals and reptiles, probably to familiarize an enclosure (Johnson 1973; Chiszar et al. 1980). It may be advantageous for tuatara to scent mark an enclosure quickly, as this may have implications for dominance (Johnson 1973; Gorman 1984). Higher occurrence of urination in males is also correlated with a high level of aggression in male-male encounters, suggesting a more intense struggle for dominance among males (Chapter 2). Animals may identify resource holders by scent marks from an occupied area, and match the scent with the owner's odour at encounters (Gosling 1982) which should lead to a higher reluctance to challenge the owner (Gosling \& McKay 1990).

Stress may be an alternative explanation for the increased frequency of urination and defecation when placed in a novel enclosure. Husbandry manipulation can have a remarkable effect on reptiles (Conant 1971; Langkilde \& Shine 2006). For example, handling can induce an acceleration of heart beats in the lizard Iguana iguana (Cabanac \& Cabanac 2000), and induce an emotional fever in the lizard Callopistes maculatus (Cabanac \& Gosselin 1993). However, handling is not always a stressor (Langkilde \& Shine 2006). Tuatara urinate when disturbed through active handling (Dawbin 1962; Susan Keall \& Nicola Nelson, personal communication; personal observation), and they were handled just prior to the start of my experiments. Stress could also be induced by the clean, novel environment alone which can inflict a health deterioration or even death in captive reptiles (Conant 1971; Langkilde \& Shine 2006). Chiszar et al. (1980) found that snakes are more likely to excrete faeces shortly after being placed back into their cleaned enclosure than after being placed back into an uncleaned enclosure, as a response to the lack of familiar odours. Although captive juvenile tuatara in New Zealand do not suffer from pronounced chronic stress (Tyrrell \& Cree 1994), tuatara react to temporary confinement with acute stress (Tyrrell \& Cree 1998). Males may be more easily stressed than females or may be more active in marking a novel environment with their own urine. This would not be surprising as sex-specific stress responses have been observed in reptiles (Guillette et al. 1995). Further, the sex and size of a 
second individual may add to or diminish the level of stress and differentially stimulate scent marking, which may explain differences among scenarios (Greenberg et al. 1984; Guillette et al. 1995).

Marking a territory with faeces or urine is not uncommon in animals (Jaeger et al. 1986; Smith et al. 1989; Brashares \& Arcese 1999; Gautier \& Miaud 2003; Marnewick et al. 2006; Palagi \& Norscia 2009). Male lberian rock lizards, Lacerta monticola cyreni, can detect and discriminate between the scent of their own faeces, usually strategically located at display sites, and those of other conspecific males (Lopez et al. 1998). Larger males may be able to differentiate between familiar and unfamiliar individuals (Aragon et al. 2000). In comparison, tuatara faeces were not deposited at display sites. No distinct pattern in the location of faecal matter could be determined. However, this may be unsurprising as territoriality is not yet established.

Scent marks elicit increased tongue-flicking in the lizard Ctenophorus pictus (Jansson et al. 2005). Interest in scent is not directly observable in tuatara as they do not exhibit tongue-flicking, nor have there been consistent observations of probing with the snout (Gillingham et al. 1995; Refsnider et al. 2008; Besson et al. 2009; personal observation). Tuatara juveniles did not spend conspicuous amounts of time close to faeces or urine that might hint at the investigation of scent (personal observation), a pattern also found in adult tuatara (Gillingham et al. 1995). However, it might not be necessary to approach faecal matter as its scent may saturate the area.

It has often been noted, but never quantitatively nor qualitatively researched, that tuatara use their water dishes in captivity for excretion (Newman et al. 1979; Blanchard 2002; Susan Keall, personal communication; personal observation). This behaviour may be linked to the marking of a valuable resource in females and males alike or the water dish may serve as a latrine (reviewed in Brown \& Macdonald 1985; Gorman \& Trowbridge 1989). For example, otter, Lutra lutra, scent mark the location of important resources (Kruuk 1992), and latrines are a dominant feature in the lizard genus Egernia with possibly social functions (Chapple 2003). Placing faeces into the water dish may make the smell last longer as it prevents drying which reduces the intensity of the scent (personal observation), but it also pollutes the water resource. The risk of transmission of disease and parasites in water dishes 
would signal replacement of water whenever faecal matter is found in water dishes in captivity. However, if excreta play a role in resource marking or social communication, frequent cleaning of the water dish and new clean water will destroy this link on a regular basis (Chiszar et al. 1993). Tuatara faeces were least likely to be found inside shelters. In two gecko species, Lepidodactylus lugubris and Hemidactylus frenatus, this behaviour was linked to parasite avoidance (Brown et al. 1998), indicating further research on defecation patterns in tuatara is warranted for understanding social and ecological host-parasite relationships.

A detailed outline of limitations of this study is presented in the discussion of Chapter 2. Briefly, the main confounding factors are a small sample size as well as a lack of independence due to the limited number of study subjects. Nevertheless, this study showed that captive tuatara at one year of age do not compete for space and that tuatara may scent mark in novel enclosures. Therefore, the emphasis for improving captive holdings for young juveniles should be redirected from space use towards decreasing aggression (Chapter 2) and food competition (Chapter 4), as long as sufficient and equally valuable shelters are provided. When introducing tuatara to a new enclosure, possible stress reactions may be minimised by adding ground cover or shelters from the old enclosure to provide some familiar scent (Conant 1971).

Future research into the development of aggression and territoriality in wild and captive juveniles of different ages would allow comparisons between captivity and the wild as well as ages, and could reveal the reasons for juvenile territoriality, and if those reasons change during ontogeny. Also, it is important to determine if tuatara, like lizards, switch from a territorial organisation to a dominance hierarchy under limited space conditions in captivity. 


\section{CHAPTER FOUR}

\section{Do captive juvenile tuatara compete for food?}

\subsection{Introduction}

Intraspecific competition for limited resources such as food and space has profound effects on individual growth rates, fecundity and survival (Beaver 1974; Minot 1981; Creese \& Underwood 1982; Baur \& Baur 1990; Price \& Secki Shields 2002). Two mechanisms are prevalent: exploitation and interference. Exploitation competition is an indirect mechanism, acting through a shared limited resource. Consuming this resource decreases the amount available to others. Interference competition is a direct mechanism where individuals interact with each other, often aggressively, over the access to a limited resource (Park 1954; Birch 1957). The outcome is often positively correlated to predictors such as body size (Froese \& Burghard 1974; Downes \& Shine 1998; Shine et al. 2000), and the winning contestant benefits from increased access to the resource, for example, food (Froese \& Burghard 1974; Boccia et al. 1988) or mates (Campanella \& Wolf 1974; Clutton-Brock \& Albon 1979; Moore et al. In press). In contrast, deprivations inflicted on the loser can affect growth rates (English \& Wilkinson 1982; Fraser 1990), reproductive output (Holekamp et al. 1996) and survival (English \& Wilkinson 1982; Ferguson \& Fox 1984),

Although institutions keeping animals try their best to provide sufficient food, a balance between overfeeding and reducing the harmful effects of competition can be difficult to achieve. If kept colonially, conspecifics reduce the foraging success of each other when food is limited. Consequently, competition in captivity, as in the wild, should be greater at higher densities and lower food availability (Ferguson \& Fox 1984; Deutsch \& Lee 1991). An unacceptable level of competition in captivity is reached when less competitive animals are unable to secure sufficient food or suffer from an unpredictable supply (Gosler 1987; Ekman \& Lilliendahl 1993; Witter \& Cuthill 1993), whereas dominant animals may overfeed. In addition, the level of aggression is likely to rise with an increase in food competition (Witter \& Swaddle 1994). The goal is to provide enough food for each animal for normal growth while allowing for acceptable levels of competition. An alternative is to keep animals solitary, but naivety in social interactions can negatively impact on those individuals 
when later held in bigger groups, for example, to promote breeding, or when released into the wild (Burghard \& Layne 1995; Sakata et al. 2002).

Larger body size can result in greater dominance, access to better territories, food and mates, earlier maturation, higher lifetime reproductive success, lower risk of predation, and higher survival rates (Froese \& Burghard 1974; Iverson 1978; Swingland \& Coe 1979; Gibbons et al. 1981; Ferguson et al. 1982; Ferguson \& Fox 1984; McKnight \& Gutzke 1993; Moore et al. 2008). Therefore, it is not surprising that growth is one of the three major life history categories (growth,survival, and reproductive effort) among which time-energy budgets are divided to maximise fitness (Gadgil \& Bossert 1970).

Many reptiles exhibit indeterminate growth (Shine \& Charnov 1992; Shine \& Iverson 1995; Nelson et al. 2002a), and higher food availability should result in higher growth rates. Growth rates of lizards generally depend on food availability (Dunham 1978; Stamps \& Tanaka 1981a), and differences in individual growth rates can be attributed to differences in prey availability (Ballinger \& Congdon 1980). However, not all studies find a relationship between growth and food availability. Charland \& Gregory (1989) offered different amounts of food to rattlesnakes, Crotalus viridis, but this treatment did not result in differential growth, possibly due to differing thermoregulation depending on food availability. Snakes fed less may have chosen to maintain lower body temperatures to minimise their metabolism and energy use (Charland \& Gregory 1989). Despite the capacity to grow faster with higher food availability, oversupply of food in captivity often results in obesity (Warwick 1995).

Tuatara, Sphenodon punctatus, are the sole living representatives of the reptile order Rhynchocephalia (Gunther 1867), the genetic sister group of the Squamata (Rest et al. 2003), and they resemble lizards in their external appearance (Gunther 1867; Dawbin 1962). Tuatara are the focus of extensive conservation efforts which include translocations and captive head-starting of potential founders for new populations (Gaze 2001; Nelson et al. 2002a; Miller et al. In press). Tuatara grow slowly, indeterminately and mature late at about $9-13$ years of age, with males being the bigger sex (Dawbin 1953, 1962, 1982; Castanet et al. 1988; Nelson et al. 2002a). Captive hatchlings and juveniles show higher growth rates than wild animals (Tintinger 1987; Goetz \& Thomas 1994a; Gruber 2007), and exhibit enormous plasticity in body size (Gruber 2007), possibly because of unequal access to food. 
Little is known about food competition in tuatara, and most information is derived from husbandry observations, anecdotes and speculations (Goetz \& Thomas 1994a, b; Hoare et al. 2006; Moore et al. 2007). The social rank of an animal is thought to affect access to food (Goetz \& Thomas 1994a, b). In captivity, dominant juveniles grow faster, but are not necessarily obese depending on the nutritional quality of food and amount of food provided (Goetz \& Thomas 1994a). Mature and immature tuatara are prone to overeating, and obesity is likely to occur when they are provided with fatty food in large quantities (Newman et al. 1979; Nelson, personal communication).

An adult tuatara's natural diet consists of a wide range of small animals, predominantly large insects (Walls 1983). Juveniles prey predominantly on small insects (Dawbin 1962). Tuatara forage with a sit-and-wait approach (Walls 1981; Meyer-Rochow \& Teh 1991), and primarily use visual cues to detect their prey. Movement triggers their interest (Dawbin 1953, 1962; Walls 1981; Meyer-Rochow 1988), and prey is often missed (Walls 1981).

Usually food is a limiting resource (Wilson 1975), and reports of possible food competition in wild reptiles are common (Stamps 1977; Ferguson \& Fox 1984). It is assumed that food competition is a reason for aggression and territoriality in many lizards (Milstead 1970; Simon 1975; Stamps 1977). Food competition is also present in captive reptiles (Warwick 1995), but scientific studies on the topic in captive holdings are rare in comparison. Even though food competition may be common in captive reptiles if food is limited, a general oversupply seems to be a more common problem (Warwick 1995), which may be the reason for the limited number of studies conducted. Food competition in captivity has mainly been studied in turtles (Evans 1940; Boice 1970; Froese \& Burghard 1974), and is essential to the establishment of dominance hierarchies in dense laboratory populations with a limited food supply. Consequently, some individuals secure more food than others depending on their position in the hierarchy (Evans 1940; Boice 1970; Froese \& Burghard 1974). Less is known about food competition in crocodiles (Bustard \& Maharana 1983; Morpurgo et al. 1993), lizards (Greenberg 1976) and tuatara (Goetz \& Thomas 1994a, b).

Mortality in tuatara could partly be due to competition for food. Injuries, likely to increase morbidity and mortality through infections (Taubes 1992), and mortality in captivity are not uncommon (Cree \& Daugherty 1990; Blanchard 2002; Gruber 
2007), and juvenile mortality during early head-starting attempts was high (Cree \& Daugherty 1990). Survival rates of captive juveniles have improved in the last decade to such an extent that survival has reached a level comparable with that of wild adults (Cree \& Daugherty 1990; Heppell et al. 1996; Gruber 2007), probably due to improved husbandry and care for juveniles (Cree \& Daugherty 1990; Gruber 2007). Despite increased overall survival rates, Gruber (2007) found a sex-bias against females in the mortality of head-started juvenile tuatara, possibly linked to increased resource competition in mixed sex holdings where males may be more competitive. Furthermore, a decline in body condition in adult tuatara on North Brother Island was more pronounced in females (Hoare et al. 2006). Hoare et al. (2006) interpreted the observation as a response to resource competition due to increased population density and low resource availability. It was suggested that this competition has a larger effect on females than males, possibly due to unequal access to food resources (Hoare et al. 2006). A long-term decline in body condition of the Stephens Island population may also be due to resource competition (Moore et al. 2007). Even though no research has yet been conducted to follow up these speculations, evidence from translocations suggests competition for limited resources such as food is very likely. Once translocated, tuatara that had exhibited a stable weight for several years on their densely populated source island showed massive weight gains (Nelson et al. 2002a).

At Victoria University of Wellington (VUW) and other facilities housing tuatara (for example, Southland Museum and Art Gallery, Invercargill, New Zealand) live food is released into an enclosure with several immature individuals (Keall \& Hazley, personal communication). This practice does not guarantee an equal distribution of food among individuals. In fact, it is more likely that some individuals will eat more than the 'sufficient' per capita rate whereas others will have to settle with less (Goetz \& Thomas 1994a).

Until now, no research has been conducted on how food is distributed and utilised among tuatara within an enclosure. I hypothesised that food availability within colonial holdings would differ among individuals. I investigated intraspecific competition for food in a captive facility for tuatara. I analysed whether sex, size, and social rank affected the occurrence and intensity of food competition in juveniles, and discussed potential consequences for growth and survival. 


\subsection{Methods}

\subsubsection{Study group, animal husbandry, experimental set-up and equipment}

Feeding behaviour was observed in one-year-old head-started juvenile tuatara, $S$. punctatus, from June to October 2008. The study group, husbandry conditions, and experimental set-up and equipment are described in detail in the methods of Chapter 2. Briefly, tuatara were observed directly and/or remotely with surveillance cameras (Grand IP Camera Pro, Model 2, Grandtec) in experimental enclosures with two shelters (with a single entrance/exit each) and a water dish (Figure 2.1). Any gaps (for example between shelters and water dish) were sealed with tape to prevent prey items from hiding. Water was provided ad libitum. Blinds were installed to avoid visual disturbance of the animals by the investigator. All tests and observations were conducted by the same observer.

Experimental pairs were chosen according to seven scenarios based on sex and relative size, and each scenario was replicated four times with different pairs. Pairs were chosen to achieve a particular sex combination and to either minimise or maximise their size differences for pairs of similar size or different size, respectively. The seven scenarios were:

(S1) different sized males - big male vs. small male;

(S2) different sized females - big female vs. small female;

(S3) different sized male and female - big male and small female;

(S4) different sized male and female - big female and small male;

(S5) similar sized male and female;

(S6) similar sized males;

(S7) similar sized females.

Each tuatara was identified by its unique toe-clips and was additionally marked with non-toxic, semi-permanent correction fluid (Twink ${ }^{\mathrm{TM}}$; for example, a strip on their back or tail) for recognition in footage. Due to the small number of tuatara available, repetition of individuals was unavoidable (Table A.1 in Appendix).

Feeding trials occurred after 72 (F1) and 144 hours (F2) during the experiments, so that both animals were likely to be hungry at the beginning of feeding trials. Feeding was phased to allow the investigator a direct observation of the first 50 minutes of each feeding trial; the second 50 minutes were analysed remotely via footage. All trials occurred within the same diurnal phase between $11 \mathrm{~h} 30$ and $17 \mathrm{~h} 40$ to stay 
within the typical feeding time regimes at VUW (0900 - 1700 h; Terezow 2005; Keall, personal communication). The ambient temperature ranged from $17.0-22.4{ }^{\circ} \mathrm{C}$ during feeding; tuatara can be expected to be active and feeding within this range (Terezow 2005; Besson 2009). An experimental dyad was supplied with one mealworm, Tenebrio molitor, and four crickets, Teleogryllus commodus, during each feeding session. The mealworm was offered at minute zero, at an equal distance from both shelters (positioned on the line between square 33 and 34; Figure 2.1), within a petri dish to limit movement and ensure visibility to both tuatara. After 15 minutes four crickets were released in the middle of the enclosure and allowed to disperse. The feeding trials were terminated after 100 minutes, and the petri dish including any remaining content was removed. Uneaten crickets remained within the enclosure. Tuatara were offered food individually after F2 to check satiation.

\subsubsection{Data collected}

The number of food items eaten by each tuatara in F1, F2 and in both combined (Fc) was recorded directly during the first 50 minutes, and remotely via footage during the second 50 minutes. Emergence of the tuatara during feeding trials was recorded. Absent individuals were located to decide if a feeding event (identified by seizure and mastication noises) inside a shelter could clearly be assigned to one individual in the first 50 minutes; this was not possible remotely as sound was not recorded. Feeding events inside shelters that could not unambiguously be linked to one individual, and feeding events after the end of feeding trials were excluded from the analysis. All interactions linked to interference competition such as chases and biting were recorded during direct observations in the first 50 minutes of each trial. It was noted if tuatara continued feeding when offered additional food after the end of F2. The dominant (ranked first) and submissive individual (ranked second) within a dyad with a clear dominance hierarchy were determined in Chapter 2 and utilized in analyses in this chapter.

\subsubsection{Data analysis}

Statistical analyses were conducted in R 2.6.2 (R-Development-Core-Team 2008). Means are reported as \pm one standard error (SE) and statistical significance was inferred at $p<0.05$.

F1, F2 and Fc were analysed and presented separately because an individual that ate more of the food during F1 did not necessarily eat more during F2, and Fc gives 
an overview over the total percentage of food eaten during a whole the experiment. The amount of food each individual in a dyad ate was expressed as a percentage of total food eaten per dyad since some food items were not eaten during trials, and this value was used in analyses.

A preliminary investigation using Akaike's information criterion (AIC; Akaike 1973; Burnham \& Anderson 1998) was conducted to investigate whether housing prior to experiments influenced the feeding behaviour in experimental settings. Housing both animals of a dyad in the same enclosure (three experiments in different scenarios) or different enclosures (25 experiments) prior to an experiment was excluded as a factor in further analyses as models that included this factor were a worse fit for the data than models without $\triangle A I C>2$ for models including this factor in addition to scenario or group).

Permutated general linear models ( $p G L M s$ ) were used to test for significant differences of the response variables among scenarios and groups (factors) as outlined in Table 4.1. Pairwise comparisons were permutated and corrected for multiple comparisons with the sequential Bonferroni method (Peres-Neto 1999). Permutations (49999 in each test) were used as the data lacked independence. For each result the permutated $p$-value $(p)$, the original, not permutated $F$-value and the degrees of freedom $\left(F_{(d f)}\right)$ are presented; for pairwise comparisons the corrected $p$ value ( $\left.p_{\text {corrected }}\right)$ is presented. The Levene's test was used to test for equal variances, and the Shapiro-Wilk test for normal distribution. Original data sets were used when data did not fit assumptions but could not be improved through transformation.

For broader comparisons, data were pooled. Food eaten by the overall winner of a dyad (Fc) was tested among scenarios, and reciprocally applies to the amounts of food losers ate since the amount winners and losers ate added up to $100 \%$ (see above). Dominant individuals and submissive individuals were identified in Chapter 2 ; only the 18 experiments with a clear dominance hierarchy were included to test if dominant individuals ate significantly more than submissive individuals. 
Table 4.1 Outline of response variables, factors and data sources used in pGLMs. $\left({ }^{*}\right)$ The amount of food each individual in a dyad ate was expressed as a percentage of total food eaten per dyad since some food items were not eaten during trials. $\left({ }^{\#}\right)$ The absolute value of the difference was used.

\begin{tabular}{|c|c|c|c|c|}
\hline Response variable & \multicolumn{3}{|c|}{ Scenarios / Groups } & $\begin{array}{l}\text { Data } \\
\text { source }\end{array}$ \\
\hline \multicolumn{5}{|l|}{ Factor: Scenario } \\
\hline $\begin{array}{l}\text { Difference }{ }^{\#} \text { between } \\
\text { food eaten* by members } \\
\text { of a dyad }\end{array}$ & \multicolumn{3}{|c|}{$\begin{array}{l}\text { S1: big male vs. small male, S2: big female vs. } \\
\text { small female, S3: big male and small female, S4: } \\
\text { big female and small male, S5: similar sized } \\
\text { male and female, S6: similar sized males, S7: } \\
\text { similar sized females. }\end{array}$} & S1-S7 \\
\hline $\begin{array}{l}\text { Food eaten* by overall } \\
\text { winner of dyad (Fc only) }\end{array}$ & \multicolumn{3}{|c|}{$\begin{array}{l}\text { S1: big male vs. small male, S2: big female vs. } \\
\text { small female, S3: big male and small female, S4: } \\
\text { big female and small male, S5: similar sized } \\
\text { male and female, S6: similar sized males, S7: } \\
\text { similar sized females. }\end{array}$} & S1-S7 \\
\hline \multicolumn{5}{|c|}{$\begin{array}{l}\text { Factor: Group - Based on sex and/or size for broader comparisons among } \\
\text { scenarios }\end{array}$} \\
\hline \multirow{8}{*}{$\begin{array}{l}\text { Food eaten }{ }^{*} \text { by group } \\
\text { member }\end{array}$} & Group 1 & \multicolumn{2}{|c|}{ vs. Group 2} & \multirow[b]{2}{*}{ S3 - S5 } \\
\hline & females & vs. & males & \\
\hline & bigger juveniles & vs. & smaller juveniles & S1 - S4 \\
\hline & big males & vs. & $\begin{array}{l}\text { small males } \\
\& \text { small females }\end{array}$ & S1 \& S3 \\
\hline & big females & vs. & $\begin{array}{l}\text { small males } \\
\& \text { small females }\end{array}$ & S2 \& S4 \\
\hline & small males & vs. & $\begin{array}{l}\text { big males } \\
\& \text { big females }\end{array}$ & S1 \& S4 \\
\hline & small females & & $\begin{array}{l}\text { big males } \\
\& \text { big females }\end{array}$ & S2 \& S3 \\
\hline & $\begin{array}{l}\text { dominant } \\
\text { individuals }\end{array}$ & & $\begin{array}{l}\text { submissive } \\
\text { individuals }\end{array}$ & S1 - S7 \\
\hline
\end{tabular}

Factor: Group - Based on sex and/or size for comparisons within scenarios (S1 - S5)

\begin{tabular}{|c|c|c|c|c|}
\hline \multirow{6}{*}{$\begin{array}{l}\text { Food eaten* by group } \\
\text { member }\end{array}$} & Group 1 & \multirow{2}{*}{$\begin{array}{l}\text { vs. } \\
\text { vs. }\end{array}$} & Group 2 & \multirow[b]{2}{*}{ S1 } \\
\hline & big males & & small males & \\
\hline & big females & vs. & small females & $\mathrm{S} 2$ \\
\hline & big males & vs. & small females & S3 \\
\hline & big females & vs. & small males & S4 \\
\hline & $\begin{array}{l}\text { similar sized } \\
\text { males }\end{array}$ & vs. & $\begin{array}{l}\text { similar sized } \\
\text { females }\end{array}$ & S5 \\
\hline
\end{tabular}




\subsection{Results}

At least one animal appeared during every feeding trial to eat $(n=56$; resulting from a total of 28 experiments with two feeding trials each). Both animals were out during a total of $82.1 \%$ of feeding trials $(n=46)$. No patterns were found in the remaining $17.9 \%$ of feeding trials $(n=10)$ in which just one participant was out to feed (occurred across several scenarios [S2, S5, S6 and S7], in both sexes, in F1 and/or $\mathrm{F} 2$, in submissive and dominant participants, in some individuals once and in others repeatedly). At least three prey items were eaten in every trial and all prey items (one meal worm and four crickets) were eaten in $71.4 \%$ of trials $(n=40)$. When not eaten, crickets were hiding and therefore inaccessible to tuatara or were motionless, thus were not detected. Of the individuals that ate more than their cage-mates or equal amounts of food as their cage-mates during $\mathrm{F} 1(n=28), 60.7 \%$ secured more food than their cage-mates during F2 ( $n=17), 35.7 \%$ ate less than their cagemates in F2 $(n=10)$ and $3.6 \%$ shared equally with their cage-mates in F2 $(n=1)$.

\subsubsection{Comparisons among scenarios and broader groups}

The difference between the amounts of food eaten by individuals of a dyad was not significantly different among scenarios $\left(F 1\left[F_{(6)}=1.50 ; p=0.23\right], F 2\left[F_{(6)}=1.34 ; p=\right.\right.$ $\left.0.28], F_{c}\left[F_{(6)}=1.16 ; p=0.36\right]\right)$. No significant differences were found during corrected pairwise comparisons. Overall winners, those individuals that ate more during an experiment $(\mathrm{Fc})$ than their cage-mates, did not differ significantly in the average amount of food they secured among scenarios (Figure $4.1 ; F_{(6)}=0.56, p=$ 0.76), which is reciprocally true among losers. Pooling data among scenarios for broader comparisons linked to sex and size did not reveal any significant patterns in food acquisition with the exception of bigger males eating significantly more than small males and small females ( 1 \& \& 3 ) during $F 2\left(F_{(1)}=3.5 ; p=0.04\right.$; Table 4.2). 


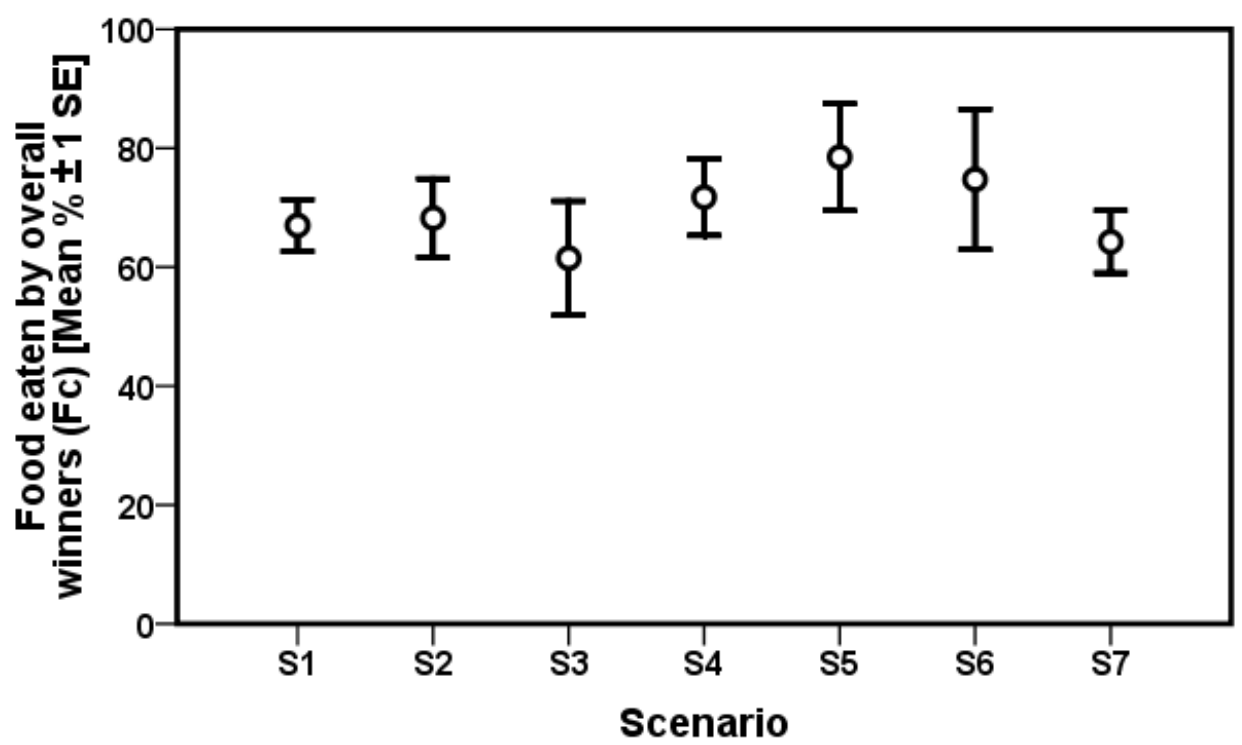

Figure 4.1 Food eaten by overall winners $(F c)$ in $S 1-S 7$ (mean $\% \pm 1 \mathrm{SE}$ ) did not differ significantly among scenarios $\left(F_{(6)}=0.56, p=0.76\right)$. The amount of food each individual in a dyad ate was expressed as a percentage of total food eaten per dyad since some food items were not eaten during trials. S1: big male vs. small male, S2: big female vs. small female, S3: big male and small female, S4: big female and small male, S5: similar sized male and female, S6: similar sized males, S7: similar sized females.

Table 4.2 Broader comparisons with pooled data from several scenarios did not reveal any significant patterns in food acquisition with the exception of bigger males eating significantly more than small males and small females (S1 \& S3) during F2. S1: big male vs. small male, S2: big female vs. small female, S3: big male and small female, S4: big female and small male, S5: similar sized male and female.

\begin{tabular}{|c|c|c|c|c|c|c|c|}
\hline \multirow[t]{2}{*}{ Group comparison } & \multirow{2}{*}{$\begin{array}{c}\text { Data } \\
\text { source }\end{array}$} & \multicolumn{2}{|c|}{$\mathrm{F} 1$} & \multicolumn{2}{|c|}{ F2 } & \multicolumn{2}{|c|}{ Fc } \\
\hline & & $F_{(1)}$ & $p$ & $F_{(1)}$ & $p$ & $F_{(1)}$ & $p$ \\
\hline Females vs. males & S3 - S5 & 0.07 & 0.80 & 0.18 & 0.66 & 0.15 & 0.72 \\
\hline $\begin{array}{l}\text { Bigger juveniles vs. } \\
\text { smaller juveniles }\end{array}$ & S1 - S4 & 0.15 & 0.71 & 2.05 & 0.16 & 0.89 & 0.35 \\
\hline $\begin{array}{l}\text { Big males vs. small } \\
\text { males \& small females }\end{array}$ & S1 \& S3 & 0.63 & 0.45 & 3.5 & 0.04 & 2.65 & 0.12 \\
\hline $\begin{array}{l}\text { Big females vs. small } \\
\text { males \& small females }\end{array}$ & S2 \& S4 & 0.03 & 0.87 & 0.05 & 0.84 & 0.01 & 0.93 \\
\hline $\begin{array}{l}\text { Small males vs. big } \\
\text { males \& big females }\end{array}$ & $S 1 \& S 4$ & 0.07 & 0.79 & 2.61 & 0.10 & 0.83 & 0.36 \\
\hline $\begin{array}{l}\text { Small females vs. big } \\
\text { males \& big females }\end{array}$ & S2 \& S3 & 0.07 & 0.79 & 0.18 & 0.66 & 0.15 & 0.73 \\
\hline
\end{tabular}

\subsubsection{Influence of dominance hierarchies (dominant vs. submissive individuals)}

Data were pooled from all experiments $(S 1-S 7)$ that had established clear dominance hierarchies ( $n=18$; Chapter 2). Dominant individuals ate more food than submissive individuals in F1, F2 and consequently overall (Fc); this trend was not 
significant in $F 1$, but was significant in $F 2$ and overall $\left(F 1\left[F_{(6)}=2.88 ; p=0.10\right], F 2\right.$ $\left[F_{(6)}=14.9 ; p<0.001\right], F_{c}\left[F_{(6)}=1.16 ; p<0.01\right] ;$ Figure 4.2).

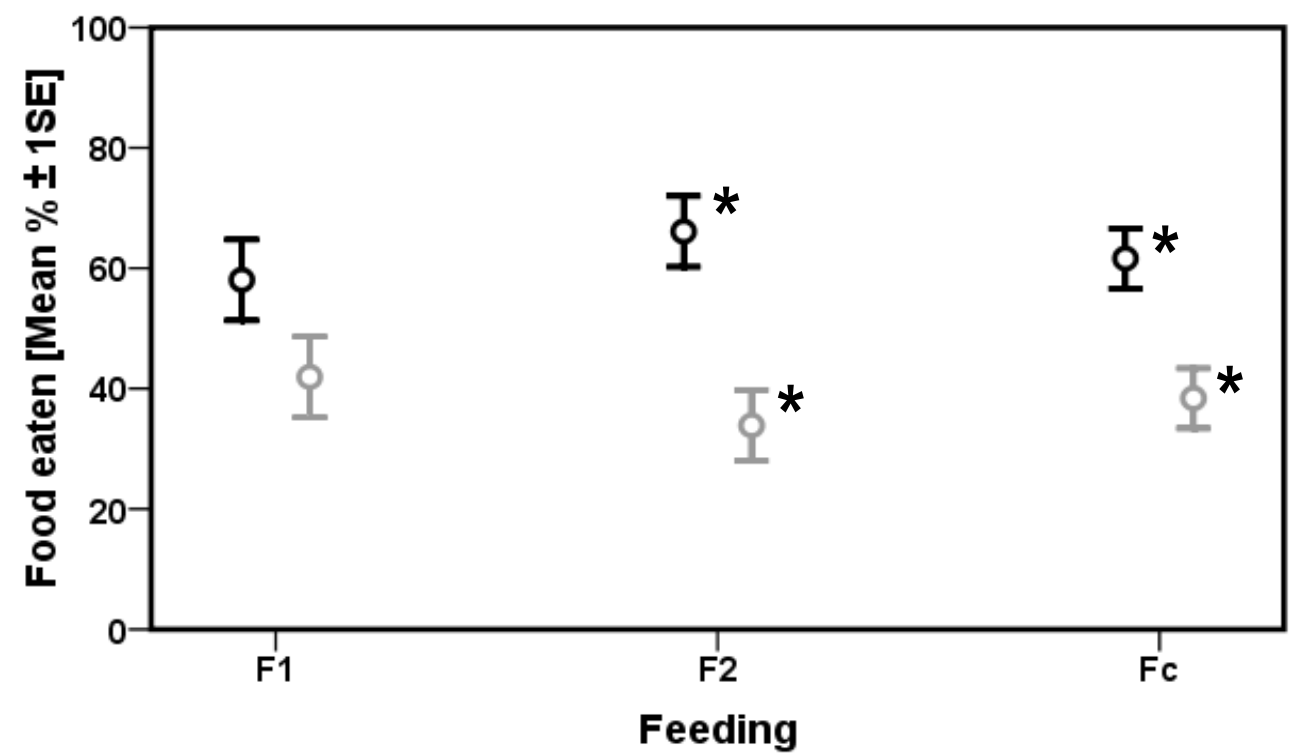

Figure 4.2 Food distribution in F1, F2 and overall (Fc) between dominant (in black) and submissive (in grey) individuals in clear dominance hierarchies (mean $\% \pm 1 \mathrm{SE}$ ). The amount of food each individual in a dyad ate was expressed as a percentage of total food eaten per dyad since some food items were not eaten during trials. Data were pooled from $S 1-S 7$, and included only experiments with clear dominance hierarchies $(n=18$; Chapter 2). Significant differences are marked with *. S1: big male vs. small male, S2: big female vs. small female, S3: big male and small female, S4: big female and small male, S5: similar sized male and female, S6: similar sized males, S7: similar sized females.

\subsubsection{Influence of sex and size in scenarios S1 - S5}

In S1 (big male vs. small male), big males ate more in F1 and F2, and consequently overall $(\mathrm{Fc})$, but this trend was not significant (Table 4.3). Overall $(\mathrm{Fc})$, small males secured $43 \pm 9.9 \%$ of the food provided whereas big males secured $57 \pm 9.9 \%$ (Figure 4.3.a). In S2 (big female vs. small female), big females ate slightly more in $\mathrm{F} 1$, however not in $\mathrm{F} 2$ or overall $(\mathrm{Fc})$ when small females ate more. The differences were not significant (Table 4.3). Overall ( $F c$ ), small females secured $54 \pm 12.1 \%$ of the food whereas big females secured $46 \pm 12.1 \%$ (Figure 4.3.b). In S3 (big male vs. small female), big males ate more in $\mathrm{F} 1$ and $\mathrm{F} 2$, and consequently overall (Fc). This trend was, however, only significant in $F 2\left(F 2\left[F_{(1)}=2.84 ; p=0.03\right]\right.$; Table 4.3). Overall $(F c)$, small females secured $41 \pm 10.5 \%$ of the food whereas big males secured $59 \pm 10.5 \%$ (Figure 4.3.c). In S4 (big female vs. small male), small males ate more during $\mathrm{F} 1$, but big females ate more during $\mathrm{F} 2$ and overall $(\mathrm{Fc})$. The differences were not statistically significant (Table 4.3). Overall (Fc), big females secured $53 \pm 13.9 \%$ of the food whereas small males secured $47 \pm 13.9 \%$ (Figure 


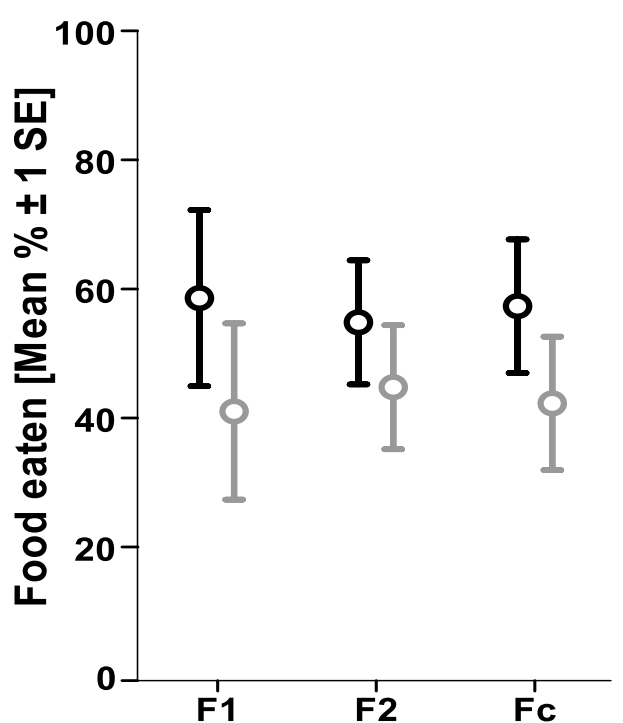

a) Feeding
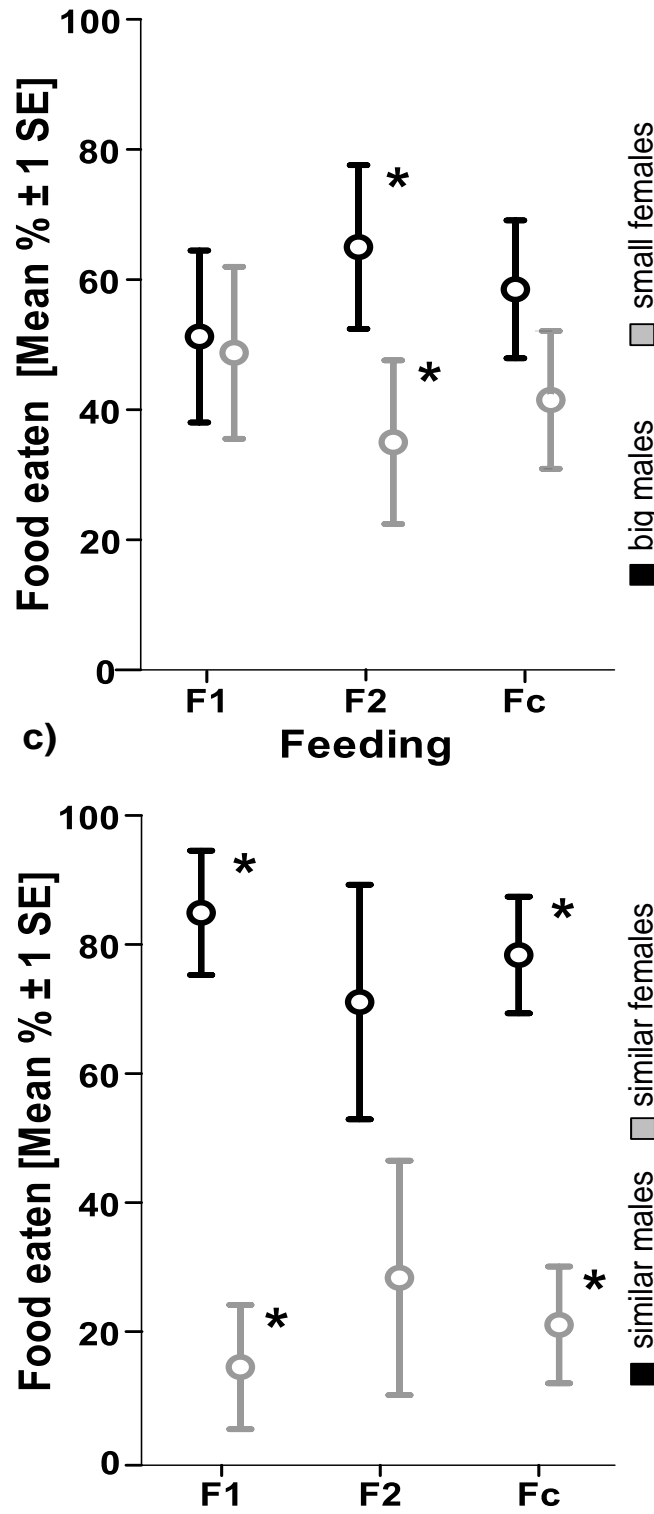

e) Feeding

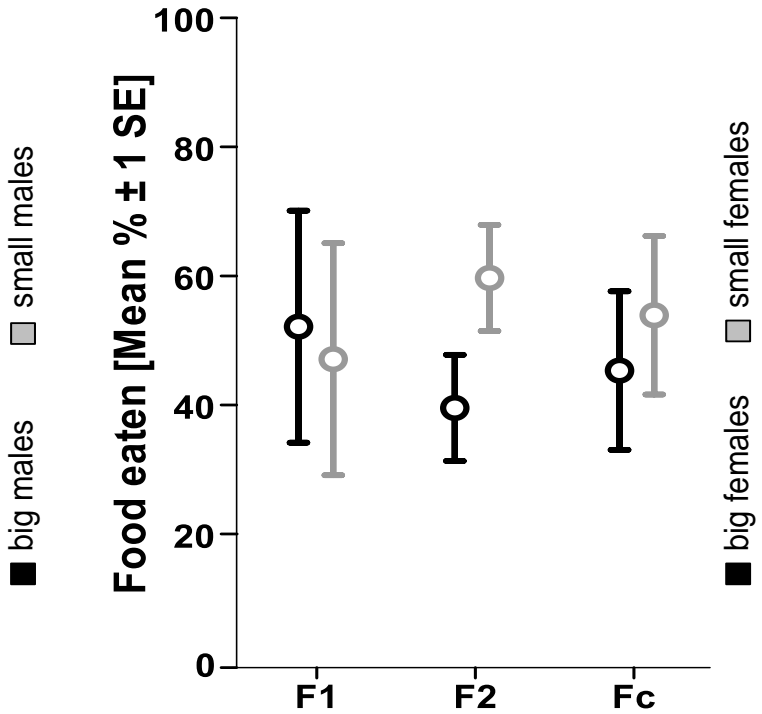

b) Feeding

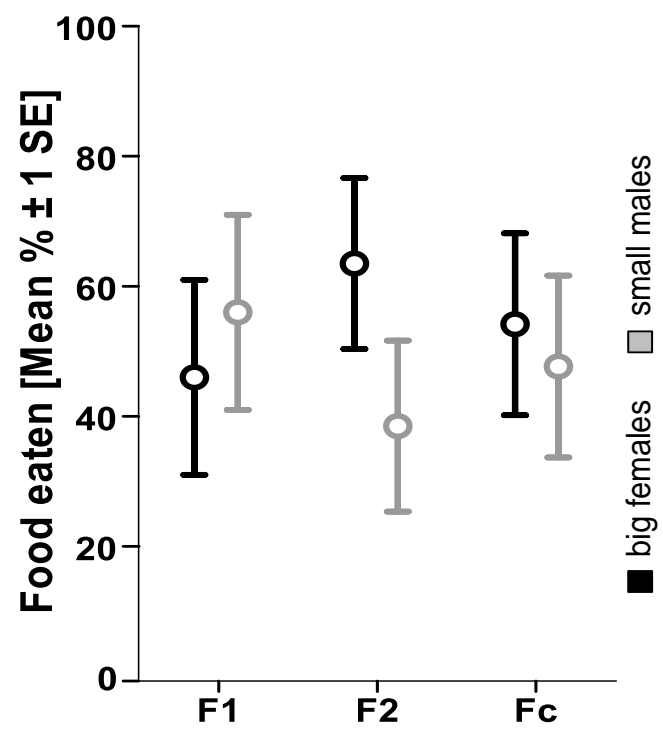

d) Feeding

Figure 4.3 Food distribution (mean $\% \pm$ $1 \mathrm{SE}$ ) in F1, F2, and Fc between a) big males (in black) and small males (in grey) in S1, b) big females (in black) and small females (in grey) in S2, c) big males (in black) and small females (in grey) in S3, d) big females (in black) and small males (in grey) in S4, e) similar sized pairs of a male (in black) and a female (in grey) in S5. Significant differences derived from the pGLMs are marked with *. The amount of food each individual in a dyad ate was expressed as a percentage of total food eaten per dyad since some food items were not eaten during trials. 
4.3.d). In S5 (similar sized male and female), males ate significantly more in F1 and overall $\left(F 1\left[F_{(1)}=26.73 ; p=0.01\right]\right.$, $\left.F c\left[F_{(1)}=20.08 ; p=0.01\right]\right)$. $F 2$ follows the same trend but was not statistically significant (Table 4.3). Overall $(\mathrm{Fc})$, males secured 78 $\pm 9.1 \%$ of the food whereas females secured $22 \pm 9.1 \%$ (Figure 4.3.e).

Table 4.3 Comparisons within scenarios $\mathrm{S} 1$ - $\mathrm{S} 5$ revealed that males ate significantly more when paired with similar sized females (S5) in F1 and Fc, and that big males ate significantly more than small females (S3) in F2, other comparisons were not significant.

\begin{tabular}{|c|c|c|c|c|c|c|c|}
\hline \multirow{2}{*}{$\begin{array}{l}\text { Group comparison } \\
\text { within scenarios }\end{array}$} & \multirow{2}{*}{$\begin{array}{l}\text { Data } \\
\text { source }\end{array}$} & \multicolumn{2}{|c|}{$\mathrm{F} 1$} & \multicolumn{2}{|c|}{$\mathrm{F} 2$} & \multicolumn{2}{|c|}{ Fc } \\
\hline & & $\mathrm{F}_{(1)}$ & $p$ & $F_{(1)}$ & $p$ & $F_{(1)}$ & $p$ \\
\hline $\begin{array}{l}\text { big male } \\
\text { vs. small male }\end{array}$ & $\mathrm{S} 1$ & 0.83 & 0.43 & 0.55 & 0.46 & 0.99 & 0.40 \\
\hline $\begin{array}{l}\text { big female } \\
\text { vs. small female }\end{array}$ & S2 & 0.04 & 0.80 & 3.00 & 0.12 & 0.24 & 0.63 \\
\hline $\begin{array}{l}\text { big male } \\
\text { vs. small female }\end{array}$ & S3 & 0.02 & 0.74 & 2.84 & 0.03 & 1.29 & 0.40 \\
\hline $\begin{array}{l}\text { big female } \\
\text { vs. small male }\end{array}$ & S4 & 0.22 & 0.60 & 1.81 & 0.29 & 0.11 & 0.70 \\
\hline $\begin{array}{l}\text { similar sized male } \\
\text { and female }\end{array}$ & S5 & 26.8 & 0.01 & 2.77 & 0.13 & 20.1 & 0.01 \\
\hline
\end{tabular}

\subsubsection{S6 \& S7}

In S6 (similar sized males), the amount of food eaten by an animal of a dyad ranged from 0 to $100 \%$ during feeding trial F1, F2 and overall (Fc). In three experimental dyads, the distribution of food is relatively consistent with the same individual getting consistently more $(\square \diamond)$ or consistently less $(O)$ food in F1 and F2. In the remaining pair $(\Delta)$ the individual that ate more during F1 ate less during F2 food and the food was shared evenly overall (Fc; Figure 4.4.a; symbols in the text correspond to Figure 4.4.a and represent one animal of each experimental pair). In S7 (similar sized females), the amounts of food eaten by an animal of a dyad ranged from 0 to $100 \%$ during feeding trial F1 and F2, but not overall (Fc; Figure 4.4.b; symbols in the text correspond to Figure 4.4.b and represent one animal of each experimental pair). In two experimental dyads, the individual that ate more in $\mathrm{F} 1$ ate less or nothing in F2 $(\Delta \diamond)$, in one experimental dyad, the individual that ate less in F1 ate more in $F 2(\square)$, and in the remaining pair, which shared food items equally in $F 1$, the represented individual ate no food in F2 (O). Only patterns are presented for S6 and S7 since individuals in a dyad could not be clustered according to sex or size for analyses. 

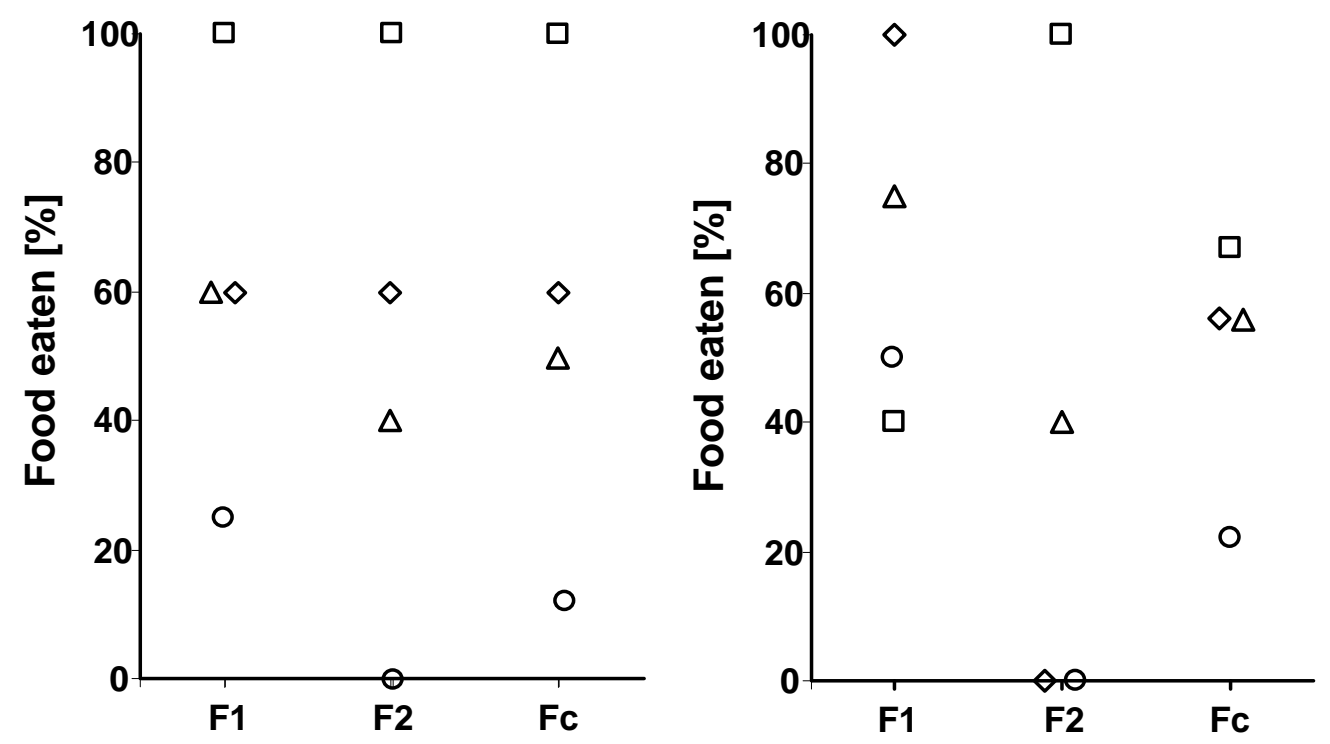

a)

Feeding

b)

Feeding

Figure 4.4 Food eaten (\%) by juveniles in dyads of a) similar sized males (S6) and b) similar sized females (S7). The amount of food each individual in a dyad ate was expressed as a percentage of total food eaten per dyad since some food items were not eaten during trials. Only one animal of each experimental pair is represented with a symbol $(n=4, \square \diamond \Delta 0)$, since the food eaten by two cage-mates added up to $100 \%$, and because individuals in a dyad of S6 and S7 could not be clustered according to sex or size (as for S1 - S5 in Figure 4.3; S1: big male vs. small male, S2: big female vs. small female, S3: big male and small female, S4: big female and small male, S5: similar sized male and female).

\subsubsection{Direct and indirect competition}

All tuatara fed readily when food was provided after F2. This was the case if an animal had previously eaten little or nothing, but also if an individual had been very successful in securing and eating prey items, suggesting that they were not fed to satiation during experiments.

Interference competition was present in all scenarios, but least common in pairs of similar sized females, where it was observed in only one experimental dyad.

Interference competition occurred in $87.5 \%$ of different sized dyads (14 of 16 dyads; S1 - S4) and in $66.7 \%$ of similar sized dyads (8 of 12 dyads; S5 - S7). In $75 \%$ of the experiments with different sized animals (12 of 16 dyads; S1 - S4), interference was predominantly directed from bigger individuals towards smaller individuals. In $12.5 \%$ of experiments smaller individuals interfered with the feeding by bigger individuals ( 2 of 16 dyads; S1 - S4), and in $12.5 \%$ of experiments no directionality could be concluded due to insufficient social interactions. In $50 \%$ of similar sized dyads of opposite sex (2 of 4 dyads; S5), males interfered with the feeding of 
females. In the remaining two dyads of that scenario, no interference behaviours were observed. In $37.5 \%$ of dyads of similar size and sex (3 of 8 dyads; S5 \& S6), one individual of a dyad interfered with the feeding of its conspecific, in the remaining five dyads no interference behaviours were observed.

A range of different interactions during my observations were linked to interference, but occurrences were low and scattered over scenarios and experiments, thus observations are represented but not analysed. In two cases, one animal pushed its cage-mate away from the petri dish containing the meal worm with a closed snout ( $\mathrm{n}$ $=2$ ). The cage-mate continued foraging for the worm. More aggressive encounters at the dish included bites at the head $(n=2)$. A bitten individual was not seen to bite back but usually retreated. The tuatara's slow mastication facilitates the phenomenon of stealing food out of a conspecifics mouth. A conspecific approaches and starts to bite at the food item protruding from the other's mouth $(n=5)$. The outcome for the interfering animal, if successful, is a part (mostly a quarter to a half) of a food item caught by another individual. Biting is inaccurate and can result in biting another tuatara's snout area. On very few occasions and for a limited time only, individuals appeared to stop foraging in the presence of a conspecific $(n=4)$, for example, some abandoned their attempts to catch the meal worm when the second individual arrived at the dish, and retreated. Some abandoned one prey item to follow another when the cage-mate started following the same prey item $(n=4)$. Animals were observed following the conspecific $(n=10)$, attacking $(n=2)$, chasing $(n=5)$ and posing $(n=5)$ during feeding trials. In response or independent of the cage-mate's behaviour, some avoided their cage-mates $(n=34)$ and some immediately ran off with a prey item $(n=13)$. Tail biting occurred during feeding but was rated non-aggressive and not linked to interference ( $n=9$; Chapter 2$)$.

\subsection{Discussion}

Captive juvenile tuatara competed directly and indirectly for food. The ability to compete for food varied with relative size, sex and social rank and influenced the amount of food an animal could secure and eat, supporting the hypothesis that access to food within colonial holdings of immature tuatara differs among individuals. Generally dominant tuatara juveniles secured more food than their submissive cagemates; dominance was linked to size (Chapter 2). Females obtained a smaller share of food when paired with similar sized or bigger males. Approximately equal shares 
were eaten when a big female was paired with a smaller male. While bigger males ate slightly more food than smaller males when paired, such an outcome was not observed in pairs of differently sized females which like the male pairs had established dominance hierarchies in most pairs with the bigger female being dominant. Similar sized females also showed the least interference behaviours of all scenarios. Males may compete more over food than females, or females may be disturbed by the presence of males. Both of which could explain why males secured more prey when competing against females of a similar or smaller size, and still obtained a similar amount of food when paired with bigger females.

Results in juvenile tuatara may explain patterns in tuatara adults. Food competition was suggested as main reason for the differential decline in body condition in a wild population of $S$. guntheri, where females have a more pronounced decline in body condition than males (Hoare et al. 2006). If my findings apply to adults, males may outcompete females for limited food resources since juvenile males are more competitive over food than juvenile females. A greater access to food is likely to correspond to a better body condition (Nelson et al. 2002a; McKenzie 2007).

The main confounding factors of my study were a small sample size as well as a lack of independence due to the limited number of study subjects, equipment and time availability (see Chapter 2 for further details). Furthermore, the social rank a tuatara had within its home enclosure and/or prior experimental pairs may have influenced its behaviour (Beaugrand \& Zayan 1985; Schuett 1997; Drummond \& Canales 1998). Nevertheless, the evident patterns are supported by observations in other reptiles.

The patterns of a bigger body size resulting in a higher social rank and therefore greater success in food acquisition, and sex-biased food acquisition are common in reptiles. In Komodo monitors, Varanus komodoensis, the order in which animals feed on a carcass is determined by size and social status (Pfeffer 1959). Likewise, the size of young painted turtles, Chrysemys picta, and the weight of young snapping turtles, Chelydra serpentina, influence the way in which they interact with conspecifics during feeding. Larger or heavier individuals secure more food than smaller or lighter ones due to dominance hierarchies (Evans 1940; Froese \& Burghard 1974). In captivity, dominant turtles are the first to attack and eat prey while submissive individuals eat what is left over (Mahmoud \& Klicka 1979). Female 
skinks, Scincella lateralis, secure significantly less food when paired with a male in experimental food contests, but females, regardless of size differences, do not impair each others' feeding success (Akin 1998). Also, female green anoles, Anolis carolinensis, of different social ranks do not differ in the amounts of food they can secure and eat (Andrews \& Summers 1996).

Interference competition observed in juvenile tuatara, such as food stealing, chasing, or retreating with seized prey, and the interference of bigger, dominant animals with the feeding of smaller, submissive individuals, concur with patterns observed in other reptiles (see Chapter 2 for social rank). Food stealing, chasing or retreating with a seized prey are common behaviours in captive lizards and turtles (Boice 1970; Greenberg 1976; Mahmoud \& Klicka 1979). Dominant individuals of the turtle species Terrapene carolina carolina are more likely to interfere with the feeding of others (Boice 1970), and dominance is positively related to body size (Evans 1940; Froese \& Burghard 1974). Larger juvenile side-blotched lizards, Uta stansburiana, outcompete smaller conspecifics over food resources, which is linked, together with other factors, to a survival advantage when food is scarce (Ferguson \& Fox 1984). Unfortunately, none of those studies accounted for sex, and hence it is not possible to compare my finding that males are more likely to interfere with a female's feeding than vice versa when of similar size but different sex.

Food stealing occurred in only five of 56 feeding trials for tuatara. Biting occurred frequently when a tuatara attempted to steal food from a conspecific as inaccuracy was common. Food stealing is well described and common in lizards and turtles in captivity (lizards: Sceloporus cyanogenys, Anolis carolinensis and Dipsosaurus dorsalis [Greenberg 1976]; turtles: Terrapene carolina carolina [Boice 1970], Chrysemys picta bellii and Trachemys scripta elegans [Mahmoud \& Klicka 1979]). The occurrence of this behaviour is linked to food abundance in lizards. Low abundance of food results in frequent stealing events whereas these are rare when food is plentiful (Greenberg 1976). Stealing food from another individual's jaws is accurate in lizards and excludes biting (Greenberg 1976). Bigger juvenile crocodiles, Crocodylus niloticus, attack smaller ones holding food, but Morpurgo et al. (1993) did not report whether this behaviour is linked to food stealing.

Tuatara occasionally retreated to eat their prey immediately after seizure. In a few cases, when a submissive tuatara detected a prey item first, it would hold off when a 
dominant tuatara approached or switch to following another food item. This behaviour suggests that some individuals were intimidated by their dominant cagemates (Chapter 2). Since no patterns were detectable in the few occurrences when individuals did not emerge to forage during feeding trials, this is likely due to animals being asleep, and thus not noticing the food items (see Figure 3.2 for emergence), rather than intimidation. Aggressive biting, as opposed to biting during food stealing, was comparatively rare during feeding events, and when bitten, the recipient tuatara did not bite back but retreated. Retreating with prey is common in lizards (Greenberg 1976), captive turtles (Harless 1979; Mahmoud \& Klicka 1979), and crocodilians (Warwick 1995). Inhibited or altered feeding behaviour in the presence of more dominant individuals is also reported for captive lizards (Greenberg 1976) and turtles (Harless 1979). For example, a submissive Terrapene carolina carolina turtle would hesitate or withdraw its head and so lose prey to its dominant conspecific. Also, biting is rare during feeding and not reciprocated (Boice 1970).

The amount of food available to tuatara in experiments did not satiate juveniles, and is likely to have amplified competition for food and interference behaviours. Fights over food should generally be avoided since they are energetically costly and can inflict injuries. However, close proximity during feeding also provides the chance of opportunistic foraging on prey that is flushed, captured and killed by another tuatara that otherwise would not have been detected or available, and may stimulate a higher food intake in general. Opportunistic feeding is common in captive lizards (Greenberg 1976), and juvenile Florida red-bellied turtles, Pseudemys nelsoni, and chuckwallas, Sauromalus obesus, eat more when provided with food in a group setting than when fed in isolation (Bjorndal 1986; Tracy 1999). Nevertheless, housing juveniles at lower densities in home enclosures and increasing the food supply should be considered. The increase in food should be kept within a reasonable limit since feeding to satiation in captive reptiles including tuatara may be disadvantageous for their health as they have a tendency towards obesity (Newman et al. 1979; Warwick 1995). Those measures are likely to help decrease the occurrence of interference competition as well as non-aggressive tail biting during feeding (Chapter 2) which would positively impact on juveniles' conditions. The depletion of energy resources may be reduced and their health may improve through the reduction of possible wounds and subsequent infections (Taubes 1992). Positive implications of lower density holdings in captivity have been shown, for example, in captive juvenile crocodiles, Crocodylus niloticus (Morpurgo et al. 1993). 
Raising juvenile tuatara in captivity is a commonly used tool in the species' conservation management (Gaze 2001; Nelson et al. 2002a). Success is determined by production of healthy juveniles, low mortality and a good transition to the wild. Housing and feeding are therefore critical components for success. My results show that the composition of groups based on sex and size can have major effects on food availability for individual group members, that males seem to be the better competitors for food than females, and that a bigger size can increase access to food. My results combined with Gruber's (2007) finding of female-biased mortality in larger groups emphasise the importance of considering sex and size of juvenile tuatara in captive housing. I strongly recommend housing males and females separately, and to continue the current practice of assigning individuals to groups of approximately similar size (Keall, personal communication; personal observation). Since competition often asymmetrically affects individuals of different sizes within a population (Begon 1984) and a higher level of competition results in a greater advantage for dominant animals (Begon 1984; Deutsch \& Lee 1991; Witter \& Swaddle 1994), the smallest tuatara juvenile within a group is likely to be most affected. Effects are likely to increase when competing with not only one (as in this study) but up to five or more individuals, as occurs frequently in head-starting facilities. Subdominant juveniles may no longer be able to secure sufficient food resources and may suffer from an unpredictable supply (Gosler 1987; Ekman \& Lilliendahl 1993; Witter \& Cuthill 1993). The long-term consequence is probably greater growth in already heavier, larger, predominantly male juveniles which will simultaneously enhance their chances of survival (Swingland \& Coe 1979; Ferguson \& Fox 1984; Gruber 2007). This could explain the higher survival rate observed in juvenile male tuatara (Gruber 2007). Over time this cycle probably further amplifies the bias in food availability, leading to an ever greater difference in the competitive ability for food, potentially explaining the enormous size and weight differences in head-started juveniles at around five years of age (SVL: $84-149 \mathrm{~mm}$, mass: 16 $124 \mathrm{~g}$; Gruber 2007). Inferences from this study regarding tuatara housing conditions should, however, be made with caution. Relationships may vary in altered contexts and between a group of two vs. a group of several individuals (Hand 1986), thus future research into feeding competition in bigger groups will further help support better practises in head-starting facilities.

The results of this study also have implications for tuatara in wild populations. North Brother Island, for example, has a population at carrying capacity, and a male- 
biased sex ratio (1.7 males: 1 female; Nelson et al. 2002b; Hoare et al. 2006). Body condition has declined in both sexes but most dramatically in females. If adult males are more competitive over food than females, as we might reasonably predict from my results on juveniles, then adult females are likely to acquire less food, remain small, and have reduced reproductive output (Cree 1994; Newman et al. 1994), potentially affecting population viability. Further, a possible increase in intersexual aggression directed towards females as seen in male-biased lizard populations, Lacerta vivipara, may further exacerbate the situation (Le Galliard et al. 2005). It may become necessary to remove males from the island to reduce competitive pressure on females and ensure long-term viability of the population. 


\section{CHAPTER FIVE}

\section{General discussion, implications and future research}

\subsection{Introduction}

Even though tuatara have been the focus of numerous studies (Cree 2005), little is known about the behaviour of the species' cryptic juveniles. Tuatara are also the focus of intense conservation efforts including head-starting of juveniles as founders for new, or to supplement existing, populations (Gaze 2001; Nelson et al. 2002a; Miller et al. In press). While captive management could profit from further knowledge on juvenile behaviour, for example, to design adequate groups for housing, and ultimately to produce more, healthy juveniles, captive colonies also provide a good opportunity for research under controlled experimental conditions. I investigated aggression and competition for space and food in juvenile tuatara, not only to shed light on some of the many unanswered questions about the biology of the elusive juveniles, but also to provide a basis to improve husbandry practises for headstarting and housing juveniles for conservation purposes. I asked three questions. (1) Do agonistic behaviours depend on sex and size in juvenile tuatara? (2) Do captive juvenile tuatara compete for space? (3) Do captive juvenile tuatara compete for food?

\subsection{Summary of main findings}

The main findings from each of the three data chapters (Chapters $2-4$ ) are summarised below.

5.2.1 Chapter 2: Do agonistic behaviours depend on sex and size in juvenile tuatara? The incidences of aggression differed among social scenarios, whereas submissive behaviours showed no significant differences. Male-male encounters, regardless whether individuals were of similar or different size, showed augmented occurrences of aggressive behaviour, as did dyads of a small submissive male, and a big aggressive female. Males were more aggressive towards one another than females, and aggressive males showed a pattern of more aggression than aggressive females. Size, but not sex, influenced the directionality of aggression with relatively bigger juveniles reacting aggressively and smaller ones submissively. Aggressive acts generally resulted in a submissive response. Clear dominance hierarchies were 
established in 18 out of the 28 experiments, predominantly, but not exclusively, in scenarios of different size with bigger animals being dominant. The occurrence of agonistic behaviours in juvenile tuatara was relatively stable during the six day experiments. Tail biting was more commonly related to mistaking a tail for food than to aggression. Size, dominance, and aggressive and submissive behaviours are also commonly correlated in adult tuatara (Buller 1879; Gillingham et al. 1995; Moore et al. In press) and other reptiles (Brattstrom 1974; Froese \& Burghard 1974; Morpurgo et al. 1993). More aggression among males than among females is also a common finding in all orders of reptiles (Formanowicz et al. 1990; Gillingham et al. 1995; Rovero et al. 1999).

\subsubsection{Chapter 3: Do captive juvenile tuatara compete for space?}

Captive tuatara at one year of age did not compete for space. Shelters were not used exclusively by individuals in most experiments, and could be shared at some time and used alone at others. Even after four days in the experimental enclosure, most tuatara used all outside space available to them, and no differences in the use of space were detected among scenarios. Spatial and temporal avoidance was negligible and did not differ with social context. Within the limits of my operational definition, the findings on space use suggest that captive one-year-old juveniles did not use space exclusively thus did not occupy territories. In conclusion, one-yearolds were slowly transitioning between obligatory clustering in captive hatchlings (Keall \& Hazley, personal communication) and territoriality in adults (Gillingham \& Miller 1991; Gillingham et al. 1995).

The number of urinations in the first 50 minutes seemed unusually high, and intriguingly males were significantly more likely to urinate than females. The numbers of defecations in the first 24 hours were also highly elevated and not linked to recent feeding. Defecation occurred in similar numbers in both sexes, and numbers did not differ significantly among scenarios. Faecal matter was found in all locations and there is no site tendency for individuals for defecation site.

Significantly high numbers of faeces were found in the water dish while the occurrence inside shelters was significantly low. The scent marking of a novel captive environment has never been described in tuatara, but is common in snakes (Chiszar et al. 1980), and may be used to familiarize an enclosure (Johnson 1973; Chiszar et al. 1980). 


\subsubsection{Chapter 4: Do captive juvenile tuatara compete for food?}

Captive juvenile tuatara competed directly and indirectly for food. Size, sex and social rank influenced the amount of food an animal could secure and eat, hence food availability within colonial holdings of immature tuatara differed among individuals. Females get a smaller share of food when paired with similar sized or bigger males. Approximately equal shares are eaten when a big female is paired with a smaller male. Different sizes do not impair the distribution of food between females, and similar sized females showed the least interference behaviours of all scenarios. However, size does matter for males with small males getting slightly less food than big males. Dominant individuals ate more than their submissive cage mates. The patterns of a bigger body size resulting in a higher social rank and therefore greater success in food acquisition, and sex-biased food acquisition are common in reptiles (Pfeffer 1959; Froese \& Burghard 1974; Mahmoud \& Klicka 1979; Akin 1998; Goetz, personal communication).

\subsection{Research Implications}

\subsubsection{Integration of chapters $2-4$}

Territoriality and dominance hierarchies can be interpreted as the two ends of a behavioural continuum which serves to allocate resources among individuals (Maher \& Lott 1995; Lott \& North 1998). One-year-old tuatara showed a subset of the aggressive territorial behavioural repertoire of adults (Gillingham et al. 1995) but had no set territories yet (Chapter $2 \& 3$ ). Aggression may be linked to the development of territorial behaviour during ontogeny (Chapter $2 \& 3$ ). My observations suggest that one-year-olds are in a transitional stage between clustering in non-aggressive hatchlings (Keall \& Hazley, personal communication) and aggressive territorial spacing in later life stages (Goetz \& Thomas 1994a; Gillingham et al. 1995). A dominance hierarchy, formed in the majority of experiments, may shift towards the acquisition of an exclusive area, and hence territoriality, as juveniles grow. More aggression among male dyads (Chapter 2 ) when compared with female dyads is also consistent with a significantly higher amount of urinations in males than females at the beginning of experiments (Chapter 3 ), suggesting a more intense struggle for dominance in which scent marking may play a role.

During the proposed transitional stage, agonistic behaviours may only be used to establish dominance hierarchies (Chapter 2) and used to compete for food (Chapter 
4) not space, as food might be the most important resource to compete over at this age. A bigger body size is commonly advantageous in food competition in reptiles since this often confers to a higher social rank (Evans 1940; Pfeffer 1959; Froese \& Burghard 1974). Dominant individuals ate significantly more of the limited number of food items than did their submissive cage-mates. The data, especially the directionality of aggressive interference from predominantly bigger individuals towards smaller individuals, suggest that that some individuals may have been intimidated by their cage-mates (Chapter $2 \& 4$ ). The occurrence of interference competition during feeding events (Chapter 4 ) is linked to the communal space use (Chapter 3). If territories had already been established, a reduced encounter rate during feeding could be expected if each individual restricts its foraging activity to its own territory.

\subsubsection{Implications for conservation management}

Captive tuatara at one year of age did not compete for space when sufficient and equally valuable shelters were provided (Chapter 3 ), thus more emphasis can be put on alleviating aggression (Chapter 2) and food competition (Chapter 4). Space competition may be an issue for older juveniles as they will develop territoriality during their ontogeny (Goetz \& Thomas 1994a). Therefore, the occurrence of competition for space should be closely monitored.

Competition and aggression in captive tuatara juveniles asymmetrically affect individuals of different size and sex. Therefore, the findings from my study have implications on how to assign groups of juvenile tuatara to minimise detrimental effects of social interactions. Gruber (2007) found a female-biased mortality rate in larger mixed sex groups of captive head-started tuatara, suggesting aggression and competition can have an impact on survival. In addition, Le Galliard et al. (2005) observed that a male-bias in adult lizards, Lacerta vivipara, can lead to increased aggression towards females with detrimental effects for their survival and reproduction. Hence, sex and size should be considered carefully when composing larger groups of juvenile tuatara for captive housing. I recommend housing female and male juveniles separately. Further, I would sort same sex groups by size, and suggest more spacious enclosures for male groups as they are more aggressive towards each other. A higher level of competition is to be expected when competing with not only one (as in this study) but several individuals (as common in husbandry) which could further exacerbate the outcomes of competition (Begon 1984; Deutsch 
\& Lee 1991; Witter \& Swaddle 1994). The lowest ranked and/or smallest tuatara juvenile within a group is therefore likely to be most affected. A limitation to my recommendations is that the sex of each individual must be known for them to be practical. Determining the sex of juveniles is feasible via knowledge of incubation temperatures (tuatara have a temperature-dependant sex determination; Cree et al. 1995; Nelson et al. 2004a), laparoscopy (Cree et al. 1990; Nelson 2001) and/or a via an analysis of external phenotypic traits (Oldman 2008). Both of the latter techniques are available from about one year of age and/or circa $60 \mathrm{~mm}$ snout-tovent-length (Nelson 2001; Oldman 2008).

Interference behaviours (Chapter 4) during feeding could be minimised by reducing density of juveniles and/or increasing food availability. For example, in captive juvenile crocodiles, Crocodylus niloticus, a reduction in density resulted in a decrease in aggression (Morpurgo et al. 1993). Both actions should have positive implications for juvenile condition by reducing the depletion of energy resources through energetically costly agonistic behaviours during feeding (Brattstrom 1974) and the consequent incidence of wounds and subsequent infections (Taubes 1992). However, feeding must be balanced with feedback information on mass and body length to avoid obesity.

The incidence of tail loss does not necessarily imply aggressiveness in juvenile tuatara. Nelson et al. (2004b) suggested that artificially incubated tuatara juveniles may be less aggressive than naturally incubated juveniles as only $73 \%$ of the former but $100 \%$ of the latter of had lost a part of their tail at ten months of age (group housing at same densities; both incubation regimes housed separately). Given that most tail bites may be related to mistaking a tail for food, tail loss may not reflect on the level of aggressiveness but readiness to feed or ability to distinguish between a tail and a food item.

My findings have implications for transferring captive tuatara to new enclosures and on cleaning practices. Tuatara may be sensitive to their own odour, which could have a calming effect similar to that in snakes (Chiszar et al. 1980). I recommend, introducing tuatara to a new or cleaned cage with ground cover or shelters from the old enclosure to minimise stress reactions as this has shown positive results in snakes (Conant 1971). Since high numbers of faeces were found in the water dish but nearly none inside shelters, the water should be replaced at short intervals and 
the dish cleaned for hygienic reasons as it is current practice (Blanchard 2002). The shelters do not require regular cleaning on a short-term basis.

The results of this study also have implications for adult tuatara in wild populations. A long-term decline in body condition in the two populations for which adequate information exists (North Brother Island and Stephens Island) has been attributed to food competition (Hoare et al. 2006; Moore et al. 2007). North Brother Island, for example, has a population at carrying capacity, and a male-biased sex ratio (1.7 males: 1 female; Nelson et al. 2002b; Hoare et al. 2006). Body condition has declined in both sexes but most dramatically in females (Hoare et al. 2006). If adult males are more competitive over food than females, as we might reasonably predict from my results on juveniles, then adult females are likely to acquire less food, remain small, and consequently have reduced reproductive output (Cree 1994; Newman et al. 1994). Further, a possible increase in intersexual aggression directed towards females as seen in male-biased lizard populations, Lacerta vivipara, may further exacerbate the situation (Le Galliard et al. 2005). Le Galliard et al.'s paper (2005) suggests these limitations on reproductive output could feedback causing extinction vortices for populations. Management to mediate effects of the malebiased sex ratio may be required to ensure long-term viability of the population.

\subsection{Future directions for research}

Although this thesis answers some of the most urgent questions regarding aggression and competition in juvenile tuatara, it also presents several new questions and can provide a basis for further investigations. While, within the limits of my project, agonistic behaviours were researched in dyads, further investigations are needed to determine how those findings apply to larger groups of juvenile tuatara. For example, how does the context of sex and size of members of larger groups, usually held colonially for practical reasons, influence the level of agonistic interactions, space use and feeding competition? What is the optimum group size to allow a reduction of aggressive behaviours and food competition in one-year-old tuatara without compromising the group housing option? Since the behaviour of juveniles changes during ontogeny, it would be interesting to explore and compare different age groups. 
More studies are needed to determine the age and/or size of the onset of territorial behaviour and what may trigger or delay it, as this may have important implications for captive holdings. The reasons for juvenile territoriality should be determined and additional research should reveal if and how those reasons change during ontogeny. Moreover, it would be important to determine if tuatara, like lizards (Warwick 1995), switch from a territorial organisation to a dominance hierarchy under limited space conditions in captivity and if so, to determine the critical density at which a switch may occur.

The finding that tuatara juveniles urinate and defecate more when transferred to a new and clean captive environment suggests that they are sensitive to their own or familiar odours similar to snakes (Chiszar et al. 1980). Little research has been done into the role of scent marking in tuatara and the results presented in this study warrant further investigation in captivity and the wild. Further, the reasons for the high numbers of faeces in the water dish and almost none in the shelters could be investigated.

Research is needed to determine the critical balance between feeding enough to provide all individuals of a group with sufficient food for comparable growth but, at the same time, not causing obesity in better competitors. In addition, further questions related to food competition are yet unanswered. For example, does foraging efficiency itself differ with sex and size and may this explain some of the differences found among the scenarios in this study? Based on the fact that not all individuals were out at all feeding trials, do different feeding times have an influence on food competition, taking into account the activity pattern and circadian rhythms of juveniles at different ages? Could different forms of food provision, for example spatial, over time, or on different backgrounds help reduce competition?

Finally, I would encourage a focal study on the development of aggression and competition for space and food in juveniles of different ages in the wild. This would shed further light on the development of those behaviours during ontogeny, broaden our knowledge on the immature life stages of this species and would offer the chance to compare between the behaviour of wild and captive juveniles. 


\subsection{Closing Remark}

This study answers the most urgent questions regarding aggression and competition for space and food in captive one-year-old juvenile tuatara, and provides a basis which should help improving captive management techniques of immature tuatara for conservation purposes. 


\section{References}

Abbott J C \& Dill L M (1989) The Relative Growth of Dominant and Subordinate Juvenile Steelhead Trout (Salmo gairdneri) Fed Equal Rations. Behaviour 108: 104-113.

Afonso P, Morato T \& Santos R S (2008) Spatial Patterns in Reproductive Traits of the Temperate Parrotfish Sparisoma cretense. Fish Res 90: 92-99.

Akaike H (1973) Information Theory and an Extension of Maximum Likelihood Principle in Second International Symposium on Information Theory. Petrov B N \& Coaki F, Eds, pp 267-281. Akademia Kiado Budapest.

Akin J A (1998) Intra- and Inter-Sexual Aggression in the Ground Skink (Scincella lateralis). Can J Zool 76: 87-93.

Alanara A, Burns M D \& Metcalfe N B (2001) Intraspecific Resource Partitioning in Brown Trout: the Temporal Distribution of Foraging Is Determined by Social Rank. J Anim Ecol 70: 980-986.

Alberts A C (2007) Behavioral Considerations of Headstarting as a Conservation Strategy for Endangered Caribbean Rock Iguanas. Appl Anim Behav Sci 102: 380-391.

Alberts A C \& Phillips J A (2004) Experimental Strategies for the Recovery of Depleted Populations of West Indian Rock Iguanas in Experimental Approaches to Conservation Biology. Gordon M S \& Bartol S M, Eds, pp 83-100. University of California Press, Berkeley.

Andrews T J \& Summers C H (1996) Aggression, and the Acquisition and Function of Social Dominance in Female Anolis carolinensis. Behaviour 133: 1265-1279.

Aragon P, Lopez P \& Martín J (2000) Size-dependent Chemosensory Responses to Familiar and Unfamiliar Conspecific Faecal Pellets by the Iberian Rock Lizard, Lacerta monticola. Ethology 106: 1115-1128.

Avery R A, Bedford J D \& Newcombe C P (1982) The Role of Thermoregulation in Lizard Biology: Predatory Efficiency in a Temperate Diurnal Basker. Behav Ecol Sociobiol 11: 261-267.

Baker R R (1983) Insect Territoriality. Annu Rev Entomol 28: 65-89.

Ballinger R E (1973) Comparative Demography of Two Viviparous Iguanid Lizards (Sceloporus jarrovi and Sceloporus poinsetti). Ecology 54: 269-283.

Ballinger R E \& Congdon J D (1980) Food Resource Limitation of Body Growth Rates in Sceloporus scalaris (Sauria: Iguanidae). Copeia: 921-923.

Baur B \& Baur A (1990) Experimental Evidence for Intraspecific and Interspecific Competition in Two Species of Rock-Dwelling Land Snails. J Anim Ecol 59: 301-315.

Beach F A \& Gilmore R W (1949) Response of Male Dogs to Urine from Females in Heat. J Mammal 30: 391-392.

Beaugrand J P \& Zayan R (1985) An Experimental Model of Aggressive Dominance in Xiphophorus helleri (Pisces, Poeciliidae). Behav Process 10: 1-52.

Beaver R A (1974) Intraspecific Competition among Bark Beetle Larvae (Coleoptera Scolytidae). J Anim Ecol 43: 455-467. 
Begon M (1984) Density and Individual Fitness: Asymmetric Competition in Evol. Ecol. Shorrocks B, Ed. pp 175-194. Blackwell Scientific Publication, Oxford.

Bell C D L, Parsons J, Austin T J, Broderick A C, Ebanks-Petrie G \& Godley B J (2005) Some of Them Came Home: the Cayman Turtle Farm Headstarting Project for the Green Turtle Chelonia mydas. Oryx 39: 137-148.

Bell T \& Kramer D L (2000) Territoriality and Habitat Use by Juvenile Blue Tangs, Acanthurus coeruleus. Environ Biol Fish 58: 401-409.

Besson A A (2009) Effects of Cool Temperature on Egg Incubation, Thermoregulation and Physiological Performance of Tuatara (Sphenodon punctatus) : Implications for Conservation Programmes. PhD thesis. Zoology, University of Otago, Dunedin, New Zealand.

Besson A A, Thierry A, Boros E, Allen K, Bradley S, Norrie C \& Cree A (2009) Evidence of Food Chemical Discrimination in Tuatara (O. Rhynchocephalia): Comparison with a Gekkotan Lizard (O. Squamata). J Herpetol 43: 124-131.

Birch L C (1957) The Meanings of Competition. Am Nat 91: 5-18.

Bjorndal K A (1986) Effect of Solitary vs. Group Feeding on Intake in Pseudemys nelsoni. Copeia: 234-235.

Blanchard B (2002) Tuatara Captive Management Plan and Husbandry Manual. Department of Conservation, Wellington, New Zealand.

Boccia M L, Laudenslager M \& Reite M (1988) Food Distribution, Dominance, and Aggressive Behaviors in Bonnet Macaques. Am J Primatol 16: 123-130.

Boehm T \& Zufall F (2006) MHC Peptides and the Sensory Evaluation of Genotype. Trends Neurosci 29: 100-107.

Boice R (1970) Competitive Feeding Behaviours in Captive Terrapene c. carolina. Anim Behav 18: 703-710.

Bowen B W, Conant T A \& Hopkins-Murphy S R (1994) Where Are They Now? The Kemp's Ridley Headstart Project. Conserv Biol 8: 853-856.

Braastad B O (1998) Effects of Prenatal Stress on Behaviour of Offspring of Laboratory and Farmed Mammals. Appl Anim Behav Sci 61: 159-180.

Brashares J S \& Arcese P (1999) Scent Marking in a Territorial African Antelope: 2. The Economics of Marking with Faeces. Anim Behav 57: 11-17.

Brattstrom B H (1974) Evolution of Reptilian Social Behavior. Am Zool 14: 35-49.

Brown R E \& Macdonald D W (1985) Social Odours in Mammals. Clarendon Press, Oxford.

Brown S G, Gomes F \& Miles F L (1998) Faeces Avoidance Behaviour in Unisexual and Bisexual Geckos. Herpetol J 8: 169-172.

Bulger J B (1993) Dominance Rank and Access to Estrous Females in Male Savanna Baboons Behav. Res. Ther. 127: 67-103.

Buller W L (1879) Further Notes on the Habits of the Tuatara Lizard. Trans N Z Inst 11: 349351. 
Burghard G M \& Layne D G (1995) Effects of Ontogenetic Processes and Rearing Conditions in Health and Welfare of Captive Reptiles. Warwick C, Frye F L \& Murphy J B, Eds, pp 205-238. Chapman \& Hall, London.

Burnham K P \& Anderson D R (1998) Model Selection and Multimodel Inference: a Practical Information-Theoretic Approach. Springer-Verlag Inc., New York.

Bustard H R (1965) Observations on the Life History and Behavior of Chamaeleo hohnelii (Steindachner). Copeia 1965: 401-410.

Bustard H R \& Maharana S (1983) Female Territoriality in Immature Salt Water Crocodiles in Captivity and its Effect on Growth and Survival. J Bombay Nat Hist Soc 79: 419-424.

Cabanac A \& Cabanac M (2000) Heart Rate Response to Gentle Handling of Frog and Lizard. Behav Process 52: 89-95.

Cabanac M \& Gosselin F (1993) Emotional Fever in the Lizard Callopistes Maculatus (Teiidae). Anim Behav 46: 200-202.

Cade T J \& Jones C G (1993) Progress in Restoration of the Mauritius Kestrel. Conserv Biol 7: $169-175$.

Campanella P J \& Wolf L L (1974) Temporal Leks as a Mating System in a Temperate Zone Dragonfly (Odonata: Anisoptera) 1. Plathemis lydia (Drury). Behaviour 51: 49-87.

Carazo P, Font E \& Desfilis E (2007) Chemosensory Assessment of Rival Competitive Ability and Scent-Mark Function in a Lizard, Podarcis hispanica. Anim Behav 74: 895-902.

Carazo P, Font E \& Desfilis E (2008) Beyond 'Nasty Neighbours' and 'Dear Enemies'? Individual Recognition by Scent Marks in a Lizard (Podarcis hispanica). Anim Behav 76: 1953-1963.

Carpenter C C (1967) Aggression and Social Structure in Iguanid Lizards in Lizard Ecology: a Symposium. Milstead W W, Ed. pp 87-105. University of Missouri Press, Columbia.

Carpenter C C (1978) Ritualistic Social Behaviors in Lizards in Behavior and Neurology of Lizards: An Interdisciplinary Colloquium. Greenberg N \& MacLean P D, Eds, pp 253268. U.S. Department of Health, Education and Welfare, Rockville, Maryland.

Carpenter C C \& Ferguson G W (1977) Variation and Evolution of Stereotyped Behavior in Reptiles in Biology of the Reptilia, Ecology and Behaviour A. Gans C \& Tinkle D W, Eds, pp 335-554. Academic Press, New York.

Castanet J, Newman D G \& Saint Girons H (1988) Skeletochronological Data on the Growth, Age, and Population Structure of the Tuatara, Sphenodon punctatus, on Stephens and Lady Alice Islands, New Zealand. Herpetologica 44: 25-37.

Caughley G (1994) Directions in Conservation Biology. J Anim Ecol 63: 215-244.

Chapple D G (2003) Ecology, Life-History, and Behavior in the Australian Scincid Genus Egernia, with Comments on the Evolution of Complex Sociality in Lizards. Herpetol Monogr: 145-180.

Charland M B \& Gregory P T (1989) Feeding Rate and Weight Gain in Postpartum Rattlesnakes - Do Animals That Eat More Always Grow More. Copeia: 211-214.

Chiszar D, Murphy J B \& Smith H M (1993) In Search of Zoo-Academic Collaborations: a Research Agenda for the 1990s. Herpetologica 49: 488-500. 
Chiszar D, Wellborn S, Wand M A, Scudder K M \& Smith H M (1980) Investigatory Behavior in Snakes 2. Cage Cleaning and the Induction of Defecation in Snakes. Anim Learn Behav 8: 505-510.

Civantos E (2000) Home-Range Ecology, Aggressive Behaviour, and Survival in Juvenile Lizards, Psammodromus algirus. Can J Zool 78: 1681-1685.

Clutton-Brock T H \& Albon S D (1979) Roaring of Red Deer and the Evolution of Honest Advertisement. Behaviour 69: 145-170.

Conant R (1971) Reptile and Amphibian Management Practices at Philadelphia Zoo. Int Zoo Yearbook 11: 224-230.

Congdon J D, Dunham A E \& Sels R C V (1994) Demographics of Common Snapping Turtles (Chelydra serpentina) - Implications for Conservation and Management of Long-Lived Organisms. Am Zool 34: 397-408.

Cooper W E \& Burghardt G M (1990) Vomerolfaction and Vomodor. J Chem Ecol 16: 103105.

Cranshaw H L (2009) The Effect of Prey Hardness on the Feeding Efficiency of Captive Juvenile Tuatara, Sphenodon punctatus. Hons thesis. School of Biological Sciences, Victoria University of Wellington, Wellington, New Zealand.

Cree A (1994) Low Annual Reproductive Output in Female Reptiles from New Zealand. N Z J Zool 21: 351-372.

Cree A (2005) Discovered by Science: an Analysis of the First 200 Years of Research on Tuatara (Sphenodon). N Z J Zool 32: 221.

Cree A \& Butler D (1993) Tuatara Recovery Plan (Sphenodon spp.). Threatened Species Recovery Plan Series No. 9., New Zealand Department of Conservation, Wellington, New Zealand.

Cree A, Cockrem J F, Brown M A, Watson P R, Guillette L J, Jr, Newman D G \& Chambers G K (1991a) Laparoscopy, Radiography, and Blood Analyses as Techniques for Identifying the Reproductive Condition of Female Tuatara. Herpetologica 47: 238-249.

Cree A \& Daugherty C H (1990) Captive Breeding of the New Zealand Tuatara: Past Results and Future Directions. Proceedings of the 5th Conference on Breeding Endangered Species in Captivity, Cincinnati Zoo and Botanical Garden Center, Cincinnati, Ohio.

Cree A, Daugherty C H, Schafer S F \& Brown D (1991b) Nesting and Clutch Size of Tuatara (Sphenodon guntheri) on North Brother Island, Cook Strait. Tuatara 31: 9-16.

Cree A, Daugherty C H, Towns D R \& Blanchard B (1994) The Contribution of Captive Management to the Conservation of Tuatara (Sphenodon) in New Zealand. J Herpetol: 377-385.

Cree A, Guillette L J J, Cockrem J F, Brown M A \& Chambers G K (1990) Absence of Daily Cycles in Plasma Sex Steroid Concentrations in Male and Female Tuatara (Sphenodon punctatus ) and the Effects of Acute Capture Stress on Females. Gen Comp Endocrinol 79: 103-113.

Cree A, Thompson M B \& Daugherty C H (1995) Tuatara Sex Determination. Nature 375: 543.

Creel S (2001) Social Dominance and Stress Hormones. Trends Ecol Evol 16: 491-497. 
Creese R G \& Underwood A J (1982) Analysis of Interspecific and Intraspecific Competition Amongst Intertidal Limpets with Different Methods of Feeding. Oecologia 53: 337-346.

Darwin C (1859) On the Origin of Species by Means of Natural Selection, or the Preservation of Favoured Races in the Struggle for Life. John Murray, London.

Daugherty C H, Cree A, Hay J M \& Thompson M B (1990) Neglected Taxonomy and Continuing Extinctions of Tuatara (Sphenodon). Nature 347: 177-179.

Daugherty C H, Patterson G B \& Hitchmough R A (1994) Taxonomic and Conservation Review of the New Zealand Herpetofauna. N Z J Zool 21: 317-323.

Dawbin W H (1949) The Tuatara. Tuatara 2: 91-96.

Dawbin W H (1953) The Fauna of Stephens Island. Forest and Bird 108: 8-9.

Dawbin W H (1962) The Tuatara in its Natural Habitat. Endeavour 21: 16-24.

Dawbin W H (1982) The Tuatara, Sphenodon punctatus (Reptilia: Rhynchocephalia): a Review in New Zealand Herpetology. Newman D G, Ed. pp 149-181. New Zealand Wildlife Service, Wellington.

Dawbin W H \& Hill L (1969) Uric Acid and Urea Excretion in the Tuatara Sphenodon punctatus. Nature 224: 1325-1326.

Deutsch J C \& Lee P C (1991) Dominance and Feeding Competition in Captive Rhesus Monkeys. Int J Primatol 12: 615-628.

Dewsbury D A (1982) Dominance Rank, Copulatory Behavior, and Differential Reproduction. Q Rev Biol 57: 135-159.

Diaz-Uriarte R (1999) Anti-Predator Behaviour Changes Following an Aggressive Encounter in the Lizard Tropidurus hispidus. Proc R Soc Lond B 266: 2457-2464.

Diaz-Uriarte R (2001) Territorial Intrusion Risk and Antipredator Behaviour: a Mathematical Model. Proc R Soc Lond B 268: 1165-1173.

Dickinson J L, Euaparadorn M, Greenwald K, Mitra C \& Shizuka D (2009) Cooperation and Competition: Nepotistic Tolerance and Intrasexual Aggression in Western Bluebird Winter Groups. Anim Behav 77: 867-872.

Dodd C K \& Seigel R A (1991) Relocation, Repatriation, and Translocation of Amphibians and Reptiles - Are They Conservation Strategies That Work. Herpetologica 47: 336350.

Dodson G N \& Schwaab A T (2001) Body Size, Leg Autotomy, and Prior Experience as Factors in the Fighting Success of Male Crab Spiders, Misumenoides formosipes. J Insect Behav 14: 841-855.

Downes S \& Shine R (1998) Heat, Safety or Solitude? Using Habitat Selection Experiments to Identify a Lizard's Priorities. Anim Behav 55: 1387-1396.

Drummond H (2006) Dominance in Vertebrate Broods and Litters. Q Rev Biol 81: 3-32.

Drummond H \& Canales C (1998) Dominance between Booby Nestlings Involves Winner and Loser Effects. Anim Behav 55: 1669-1676.

Dunham A E (1978) Food Availability as a Proximate Factor Influencing Individual Growth Rates in the Iguanid Lizard Sceloporus merriami. Ecology 59: 770-778. 
Eggert F, Muller-Ruchholtz W \& Ferstl R (1999) Olfactory Cues Associated with the Major Histocompatibility Complex. Genetica 104: 191-197.

Ehrenfeld J G (2000) Defining the Limits of Restoration: the Need for Realistic Goals. Restor Ecol 8: 2-9.

Ekman J B \& Lilliendahl K (1993) Using Priority to Food Access - Fattening Strategies in Dominance Structured Willow Tit (Parus montanus) Flocks. Behav Ecol 4: 232-238.

Endler J A (1986) Natural Selection in the Wild. Princeton University Press, Princeton, New Jersey.

English P R \& Wilkinson V (1982) Management of Sow and Litter Late Pregnancy and Lactation in Relation to Piglet Survival and Growth in Control of Pig Reproduction. Cole D J A \& Foxcroft G R, Eds, pp 479-506. Butterworths, London.

Evans L T (1940) Effects of Testosterone Propionate upon Social Dominance in Young Turtles, Chrysemys picta. Biological Bulletin 79: 371.

Ewald P W, Hunt G L \& Warner M (1980) Territory Size in Western Gulls - Importance of Intrusion Pressure, Defense Investments, and Vegetation Structure. Ecology 61: 80-87.

Ferguson G W, Brown K L \& Demarco V G (1982) Selective Basis for the Evolution of Variable Egg and Hatchling Size in Some Iguanid Lizards. Herpetologica 38: 178-188.

Ferguson G W \& Fox S F (1984) Annual Variation of Survival Advantage of Large Juvenile Side-Blotched Lizards, Uta stansburiana - its Causes and Evolutionary Significance. Evolution 38: 342-349.

Fischer J \& Lindenmayer D B (2000) An Assessment of the Published Results of Animal Relocations. Biol Conserv 96: 1-11.

Flachsbarth B, Fritzsche M, Weldon P J \& Schulz S (2009) Composition of the Cloacal Gland Secretion of Tuatara, Sphenodon punctatus. Chem Biodivers 6: 1-37.

Formanowicz D R, Jr., Brodie E D, Jr. \& Campbell J A (1990) Intraspecific Aggression in Abronia vasconcelosii (Sauria, Anguidae), a Tropical, Arboreal Lizard. Biotropica 22: 391-396.

Formica V A, Gonser R A, Ramsay S \& Tuttle E M (2004) Spatial Dynamics of Alternative Reproductive Strategies: the Role of Neighbors. Ecology 85: 1125-1136.

Forster G L, Watt M J, Korzan W J, Renner K J \& Summers C H (2005) Opponent Recognition in Male Green Anoles, Anolis carolinensis. Anim Behav 69: 733-740.

Fox M W (1973) Social Dynamics of Three Captive Wolf Packs. Behaviour 47: 290-301.

Fraser D (1990) Behavioural Perspectives on Piglet Survival. J Reprod Fertil, Suppl 40: 355370.

Frazer N B (1992) Sea Turtle Conservation and Halfway Technology. Conserv Biol 6: 179184.

Freeman S \& Herron J C (2004) Evolutionary Analysis 3rd Edition. Pearson Prentice Hall, Upper Saddle River.

Froese A D \& Burghard G M (1974) Food Competition in Captive Juvenile Snapping Turtles, Chelydra serpentina. Anim Behav 22: 735-740. 
Gadgil M \& Bossert W H (1970) Life Historical Consequences of Natural Selection. Am Nat 104: 1-24.

Gans C, Gillingham J C \& Clark D L (1984) Courtship, Mating and Male Combat in Tuatara, Sphenodon punctatus. J Herpetol 18: 194-197.

Gautier P \& Miaud C (2003) Faecal Pellets Used as an Economic Territorial Marker in Two Terrestrial Alpine Salamanders. Ecoscience 10: 134-139.

Gaze P (2001) Tuatara Recovery Plan 2001-2011. Department of Conservation, Nelson, New Zealand.

Genner M J, Turner G F \& Hawkins S J (1999) Resource Control by Territorial Male Cichlid Fish in Lake Malawi. J Anim Ecol 68: 522-529.

Germano J M \& Bishop P J (2009) Suitability of Amphibians and Reptiles for Translocation. Conserv Biol 23: 7-15.

Gibbons J W, Semlitsch R D, Greene J L \& Schubauer J P (1981) Variation in Age and Size at Maturity of the Slider Turtle (Pseudemys scripta). Am Nat 117: 841-845.

Gillingham J C, Carmichael C \& Miller T (1995) Social Behaviour of the Tuatara, Sphenodon punctatus. Herpetol Monogr 9: 5-16.

Gillingham J C \& Miller T J (1991) Reproductive Ethology of the Tuatara Sphenodon punctatus: Applications in Captive Breeding. Int Zoo Yearbook 30: 157-164.

Goetz B G R \& Thomas B W (1994a) A Study on the Captive Maintenance of Tuatara (Sphenodon punctatus). Manaaki Whenua - Landcare Research New Zealand Ltd, Auckland.

Goetz B G R \& Thomas B W (1994b) Use of Annual Growth and Activity Patterns to Assess Management Procedures for Captive Tuatara (Sphenodon punctatus). N Z J Zool 21: 473-485.

Gopi G V \& Pandav B (2009) Humans Sharing Space with Crocodylus porosus in Bhitarkanika Wildlife Sanctuary: Conflicts and Options. Curr Sci 96: 459-460.

Gorman M L (1984) Scent Marking and Territoriality. Acta Zool Fenn 171 49-53.

Gorman M L \& Trowbridge B J (1989) Role of Odor in the Social Lives of Carnivores in Carnivore Behavior, Ecology and Evolution. Gittleman J L, Ed. pp 57-88. Cornell University Press, New York.

Gosler A (1987) Aspects of Bill Morphology in Relation to Ecology in the Great Tit, Parus major. PhD thesis. University of Oxford, Oxford, United Kingdom.

Gosling L M (1982) A Reassessment of the Function of Scent Marking in Territories. Z Tierpsychol 60: 89-118.

Gosling L M \& McKay H V (1990) Competitor Assessment by Scent Matching - an Experimental Test. Behav Ecol Sociobiol 26: 415-420.

Greenberg N (1976) Observations of Social Feeding in Lizards. Herpetologica 32: 348-352.

Greenberg N (1977) Ethogram of Blue Spiny Lizard, Sceloporus cyanogenys (Reptilia, Lacertilia, Iguanidae). J Herpetol 11: 177-195. 
Greenberg N, Chen T \& Crews D (1984) Social Status, Gonadal State, and the Adrenal Stress Response in the Lizard, Anolis carolinensis. Horm Behav 18: 1-11.

Griffiths R A \& Pavajeau L (2008) Captive Breeding, Reintroduction, and the Conservation of Amphibians. Conserv Biol 22: 852-861.

Grossman G D (1980) Food, Fights, and Burrows: the Adaptive Significance of Intraspecific Aggression in the Bay Goby (Pisces: Gobiidae) Oecologia 45: 261-266.

Gruber M A M (2007) Conservation of Tuatara (Sphenodon): an Evaluation of the Survival and Growth of Artificially Incubated, Head-Started Juveniles. Hons thesis. School of Biological Sciences, Victoria University of Wellington, Wellington, New Zealand.

Guillette L J, Cree A \& Rooney A A (1995) Biology of Stress: Interactions with Reproduction, Immunology and Intermediary Metabolism in Health and welfare of captive reptiles. Warwick C, Frye F L \& Murphy J B, Eds, pp 32-81. Chapman and Hall, London.

Gunther A (1867) Contribution to the Anatomy of Hatteria (Rhynchocephalus, Owen). Phil Trans Roy Soc Lond 157: 595-629.

Hand J L (1986) Resolution of Social Conflicts: Dominance, Egalitarinism, Spheres of Dominance, and Game Theory. Q Rev Biol 61: 201-220.

Harless M (1979) Social Behavior in Turtles: Perspectives and Research. Harless M \& Morlock H, Eds, pp 475-492. John Wiley \& Sons, New York.

Haskell A, Graham T E, Griffin C R \& Hestbeck J B (1996) Size Related Survival of Headstarted Redbelly Turtles (Pseudemys rubriventris) in Massachusetts. J Herpetol 30: 524-527.

Hay J M, Sarre S D, Lambert D M, Allendorf F W \& Daugherty C H (2009) Genetic Diversity and Taxonomy: a Reassessment of Species Designation in Tuatara (Sphenodon: Reptilia). Conserv Genet: DOI 10.1007/s10592-009-9952-7.

Hayward L S \& Wingfield J C (2004) Maternal Corticosterone Is Transferred to Avian Yolk and May Alter Offspring Growth and Adult Phenotype. Gen Comp Endocrinol 135: 365-371.

Heinsohn R, Packer C \& Pusey A E (1996) Development of Cooperative Territoriality in Juvenile Lions. Proc R Soc Lond B 263: 475-479.

Heppell S S, Crowder L B \& Crouse D T (1996) Models to Evaluate Headstarting as a Management Tool for Long-Lived Turtles. Ecol Appl 6: 556-565.

Hinde R A (1956) The Biological Significance of the Territories of Birds. Ibis 98: 340-369.

Hitchmough R, Bull L \& Cromarty P (2007) New Zealand Threat Classification System Lists 2005. Science \& Technical Publishing, Department of Conservation, Wellington.

Hoare J M, Pledger S, Keall S N, Nelson N J, Mitchell N J \& Daugherty C H (2006) Conservation Implications of a Long-Term Decline in Body Condition of the Brothers Island tuatara (Sphenodon guntheri). Anim Conserv 9: 456-462.

Holekamp K E, Smale L \& Szykman M (1996) Rank and Reproduction in the Female Spotted Hyaena. J Reprod Fertil 108: 229-237.

Huey R B \& Janzen F J (2008) Climate Warming and Environmental Sex Determination in Tuatara: the Last of the Sphenodontians? Proc R Soc B 275: 2181-2183. 
Huey R B, Peterson C R, Arnold S J \& Porter W P (1989) Hot Rocks and Not-So-Hot Rocks Retreat-Site Selection by Garter Snakes and its Thermal Consequences. Ecology 70: 931-944.

Hunt R H (1977) Aggressive Behavior by Adult Morelet's Crocodiles Crocodylus moreleti toward Young Herpetologica 33: 195-201.

Hutchings M R \& White P C L (2000) Mustelid Scent-Marking in Managed Ecosystems: Implications for Population Management. Mamm. Rev. 30: 157 - 169.

IUCN (2009) IUCN Red List of Threatened Species. Version 2009.1. Downloaded on 28 August 2009. http://www.iucnredlist.org

Iverson J B (1978) Reproductive Cycle of Female Loggerhead Musk Turtles (Sternotherus minor minor) in Florida. Herpetologica 34: 33-39.

Jaeger R G, Goy J M, Tarver M \& Marquez C E (1986) Salamander Territoriality Pheromonal Markers as Advertisement by Males. Anim Behav 34: 860-864.

Jansson N, Uller T \& Olsson M (2005) Female Dragons, Ctenophorus pictus, Do Not Prefer Scent from Unrelated Males. Aust J Zool 53: 279-282.

Johnson R P (1973) Scent Marking in Mammals. Anim Behav 21: 521-535.

King R B \& Stanford K M (2006) Headstarting as a Management Tool: a Case Study of the Plains Gartersnake. Herpetologica 62: 282-292.

Kruuk H (1992) Scent Marking by Otters (Lutra lutra) - Signaling the Use of Resources. Behav Ecol 3: 133-140.

Kuehler C, Lieberman A, Oesterle P, Powers T, Kuhn M, Kuhn J, Nelson J, Snetsinger T, Herrmann C, Harrity P, et al. (2000) Development of Restoration Techniques for Hawaiian Thrushes: Collection of Wild Eggs, Artificial Incubation, Hand-Rearing, Captive-Breeding, and Re-Introduction to the Wild. Zoo Biol 19: 263-277.

Langkilde T, Lance V A \& Shine R (2005) Ecological Consequences of Agonistic Interactions in Lizards. Ecology 86: 1650-1659.

Langkilde T \& Shine R (2006) How Much Stress Do Researchers Inflict on their Study Animals? A Case Study Using a Scincid Lizard, Eulamprus heatwolei. J Exp Biol 209: 1035-1043.

Le Galliard J, Fitze P S, Ferrière R \& Clobert J (2005) Sex Ratio Bias, Male Aggression, and Population Collapse in Lizards. Proc Natl Acad Sci U S A 102: 18231-18236.

Lopez P, Aragon P \& Martin J (1998) Iberian Rock Lizards (Lacerta monticola cyreni) Assess Conspecific Information Using Composite Signals from Faecal Pellets. Ethology 104: 809-820.

Lott D F \& North G J (1998) A Technique for Quantitative Description of AggressionProduced Social Systems. Ethology 104: 399-406.

Maher C R \& Lott D F (1995) Definitions of Territoriality Used in the Study of Variation in Vertebrate Spacing Systems. Anim Behav 49: 1581-1597.

Maher C R \& Lott D F (2000) A Review of Ecological Determinants of Territoriality Within Vertebrate Species. Am Midl Nat 143: 1-29. 
Mahmoud I Y \& Klicka J (1979) Feeding, Dringking, and Excretion in Turtles: Perspectives and Research. Harless M \& Morlock H, Eds, pp 229-243. John Wiley \& Sons, New York.

Mantel N (1967) The Detection of Disease Clustering and a Generalized Regression Approach. Cancer Res 27: 209-220.

Marnewick K A, Bothma J d P \& Verdoorn G H (2006) Using Camera-Trapping to Investigate the Use of a Tree as a Scent-Marking Post by Cheetahs in the Thabazimbi District. S Afr J Wildl Res 36: 139-145.

Martin J \& Lopez P (2007) Scent May Signal Fighting Ability in Male Iberian Rock Lizards. Biol Lett-Uk 3: 125-127.

Mason R T (1992) Reptilian Pheromones in Biology of the Reptilia. Gans C \& Crews D, Eds, pp 114-228. The University of Chicago Press, Chicago.

McIntyre M E (1988) Management Implications of Habitat Use and Dispersal of Juvenile Tuatara, Sphenodon punctatus, on Stephens Island. Victoria University of Wellington, Wellington, New Zealand.

McKenzie (2007) Returning Tuatara (Sphenodon punctatus) to the New Zealand Mainland. MSc thesis. School of Biological Sciences, Victoria University of Wellington, Wellington, New Zealand.

McKnight C M \& Gutzke W H N (1993) Effects of the Embryonic Environment and of Hatchling Housing Conditions on Growth of Young Snapping Turtles (Chelydra serpentina). Copeia: 475-482.

Meyer-Rochow V B (1988) Behaviour of Young Tuatara (Sphenodon punctatus) in Total Darkness. Tuatara 30: 36-38.

Meyer-Rochow V B \& Teh K L (1991) Visual Predation by Tuatara (Sphenodon punctatus) on the Beach Beetle (Chaerodes trachyscelides) as a Selective Force in the Production of Distinct Colour Morphs. Tuatara 31: 1-8.

Miller H C, Moore J A, Nelson N J \& Daugherty C H (2009) Influence of Major Histocompatibility Complex Genotype on Mating Success in a Free-Ranging Reptile Population. Proc R Soc B 276: 1695-1704.

Miller K A, Nelson N J, Smith H G \& Moore J A (In press) How Do Founder Group Size and Reproductive Skew Affect Genetic Diversity in Reintroduced Populations? Mol Ecol.

Milstead W W (1970) Late Summer Behavior of the Lizards Sceloporus merriami and Urosaurus ornatus in the Field. Herpetologica 26: 343-354

Minot E O (1981) Effects of Interspecific Competition for Food in Breeding Blue and Great Tits. J Anim Ecol 50: 375-385.

Mitchell N J, Allendorf F W, Keall S N, Daugherty C H \& Nelson N J (2009) Demographic Effects of Temperature-Dependent Sex Determination: Will Tuatara Survive Global Warming? Global Change Biol: DOI 10.1111/j.1365-2486.2009.01964.x.

Moore J A (2008) Fitness Implications of the Mating System and Reproductive Ecology of Tuatara. PhD thesis. School of Biological Sciences, Victoria University of Wellington, Wellington, New Zealand.

Moore J A, Daugherty C H \& Nelson N J (In press) Large Male Advantage: Phenotypic and Genetic Correlates of Territoriality in Tuatara. J Herpetol. 
Moore J A, Hoare J M, Daugherty C H \& Nelson N J (2007) Waiting Reveals Waning Weight: Monitoring over 54 Years Shows a Decline in Body Condition of a Long-Lived Reptile (Tuatara, Sphenodon punctatus). Biol Conserv 135: 181-188.

Moore J A, Nelson N J, Keall S N \& Daugherty C H (2008) Implications of Social Dominance and Multiple Paternity for the Genetic Diversity of a Captive-Bred Reptile Population (Tuatara). Conserv Genet 9: 1243-1251.

Moreira P L, Lopez P \& Martin J (2008) Discrimination of Conspecific Faecal Chemicals and Spatial Decisions in Juvenile Iberian Rock Lizards (Lacerta monticola). Acta Ethol 11: 26-33.

Morpurgo B, Gvaryahu G \& Robinzon B (1993) Aggressive Behavior in Immature Captive Nile Crocodiles, Crocodylus niloticus, in Relation to Feeding. Physiol Behav 53: 11571161.

Nelson N J (2001) Temperature-Dependent Sex Determination and Artificial Incubation of Tuatara, Sphenodon punctatus. PhD thesis. School of Biological Sciences, Victoria University of Wellington, Wellington, New Zealand.

Nelson N J, Cree A, Thompson M B, Keall S N \& Daugherty C H (2004a) TemperatureDependent Sex Determination in Tuatara in Temperature-Dependent Sex Determination in Vertebrates. Valenzuela N \& Lance V, Eds, pp 53-58. Smithsonian Books, Washington D.C.

Nelson N J, Keall S N, Brown D \& Daugherty C H (2002a) Establishing a New Wild Population of Tuatara (Sphenodon guntheri). Conserv Biol 16: 887-894.

Nelson N J, Keall S N, Pledger S \& Daugherty C H (2002b) Male-Biased Sex Ratio in a Small Tuatara Population. J Biogeogr 29: 633-640.

Nelson N J, Thompson M B, Pledger S, Keall S N \& Daugherty C H (2004b) Egg Mass Determines Hatchling Size, and Incubation Temperature Influences Post-Hatching Growth, of Tuatara Sphenodon punctatus. J Zool 263: 77-87.

Nelson N J, Thompson M B, Pledger S, Keall S N \& Daugherty C H (2006) Performance of Juvenile Tuatara Depends on Age, Clutch, and Incubation Regime. J Herpetol 40: 399-403.

Newman A K (1878) Notes on the Physiology and Anatomy of the Tuatara (Sphenodon guntheri). Trans N Z Inst 10: 222-239.

Newman D G, Crook I G \& Moran L R (1979) Some Recommendations on the Captive Maintenance of Tuataras Sphenodon punctatus Based on Observations in the Field. Int Zoo Yearbook 19: 68-74.

Newman D G, Watson P R \& McFadden I (1994) Egg Production by Tuatara on Lady Alice and Stephen Island, New Zealand. N Z J Zool 21: 387-398.

Noble G K (1939) The Role of Dominance in the Social Life of Birds. The Auk 56: 263-273.

Oldman J M (2008) Non-Surgical Methods for Sexing Small Juvenile Tuatara (Sphenodon punctatus) MSc thesis. Zoology, University of Otago Dunedin, New Zealand

Olsson M \& Shine R ( 2000) Ownership Influences the Outcome of Male-Male Contests in the Scincid Lizard, Niveoscincus microlepidotus. Behav Ecol 11: 587-590. 
Packer C, Herbst L, Pusey A E, Bygott J D, Cairns S J, Hanby J P \& Borgerhoff-Mulder M (1988) Reproductive Success of Lions in Reproductive Success. Clutton-Brock T H, Ed. pp. University of Chicago Press, Chicago.

Palagi E \& Norscia I (2009) Multimodal Signaling in Wild Lemur catta: Economic Design and Territorial Function of Urine Marking. Am J Phys Anthropol 139: 182-192.

Park T (1954) Experimental Studies of Interspecies Competition: 2. Temperature, Humidity, and Competition in Two Species of Tribolium. Physiol Zool 27: 177-238.

Parsons T S (1970) The Nose and Jacobson's Organ in Biology of the Reptilia. Gans C \& Parsons T S, Eds, pp 99-191. Academic, London.

Pedrono M \& Sarovy A (2000) Trial Release of the World's Rarest Tortoise Geochelone yniphora in Madagascar. Biol Conserv 95: 333-342.

Pelletier F \& Festa-Bianchet M (2006) Sexual Selection and Social Rank in Bighorn Rams. Anim Behav 71: 649-655.

Peres-Neto P R (1999) How Many Statistical Tests Are Too Many? The Problem of Conducting Multiple Inferences Revisited. Mar Ecol Prog Ser 176: 303-306.

Perez-Buitrago N, Garcia M A, Sabat A, Delgado J, Alvarez A, McMillan O \& Funk S M (2008) Do Headstart Programs Work? Survival and Body Condition in Headstarted Mona Island Iguanas Cyclura cornuta stejnegeri. Endang Species Res 6: 55-65.

Pfeffer P (1959) Observations sur le Varan de Komodo Varanus komodoensis Ouwens 1912. La Terre et la Vie 106: 195-243.

Pitelka F A (1959) Numbers, Breeding Schedule, and Territoriality in Pectoral Sandpipers of Northern Alaska. The Condor 61: 233-264.

Prenter J, Taylor P W \& Elwood R W (2008) Large Body Size for Winning and Large Swords for Winning Quickly in Swordtail Males, Xiphophorus helleri. Anim Behav 75: 19811987.

Price J E \& Secki Shields J A (2002) Size-Dependent Interactions between Two Terrestrial Amphibians, Plethodon cinereus and Plethodon glutinosus. Herpetologica 58: 141-155.

Prieto A A \& Ryan M J (1978) Some Observations of Social Behavior of Arizona Chuckwalla, Sauromalus obesus tumidus (Reptilia, Lacertilia, Iguanidae). J Herpetol 12: 327-336.

Pritchard P C H (1979) Head-Starting and Other Conservation Techniques for Marine Turtles Cheloniidae and Dermochelyidae. Int Zoo Yearbook 19: 38-42.

R-Development-Core-Team (2008) R: a Language and Environment for Statistical Computing 2.6.2. Vienna, Austria. R Foundation for Statistical Computing.

Railsback S F, Harvey B C, Hayse J W \& LaGory K E (2005) Tests of Theory for Diel Variation in Salmonid Feeding Activity and Habitat Use. Ecology 86: 947-959.

Rand A S (1967) The Adaptive Significance of Territoriality in Iguanid Lizards in Lizard Ecology: a Symposium. Milstead W W, Ed. pp 106-115. University of Missouri Press, Columbia.

Refsnider J, Moore J A \& Streby H (2008) Sphenodon punctatus Prey Detection. Herpetological Review 39: 347-348. 
Regal P J \& Connolly M S (1980) Social Influences on Biological Rhythms. Behaviour 72: 171-199.

Rest J S, Ast J C, Austin C C, Waddell P J, Tibbetts E A, Hay J M \& Mindell D P (2003) Molecular Systematics of Primary Reptilian Lineages and the Tuatara Mitochondrial Genome. Mol Phylogenet Evol 29: 289-297.

Ridley M (1995) Animal Behavior: an Introduction to Behavioral Mechanisms, Development, and Ecology. Blackwell Scientific Publications, Boston.

Robb J (1980) New Zealand Amphibians and Reptiles in Colour. Collins, Auckland.

Rostain R R, Ben-David M, Groves P \& Randall J A (2004) Why Do River Otters Scent-Mark? An Experimental Test of Several Hypotheses. Anim Behav 68: 703-711.

Rovero F, Lebboroni M \& Chelazzi G (1999) Aggressive Interactions and Mating in Wild Populations of the European Pond Turtle Emys orbicularis. J Herpetol 33: 258-263.

Rubenstein D I (1982) Risk, Uncertainty, and Evolutionary Strategies in Current Problems in Sociobiology. Bertram B C R, Clutton-Brock T H, Dunbar R I M, Rubenstein D I \& Wrangham R W, Eds, pp 91-111. Cambridge University Press, U.K.

Sacchi R, Pupin F, Gentilli A, Rubolini D, Scali S, Fasola M \& Galeotti P (2009) Male-Male Combats in a Polymorphic Lizard: Residency and Size, but not Color, Affect Fighting Rules and Contest Outcome. Aggressive Behav 35: 274-283.

Sakata J T, Gupta A, Chuang C P \& Crews D (2002) Social Experience Affects Territorial and Reproductive Behaviours in Male Leopard Geckos, Eublepharis macularius. Anim Behav 63: 487-493.

Santos J, Benjamin M, Yang P C, Prior T \& Perdue M H (2000) Chronic Stress Impairs Rat Growth and Jejunal Epithelial Barrier Function: Role of Mast Cells. Am J Physiol-Gastr L 278: 847-854.

Schofield G, Katselidis K A, Pantis J D, Dimopoulos P \& Hays G C (2007) Female-Female Aggression: Structure of Interaction and Outcome in Loggerhead Sea Turtles. Mar Ecol Prog Ser 336: 267-274.

Schuett G W (1997) Body Size and Agonistic Experience Affect Dominance and Mating Success in Male Copperheads. Anim Behav 54: 213-224.

Scott J P \& Fredericson E (1951) The Causes of Fighting in Mice and Rats. Physiol Zool 24: 273-309.

Seebacher F \& Grigg G C (1997) Patterns of Body Temperature in Wild Freshwater Crocodiles, Crocodylus johnstoni: Thermoregulation Versus Thermoconformity, Seasonal Acclimatization, and the Effect of Social Interactions. Copeia: 549-557.

Shine R \& Charnov E L (1992) Patterns of Survival, Growth, and Maturation in Snakes and Lizards. Am Nat 139: 1257-1269.

Shine R \& Iverson J B (1995) Patterns of Survival, Growth and Maturation in Turtles. Oikos 72: 343-348.

Shine R, Olsson M M, Moore I T, Lemaster M P, Greene M \& Mason R T (2000) Body Size Enhances Mating Success in Male Garter Snakes. Anim Behav 59: F4-F11.

Simon C A (1975) Influence of Food Abundance on Territory Size in Iguanid Lizard Sceloporus jarrovi. Ecology 56: 993-998. 
Simon C A (1976) Lizard Coexistence in Four Dimensions. Nat Hist 85: 70-74.

Simon C A \& Middendorf G A (1976) Resource Partitioning by an Iguanid Lizard: Temporal and Microhabitat Aspects. Ecol Lett 57: 1317-1320.

Simon C A \& Middendorf G A (1980) Spacing in Juvenile Lizards (Sceloporus Jarrovi). Copeia: 141-146.

Slater K Y, Schaffner C M \& Aureli F (2009) Sex Differences in the Social Behavior of Wild Spider Monkeys (Ateles geoffroyi yucatanensis). Am J Primatol 71: 21-29.

Smith J L D, Mcdougal C \& Miquelle D (1989) Scent Marking in Free Ranging Tigers, Panthera tigris. Anim Behav 37: 1-10.

Smouse P E, Long J C \& Sokal R R (1986) Multiple Regression and Correlation Extensions of the Mantel Test of Matrix Correspondence. Syst Zool 35: 627-632.

Sokolov V E \& Gromov V S (1993) Chemical Communication in Roe Deer (Capreolus). Zool Zh 72: 123-136.

Stamps J (1983a) Territoriality and the Defense of Predator-Refuges in Juvenile Lizards. Anim Behav 31: 857-870.

Stamps J \& Tanaka S (1981a) The Influence of Food and Water on Growth Rates in a Tropical Lizard (Anolis aeneus). Ecology 62: 33-40.

Stamps J A (1977) Relationship between Resource Competition, Risk, and Aggression in a Tropical Territorial Lizard. Ecology 58: 349-358.

Stamps J A (1978) Field Study of Ontogeny of Social Behavior in Lizard Anolis aeneus. Behaviour 66: 1-31.

Stamps J A (1983b) The Relationship between Ontogenetic Habitat Shifts, Competition and Predator Avoidance in a Juvenile Lizard (Anolis aeneus). Behav Ecol Sociobiol 12: 1933.

Stamps J A \& Krishnan V V (1994a) Territory Acquisition in Lizards: 1. First Encounters. Anim Behav 47: 1375-1385.

Stamps J A \& Krishnan V V (1994b) Territory Acquisition in Lizards: 2. Establishing Social and Spatial Relationships. Anim Behav 47: 1387-1400.

Stamps J A \& Krishnan V V (1997) Functions of Fights in Territory Establishment. Am Nat 150: 393-405.

Stamps J A \& Tanaka S (1981b) The Relationship between Food and Social Behavior in Juvenile Lizards (Anolis aeneus). Copeia: 422-434.

Stapley J \& Keogh J S (2004) Exploratory and Antipredator Behaviours Differ between Territorial and Nonterritorial Male Lizards. Anim Behav 68: 641-646.

Swaisgood R R, Lindburg D G \& Zhang H (2002) Discrimination of Oestrous Status in Giant Pandas (Ailuropoda melanoleuca) Via Chemical Cues in Urine. J Zool 257: 381-386.

Swingland I R \& Coe M J (1979) Natural Regulation of Giant Tortoise Populations on Aldabra-Atoll - Recruitment. Philos T Roy Soc B 286: 177-188.

Taubes G (1992) A Dubious Battle to Save the Kemp's Ridley Sea Turtle. Science 256: 614616. 
Terezow M G (2005) Circadian and Ontogenetic Changes in Activity and Anti-Predator Responses of Captive Juvenile Tuatara (Sphenodon spp.). MSc thesis. School of Biological Sciences, Victoria University of Wellington, Wellington, New Zealand.

Terezow M G, Nelson N J \& Markwell T J (2008) Circadian Emergence and Movement of Captive Juvenile Tuatara (Sphenodon spp.). N Z J Zool 35: 205-216.

Thompson M B, Packard G C, Packard M J \& Rose B (1996) Analysis of the Nest Environment of Tuatara (Sphenodon punctatus). J Zool Lond 238: 239-251.

Tintinger V (1987) Breeding the Tuatara Sphenodon punctatus at the Auckland Zoo. Int Zoo Yearbook 26: 184-186.

Torr G A \& Shine R (1996) Patterns of Dominance in the Small Scincid Lizard Lampropholis guichenoti. J Herpetol 30: 230-237.

Towns D, Ussher G \& Parrish R (2001) Reptile Conservation in the Marotere Islands: Trip Report for March 2001. Department of Conservation, Auckland, New Zealand.

Tracy C R (1999) Differences in Body Size Among Chuckwalla (Sauromalus obesus) populations. Ecology 80: 259-271.

Tyrrell C \& Cree A (1994) Plasma Conrticosterone Concentrations in Wild and Captive Juvenile Tuatara (Sphenodon punctatus). N Z J Zool 21: 407-416.

Tyrrell C L \& Cree A (1998) Relationships Between Corticosterone Concentration and Season, Time of Day and Confinement in a Wild Reptile (Tuatara, Sphenodon punctatus). Gen Comp Endocrinol 110: 97-108.

Walls G Y (1981) Feeding Ecology of the Tuatara (Sphenodon punctatus) on Stephens Island, Cook Strait. N. Z. J. Ecol. 4: 89-97.

Walls G Y (1983) Activity of the Tuatara and its Relationships to Weather Conditions on Stephens Island, Cook Strait, with Observations on Geckos and Invertebrates. N Z J Zool 10: 309-318.

Warner R R \& Hoffman S G (1980) Population Density and the Economics of Territorial Defense in a Coral Reef Fish. Ecology 61: 772-780.

Warwick C (1995) Psychological and Behavioural Principles and Problems in Health and Welfare of Captive Reptiles. Warwick C, Frye F L \& Murphy J B, Eds, pp 205-238. Chapman \& Hall, London.

Watson A \& Miller G R (1971) Territory Size and Aggression in a Fluctuating Red Grouse Population. J Anim Ecol 40: 367-383.

Wells K D (1980) Behavioral Ecology and Social Organization of a Dendrobatid Frog (Colostethus inguinalis) Behav Ecol Sociobiol 6: 199-209.

Wilson E O (1975) Sociobiology: The New Synthesis. Belknap Press of Harvard University Press, Cambridge, Massachusetts.

Witter M S \& Cuthill I C (1993) The Ecological Costs of Avian Fat Storage. Philos T Roy Soc B 340: 73-92.

Witter M S \& Swaddle J P (1994) Fluctuating Asymmetries, Competition and Dominance. Proc R Soc Lond B 256: 299-303. 
Wojtusiak R J (1973) Some Ethological and Biological Observations on the Tuatara in Laboratory Conditions. Tuatara 20: 97-109.

Ydenberg R C \& Krebs J R (1987) The Tradeoff Between Territorial Defense and Foraging in the Great Tit (Parus major). Am Zool 27: 337-346.

Young B A (1998) Hearing, Taste, Tactile Reception, and Olfaction in The Biology, Husbandry and Health Care of Reptiles. Ackerman L, Ed. pp 185-213. T.F.H. Publications, Inc. 


\section{Appendix}

Table A.1 Number of experiments and scenarios in which an individual was used. All 23 tuatara juveniles are listed according to sex (11 males and 12 females). Some individuals had to be used repeatedly (up to four times [total]) within the same or different scenarios (S1 - S7) base on sex and relative size. S1: big male vs. small male, S2: big female vs. small female, S3: big male vs. small female, S4: big female vs. small male, S5: similar sized male and female, S6: similar sized males, S7: similar sized females.

\begin{tabular}{|c|c|c|c|c|c|c|c|c|c|c|c|c|c|}
\hline \multicolumn{7}{|c|}{ Females } & \multicolumn{7}{|c|}{ Males } \\
\hline Toe-clips & Total & $\mathrm{S} 2$ & S3 & S4 & S5 & S7 & Toe-clips & Total & S1 & S3 & S4 & S5 & S6 \\
\hline $53-(45)$ & 3 & & 1 & & & 2 & $45-(23)$ & 2 & & & & 1 & 1 \\
\hline $52-(45)$ & 3 & 2 & & 1 & & & $6 \ldots$ & 4 & 1 & & 3 & & \\
\hline $52-(34)$ & 1 & & & & & 1 & $52-(25)$ & 3 & & & & 1 & 2 \\
\hline $45-(35)$ & 4 & 1 & & 2 & & 1 & $54-(45)$ & 1 & & & & & 1 \\
\hline $44-(45)$ & 1 & 1 & & & & & 53-(34) & 2 & & & & 2 & \\
\hline 43-(23) & 1 & & & & & 1 & 53-(23) & 2 & 1 & & & & 1 \\
\hline $45-(24)$ & 4 & 1 & & 1 & 1 & 1 & 54-(24) & 4 & 2 & 2 & & & \\
\hline $45-(45)$ & 2 & & & & & 2 & 54-(35) & 1 & & & & & 1 \\
\hline 44-(25) & 2 & & & & 2 & & $52-(23)$ & 3 & 1 & & 1 & & 1 \\
\hline $44-(34)$ & 1 & & & & 1 & & 53-(24) & 2 & 1 & & & & 1 \\
\hline 44-(35) & 2 & 1 & 1 & & & & 54-(34) & 4 & 2 & 2 & & & \\
\hline $52-(24)$ & 4 & 2 & 2 & & & & & & & & & & \\
\hline
\end{tabular}

